\title{
Révision lithostratigraphique et biostratigraphique de l'Oligocène d'Aquitaine occidentale (France)
}

\author{
Károly SZTRÁKOS \\ Hall A3, 35 rue Savier, F-92240 Malakoff (France) \\ k.sztrakos@yahoo.fr
}

Etienne STEURBAUT

Royal Belgian Institute of Natural Sciences (RBINS), OD Earth and History of Life, Vautierstraat 29, 1000 Brussels \& KU Leuven (Belgique) etienne.steurbaut@naturalsciences.be (auteur correspondant)

Publié le 29 décembre 2017

urn:Isid:zoobank.org:pub:61BD6267-B630-4714-B88F-2CFD075711F5

Sztrákos K. \& Steurbaut E. 2017. - Révision lithostratigraphique et biostratigraphique de l'Oligocène d'Aquitaine occidentale (France). Geodiversitas 39 (4): 741-781. https://doi.org/10.5252/g2017n4a6

\section{RÉSUMÉ}

La stratigraphie de l'Oligocène d'Aquitaine occidentale est revue en synthétisant les données bibliographiques et en réexaminant 93 sondages, dont 60 sont datés à l'aide de foraminifères ou nannofossiles calcaires. La révision de ces sondages a permis de reconstituer l'évolution sédimentaire de l'Aquitaine occidentale en relation avec les évènements tectoniques correspondants. Les petits foraminiferes benthiques ont permis d'estimer les variations de la tranche d'eau dans les coupes, qui s'étendent du domaine épibathyal jusqu'au domaine saumâtre. Environ $60 \%$ des foraminiferes présents au Priabonien disparaissent au cours de cet étage et à la limite Éocène/Oligocène. L'apparition et la disparition des espèces est progressive dans l'Oligocène, ce qui permet d'en utiliser certaines comme marqueurs pour la stratigraphie du Bassin d'Aquitaine. Les foraminiferes du Bassin d'Aquitaine montrent de nombreuses affinités avec ceux de la Paratéthys centrale, indiquant que ces deux régions étaient interconnectées à cette époque par le détroit de Gibraltar et la zone bétique. Sept formations sont retenues dans l'Oligocène marin du Bassin de l'Adour, dont une nouvellement introduite (Formation de Capcosle d'âge Rupélien-Aquitanien) et deux redéfinies (Formation de Biarritz d'âge Rupélien inférieur et Formation d'Escornebéou d'âge Chattien supérieur); trois sont distinguées dans le domaine continental (les Formations de Jurançon et de Campagne puis celle de l'Agenais). L'Oligocène de la plate-forme nord-aquitaine comprend deux formations marines (la Formation de Bel-Air et la Formation du Calcaire à Astéries avec le Membre à Crassostrea longirostris à la base) et trois formations continentales (du bas vers le haut: les Formations du Fronsadais, de Castillon et de l'Agenais). Trois grandes aires sédimentaires se différencient au cours de l'Oligocène dans la région aquitaine. La première, entre Labenne et Arcachon, se caractérise par les dépôts à dominance argileuse, bathyaux, épais (jusqu’à $1700 \mathrm{~m}$ ). La deuxième aire forme un arc de cercle autour de la première et représente la plate-forme avec des sédiments plus variés: calcaires bioclastiques, argiles et sables coquilliers de 400-500 m d'épaisseur. La troisième comprend les sédiments continentaux à

MOTS CLÉS

Lithostratigraphie, Biostratigraphie, Foraminiferes, Oligocène, Aquitaine. l'est et au sud du bassin. Les événements tectoniques pyrénéens influencent la sédimentation, comme le montrent, en premier lieu, la transgression du Rupélien moyen, qui est plus importante au nord qu'au sud, tandis que le phénomène inverse s'observe au Rupélien supérieur, et, deuxièmement, les transgressions du Chattien inférieur et supérieur, qui sont conditionnées par la subsidence locale et la réactivation d'anciennes structures. 
KEY WORDS

Lithostratigraphy,

Biostratigraphy,

Foraminifera

Oligocene,

Aquitaine.

\begin{abstract}
Lithostratigraphic and biostratigraphic revision of the Oligocene of Western Aquitaine (France).

The Oligocene stratigraphy of western Aquitaine is reviewed through detailed literature screening and re-examination of 93 boreholes, 60 of which have been dated on the basis of foraminifera or calcareous nannofossils. The revision of these boreholes allowed reconstructing the sedimentary evolution of Western Aquitaine in relation to its tectonic history. The small benthic foraminifera enabled estimating the variations in water depth along the sections, ranging from epibathyal to brackish water settings. Around $60 \%$ of the Priabonian foraminifera went extinct during this stage and at the Eocene/Oligocene boundary. During the Oligocene, species appeared and disappeared progressively in the Aquitaine Basin, allowing some of them to be used as stratigraphic markers. The foraminifera of the Aquitaine Basin show close affinities with those of the Central Paratethys, indicating that during this period both regions were interconnected through the Strait of Gibraltar and the Betic zone. Seven formations have been retained in the marine Oligocene of the Adour Basin, of which one is newly introduced (the Capcosle Formation of RupelianAquitanian age) and two are redefined (the Biarritz Formation of early Rupelian age and the Escornebéou Formation of late Chattian age). Three are distinguished in the continental domain (the Jurançon and Campagne Formations and finally the Agenais Formation). The Oligocene of the North Aquitanian shelf includes two marine (the Bel-Air Formation and the "Calcaire à Astéries" Formation with the Crassostrea longirostris Member at the base) and three continental formations (in ascending order the Fronsadais, the Castillon and the Agenais Formations). Three major sedimentary areas are differentiated in the Aquitaine region during the Oligocene. The first area, between Labenne and Arcachon, is characterized by thick (up to $1700 \mathrm{~m}$ ) bathyal clayey deposits. The second area, forming a circular arc around the first, represents the shelf zone with a much larger variety in sedimentation, including bioclastic limestone, clay and shelly sand, reaching up to 400 to $500 \mathrm{~m}$ in thickness. The third area includes the continental sediments from the east and south of the basin. The Pyrenean tectonic events influenced the sedimentation, as shown, firstly, by the middle Rupelian transgression, which was vaster in the north than in the south, and by the reverse phenomenon during the late Rupelian, and, secondly, by the early and late Chattian transgressions, which were conditioned by local subsidence and reactivation of ancient structures.
\end{abstract}

\section{INTRODUCTION}

L'Aquitaine occidentale est largement couverte par des sédiments continentaux du Miocène supérieur au Quaternaire, percés par les affleurements des formations marines, essentiellement infralittorales, de l'Oligocène. Compte tenu de leur taille réduite, ceux-ci ne couvrent qu'une petite partie de la série sédimentaire.

L'étude des formations oligocènes a commencé au milieu $\mathrm{du} 19^{\mathrm{e}}$ siècle et a continué au début du $20^{\mathrm{e}}$. Les plus importants travaux de cette époque sont ceux de Delbos (1848, 1854), Tournouer (1863), Jacquot (1864), Douvillé (1906) et Dollfus (1917) portant sur le sud d'Aquitaine, et Delbos (1847), Raulin (1848) et Benoist (1883, 1884, 1885, 1887) sur des zones plus septentrionales. Ces affleurements ont été étudiés de nouveau lors de la réalisation des cartes géologiques à l'échelle 1/50 000e (Dubreuilh \& Marionnaud 1972, 1973; Kieken \& Thibault 1972, 1975; Le Pochat \& Thibault 1977; Alvinerie et al. 1977; Henry et al. 1989). Les affleurements du Bassin de l'Adour ont été révisés grâce aux travaux de Nolf et al. (2002) et Cahuzac \& Janssen (2010).

La position biostratigraphique de ces affleurements est bien connue actuellement à la suite des travaux de Poignant (1967), Cahuzac (1984), Cahuzac et al. (1995) et Cahuzac \& Poignant
$(1997,2002)$. Cependant, il est difficile de les situer dans les coupes complètes qu'offrent les sondages profonds. En effet, ils ont une hauteur réduite, quelques mètres par rapport à l'épaisseur totale des formations qui peut en avoir plusieurs centaines. De plus, ils montrent rarement le contact avec les formations du mur et du toit. L'étude des sondages profonds est donc indispensable pour comprendre la sédimentation dans cette région. L'Aquitaine occidentale a été explorée par de très nombreux sondages pétroliers. Les données bibliographiques les concernant sont limitées aux articles de Magné \& Malmoustier (1964) et Szőts et al. (1964). Notre publication est fondée sur la révision de ces sondages, permettant ainsi de décrire l'évolution sédimentaire de l'Aquitaine occidentale en lien avec les évènements tectoniques pyrénéens.

Pendant notre révision, nous avons été confrontés aux problèmes de la nomenclature stratigraphique. Ces règles exigent entre autres, qu'une nouvelle unité soit «dûment proposée et dûment décrite [...] Une mention accidentelle ou une référence en dehors des règles n'établit pas une nouvelle unité officielle, pas plus qu'une simple mention dans un tableau [...]» (Hedberg 1979: 24). Quelques noms de formation ne sont pas conformes à ces exigences. Ces unités (Grès de Biarritz, Falun d'Escornebéou) sont redéfinies et décrites dans les pages suivantes. 


\section{MATÉRIEL ET MÉTHODES}

Le Cénozoïque - ne représentant pas d'intérêt pour les compagnies pétrolières - a été très peu étudié dans les sondages $\mathrm{du}$ Bassin d'Aquitaine. Les rapports de fin de sondage y différencient le Miocène et l'Oligocène avec plus ou moins de précision; ils correspondent aux connaissances des années soixante, date d'exécution de la plupart des sondages. Les données disponibles sont très disparates, issues primo des coupes géologiques établies à l'aide des échantillons de déblais et de la vitesse d'avancement, et secundo des coupes basées sur les diagraphies de potentiel spontané et de résistivité, et de radioactivité naturelle (gamma ray) et acoustiques dans les puits plus récents.

Les échantillons de déblais, prélevés tous les $10 \mathrm{~m}$, ont été déposés par les compagnies au Bureau Exploration-Production des Hydrocarbures du Ministère de l'Industrie (BEPH). Ils se présentent sous forme lavée ou non lavée d'un volume de quelques $\mathrm{cm}^{3}$. Dans le cas des échantillons lavés, seule la fraction grossière, très pauvre en microfaune a été conservée. Les échantillons non lavés offrent une microfaune plus variée, mais les marqueurs peuvent être absents à cause du faible volume disponible. À ces inconvénients s'ajoute la présence des retombées, liée à ce mode d'échantillonnage. Les renseignements obtenus à partir de la microfaune doivent donc être recoupés par les informations des sondages voisins, en se servant des corrélations diagraphiques et des principes de l'analyse séquentielle.

Les prélèvements étaient espacés de telle manière, que la base et le sommet des variations lithologiques repérés sur les diagraphies soient échantillonnés. Les échantillons étaient espacés de 50 à $100 \mathrm{~m}$ dans les séries épaisses, monotones.

93 sondages sont revus ici, dont 60 ont été datés à l'aide de foraminifères ou nannofossiles calcaires. Les corrélations diagraphiques entre les sondages datés et les autres ont permis d'identifier les formations dans ces derniers et de définir leur extension stratigraphique et géographique. Les coupes d'autres forages (forages d'eau dans la majorité des cas) ont été consultées dans la Banque des Données du Sous-sol du Bureau de Recherche géologique et minière (BRGM; Fig. 1; Tableau 1).

La zonation utilisée est celle de Martini (1971) pour les nannofossiles calcaires, de Berggren et al. (1995) pour les foraminiferes planctoniques, de Cahuzac \& Poignant (1997) pour les foraminiferes benthiques et Riveline et al. (1996) pour les charophytes. La corrélation entre les biozones est basée sur la publication de Hardenbol et al. (1998), modifiée par Ogg et al. (2008). La définition et l'âge absolu des étages sont basés sur la même publication.

Les échantillons des sondages étudiés et les foraminiferes déterminés ont été déposés dans la collection du Muséum national d'Histoire naturelle (Paléontologie) de Paris.

\section{ZONES DE FORAMINIFÈRES PLANCTONIQUES}

La présence de tous les marqueurs utilisés par Berggren et al. (1995) permet d'appliquer la zonation décrite pour les régions tropicales dans l'Oligocène de l'Aquitaine. La nouvelle zonation proposée par Berggren \& Pearson (2005) semble être moins adaptée aux sections de l'Aquitaine au niveau des zones P 18 et P 21a (= E 16, O 1 et O 4 de Berggren \& Pearson 2005). En effet, Hantkenina alabamensis Cushman, 1925 est absente dans le Priabonien supérieur en Aquitaine et Pseudohastigerina naguewichiensis (Myatlyuk, 1950) n'y a pas encore été signalée. Les disparitions de ces espèces déterminent respectivement la base et le sommet de la zone O 1. La disparition de Chiloguembelina cubensis (Palmer, 1934) définie le sommet de la zone P 21a de Berggren et al. (1995). Cette proposition a été modifiée par Berggren \& Pearson (2005) : le sommet de la zone y est défini par la raréfaction de cette espèce. Celle-ci est rare dans les coupes d'Aquitaine et sa disparition peut se situer dans la zone P 21a.

Les publications de Pujol (1970), Groupe français d'Étude du Néogène (1974), Müller \& Pujol (1979) et Pujol \& Cahuzac (1984) donnent des détails supplémentaires sur cette faune. La répartition stratigraphique des espèces rencontrées figure dans l'Annexe 1.

\section{P 18. ZONE À TURBOROTALIA CERROAZULENSIS- \\ PSEUDOHASTIGERINA SPP.}

Cette zone a été définie par la disparition de T. cerroazulensis (Cole, 1928) à la base et par celle du genre Pseudohastigerina Banner \& Blow, 1959 au sommet. Les espèces du groupe de T. cerroazulensis sont fréquentes dans le Priabonien aquitain et leur disparition est facile à identifier, d'autant plus que la limite des zones P 17/P 18 est soulignée par une discordance régionale avec érosion (Sztrákos et al. 1998; Gély \& Sztrákos 2000). La seule espèce de Pseudohastigerina présente dans l'Oligocène du Bassin d'Aquitaine est $P$. barbadoensis Blow, 1969. Sa rareté rend la détermination de la limite supérieure de la zone P 18 incertaine dans les coupes. La présence de Turborotalia increbescens (Bandy, 1949), Subbotina angiporoides (Hornibrook, 1965), S. linaperta utilisindex (Jenkins \& Orr, 1973), Subbotina gortanii (Borsetti, 1959), Globoquadrina tapuriensis (Blow \& Banner, 1962) caractérise la zone dans notre région; Cassigerinella chipolensis (Cushman \& Ponton, 1932) et Globoquadrina sellii (Borsetti, 1959) apparaissent dans cet intervalle.

\section{P 19. ZONE À TURBOROTALIA AMPLIAPERTURA}

Le sommet de la zone est défini par la disparition de T. ampliapertura (Bolli, 1957), espèce commune en Aquitaine. Par conséquent, cet événement est facile à repérer dans les coupes.

\section{P 20. ZONE À GLOBOQUADRINA SELLII}

Lapparition de Globigerina angulisuturalis Bolli, 1957 marque la limite supérieure de la zone. Cette espèce est fréquente en Aquitaine, la zone est donc aisément identifiable. Paragloborotalia opima opima (Bolli, 1957) apparaît dans le même niveau.

\section{P 21. ZONE À GLOBIGERINA ANGULISUTURALIS- \\ PARAGLOBOROTALIA OPIMA OPIMA}

Cette zone a été divisée en deux sous-zones, P 21a et P 21b, dont la limite a été définie par la disparition de Chiloguembelina cubensis (Palmer, 1934).

\section{P 21A. SOUS-ZONE À GLOBIGERINA ANGULISUTURALIS- CHILOGUEMBELINA CUBENSIS \\ Cette sous-zone est définie par la coexistence de Globige- rina angulisuturalis Bolli, 1957 et Chiloguembelina cubensis}


TABLEAU 1. - Coordonnées des sondages étudiés/Coordinates of the studied boreholes.

\begin{tabular}{|c|c|c|c|c|}
\hline Sondage & $x$ & $\mathbf{Y}$ & Zt réf. & Z sol \\
\hline Ares 1 & 328,800 & 3280,700 & 21,4 & 17,90 \\
\hline Argenteyres 1 & 344,330 & 3265,500 & 39,1 & 34,60 \\
\hline Argenteyres 2 & 343,400 & 3264,070 & 39,6 & 36,10 \\
\hline Artiguillon 1 & 346,365 & 3334,530 & 25,3 & 28,41 \\
\hline Baloze 1 & 326,710 & 3238,650 & 71,5 & 67,00 \\
\hline Bazas 1 & 400,300 & 3243,150 & 99,4 & 95,10 \\
\hline Benquet 1 & 372,350 & 3177,924 & 93,7 & 89,00 \\
\hline Bernon 1 & 331,510 & 3253,330 & 29,5 & 25,00 \\
\hline Biscarrosse-Plage 1 & 314,600 & 3246,995 & 17,06 & 12,11 \\
\hline Bouliac 1 & 377,175 & 3283,980 & 75,4 & 71,90 \\
\hline Brocas Franks 1 & 369,912 & 3192,508 & 63,1 & 61,27 \\
\hline Cabeil 1 & 336,300 & 3229,330 & 56,7 & 51,80 \\
\hline Cadillac 1 & 396,600 & 3264,500 & 77,77 & 74,27 \\
\hline Cagnotte 1 & 326,369 & 3147,372 & 58,28 & 53,85 \\
\hline Cagnotte 101 & 327,423 & 3147,118 & 63,2 & 58,40 \\
\hline Capcosle 3 & 313,215 & 3174,685 & 51,4 & 48,50 \\
\hline Carcans 2 & 335,740 & 3308,720 & 28,8 & 25,30 \\
\hline Carrate 1 & 347,948 & 3209,225 & 82,24 & 77,72 \\
\hline Cazaux 1 & 320,415 & 3254,945 & 34,6 & 30,00 \\
\hline Caudos 1 & 336,326 & 3255,287 & 29,7 & 26,70 \\
\hline Clermont 7 & 333,458 & 3154,060 & 24,82 & 18,57 \\
\hline Contis 1 & 309,192 & 3205,965 & 28,1 & 24,30 \\
\hline Courchade 1 & 341,130 & 3226,871 & 23,4 & 18,60 \\
\hline Estibaux 101 & 337,824 & 3152,978 & 59,96 & 53,63 \\
\hline Garein 1 & 360,250 & 3198,450 & 88 & 84,00 \\
\hline Garrosse 1 & 338,567 & 3192,392 & 82,9 & 78,33 \\
\hline $\begin{array}{l}\text { Geothermie Dax 1- } \\
\text { GDX } 1\end{array}$ & 323,680 & 3161,950 & - & 6,00 \\
\hline $\begin{array}{l}\text { Geoth. Mont-de-Marsan } \\
\text { 2-GMM } 2\end{array}$ & 375,275 & 3182,275 & 60 & 48,00 \\
\hline Gourbera 1 & 328,700 & 3171,004 & - & 55,29 \\
\hline Grenade-sur-l'Adour 1 & 379,375 & 3171,615 & 87,75 & 83,26 \\
\hline Heulies 1 & 408,275 & 3229,713 & 134,65 & 130,00 \\
\hline Hourquet 1 & 320,930 & 3297,060 & 20 & 15,00 \\
\hline Hourtin 1 bis & 325,257 & 3330,635 & - & 15,20 \\
\hline Labenne 1 & 291,997 & 3150,392 & 18,5 & 12,00 \\
\hline Labrit 1 & 365,684 & 3203,397 & 84,7 & 82,80 \\
\hline Labrit 2 & 368,374 & 3204,174 & 82,4 & 80,57 \\
\hline Lacquy 1 & 391,288 & 3188,663 & 127,89 & 122,89 \\
\hline Lacquy 101 & 390,625 & 3187,785 & 112,65 & 107,77 \\
\hline Landes-de-Siougos 2-LS 2 & 354,903 & 3183,448 & - & 50,85 \\
\hline Landes-de-Siougos 4-LS 4 & 365,803 & 3176,986 & - & 81,13 \\
\hline Landes-de-Siougos 7-LS 7 & 362,058 & 3180,683 & - & 56,68 \\
\hline Larrouy 1 & 336,202 & 3151,591 & 58,6 & 54,50 \\
\hline Lavergne-la-Teste 1 & 315,329 & 3264,661 & 14,1 & 9,10 \\
\hline Le Brain 1 & 347,200 & 3250,750 & 33,5 & 30,00 \\
\hline Le Teich 1 & 332,325 & 3264,074 & 28,7 & 13,70 \\
\hline Le Teich 2 & 334,250 & 3263,400 & 14,7 & 10,00 \\
\hline
\end{tabular}

\begin{tabular}{|c|c|c|c|c|}
\hline Sondage & $\mathbf{x}$ & $\mathbf{Y}$ & Zt réf. & Z sol \\
\hline Le Terme 1 & 338,860 & 3242,820 & 53,4 & 48,30 \\
\hline Lenan 1 & 333,815 & 3272,646 & 13,1 & 9,00 \\
\hline Le Porge 1 & 330,410 & 3291,920 & 28,25 & 23,75 \\
\hline Les Acacias 1 & 321,314 & 3266,871 & 36,9 & 32,50 \\
\hline Lesgor 1 & 339,853 & 3176,550 & 31,8 & 28,40 \\
\hline Le Vigneau 1 & 389,893 & 3168,031 & 125,38 & 117,63 \\
\hline Listrac 1 & 353,664 & 3314,180 & 31,37 & 35,00 \\
\hline Lit-et-Mixe 1 & 310,981 & 3195,557 & 34,63 & 30,00 \\
\hline Losse 1 & 405,825 & 3199,750 & - & 137,00 \\
\hline Magenta 1 & 386,875 & 3209,598 & 104,47 & 102,57 \\
\hline Magenta 2 & 389,704 & 3205,291 & 101,9 & 100,00 \\
\hline Magescq 1 & 321,262 & 3172,042 & 62,9 & 59,60 \\
\hline Maillas 1 & 398,440 & 3216,650 & 125,4 & 120,00 \\
\hline Marlen & 332,170 & 3218,513 & 63 & 55,00 \\
\hline Maubuisson 1 & 326,576 & 3316,400 & 19,8 & 15,30 \\
\hline & & & 95,81 & 89,36 \\
\hline Mez & 50 & 3211,4 & 58,2 & 53,40 \\
\hline Mez & 22,140 & 3204,930 & 46,8 & 42,00 \\
\hline Mimi & & & 11,3 & 7,30 \\
\hline Mimizan $\mathrm{Pl}$ & 312,870 & 3217,548 & 19,5 & 14,40 \\
\hline Montagnottes 1 & 303,210 & 3168,496 & 14,95 & 11,50 \\
\hline $\begin{array}{l}\text { Montaut-09515X0038/ } \\
\text { SMON }\end{array}$ & 359,150 & 3164,750 & - & \\
\hline Mont de Marsan 1 & & 3177,1 & - & 69,30 \\
\hline & & & 91,2 & 86,30 \\
\hline & 00 & 3232,000 & 26,9 & - \\
\hline -Village 1 & 324,434 & 3224,272 & 44,5 & 39,90 \\
\hline & & & 81,85 & 75,40 \\
\hline & & & 85 & 80,30 \\
\hline n-d'lllac 1 & & 3279,180 & 59,5 & 55,00 \\
\hline & & $3243, \subseteq$ & 39,3 & 34,80 \\
\hline Sau & & 3265,460 & 61,5 & 58,00 \\
\hline & & 3232,100 & 70,32 & 65,3 \\
\hline & & 3306,3 & 43 & 38,00 \\
\hline Marensin 1 & 305,500 & 3191,5 & 47,6 & 43,80 \\
\hline St-Jean-d & & 3153,4 & 36,07 & 31,97 \\
\hline St-Mart & 298,438 & 3146,577 & 56,4 & 53,00 \\
\hline dard-En-Jalles 1 & 348,8 & 3294,600 & 47,5 & 44,00 \\
\hline Sebastopol 1 bis & & 3165,8 & 39,3 & 34,80 \\
\hline & & & 22,73 & 18,90 \\
\hline & 296,2 & 3163,3 & 8,49 & 4,48 \\
\hline Sou & 313,000 & 3168,060 & 43,58 & 39,0 \\
\hline & & & 84,25 & 79,70 \\
\hline & 358,6 & 3165,8 & 32,9 & - \\
\hline Trens: & 358,492 & 3216,609 & 93,5 & 89,00 \\
\hline & & & 51,75 & 47,25 \\
\hline Villenave 2 & 343,594 & 3193,538 & 79,37 & 74,87 \\
\hline Villeneuve-De-Marsan 1 & 393,966 & 3184,406 & 104,32 & 100,92 \\
\hline
\end{tabular}

(Palmer, 1934). Cette dernière espèce a été bien identifiée en Aquitaine, mais sa rareté rend la détermination de la limite supérieure de la sous-zone peu aisée. À cela s'ajoute que son statut de marqueur biostratigraphique a été remise en question puisque sa disparition s'est avérée discontinue au niveau mondial (Van Simaeys et al. 2004: fig. 3). C'est dans cet intervalle que s'observent les premiers représentants de Globigerina ciperoensis Bolli, 1957.

\section{P 21B. SOUS-ZONE À GLOBIGERINA ANGULISUTURALIS- PARAGLOBOROTALIA OPIMA OPIMA}

La limite supérieure de la sous-zone est définie par la dispa- rition de Paragloborotalia opima opima (Bolli, 1957), espèce rare en Aquitaine. Globorotaloides testarugosa (Jenkins, 1960) et Globigerinoides primordius Blow \& Banner, 1962 apparaissent dans cet intervalle, mais restent rares.

\section{P 22. ZONE À GLOBIGERINA CIPEROENSIS}

La limite supérieure de la zone est définie par l'apparition de Globorotalia kugleri Bolli, 1957 s.s. et correspond à la limite Chattien/Aquitanien (Berggren et al. 1995; Ogg et al. 2008). Paragloborotalia gr. acrostoma (Wezel, 1966) et $P$. mendacis (Blow, 1969) apparaissent dans cette zone (Groupe français d'Étude du Néogène 1974). 


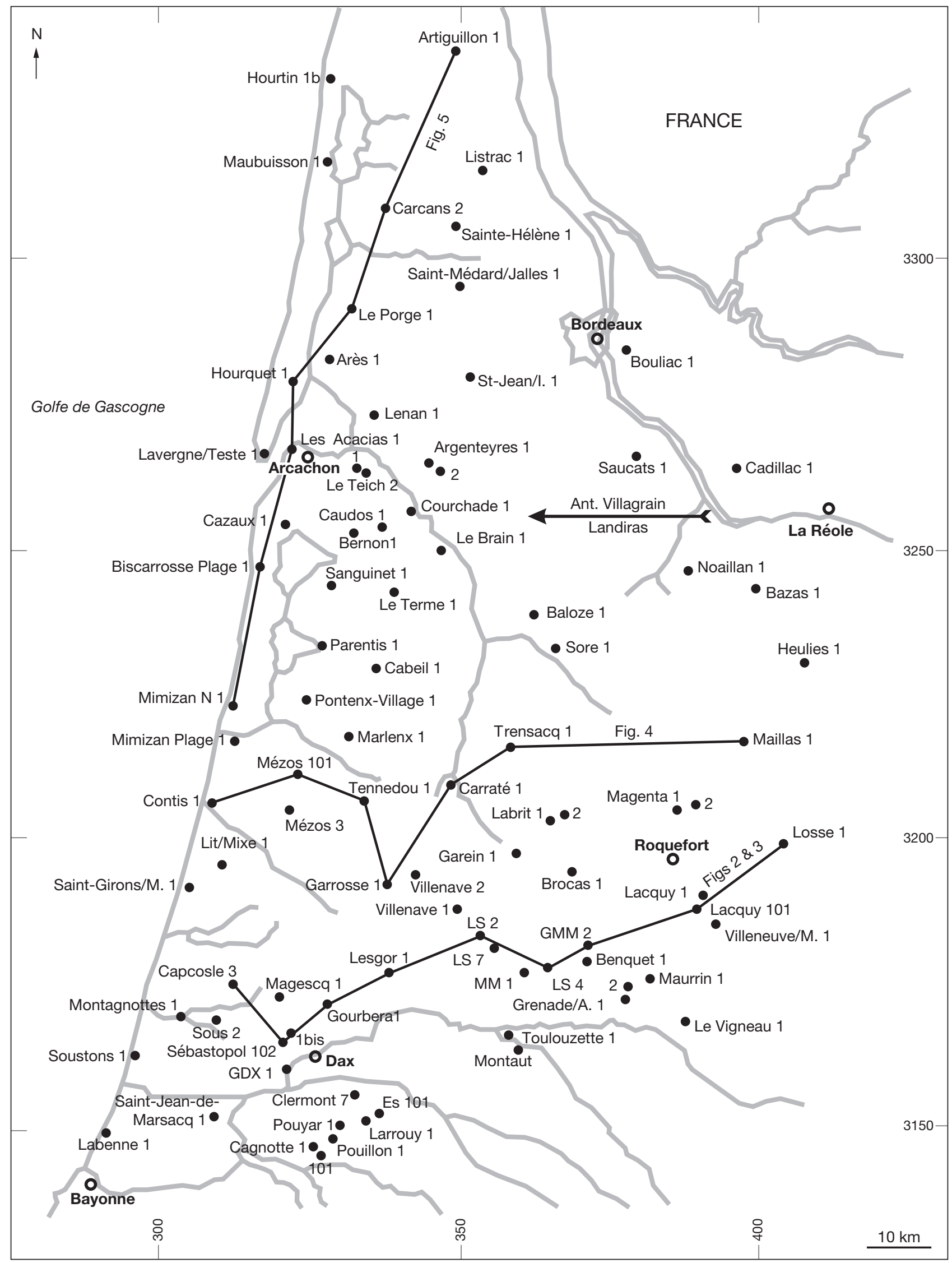

FIG. 1. - Plan de position des sondages étudiés (voir Tableau 1 pour la liste alphabétique). Maillage kilométrique de la zone Lambert III. Abréviations: Es, Estibaux; Pouyar, Pouyarramon; Sous, Soustons/Location of the studied boreholes (see Table 1 for the alphabetical listing). Lambert III kilometer grid. Abbreviations: Es, Estibaux; Pouyar, Pouyarramon; Sous, Soustons. 
TABLEAU 2. - Apparition de quelques foraminifères d'importance stratigraphique. $\mathbf{r}$, Apparition; - 1 , Disparition/Appearance of some stratigraphically important foraminifera. $\vdash$, Appearance; - 1 , Disappearance.

Spirorutilis carinatus (d'Orbigny, 1846)

Pavonitina kiscelliana (Sztrákos, 1979)

Dorothia asiphonia (Andreae, 1884)

Karreriella siphonella (Reuss, 1851)

Martinottiella rhumbleri (Cushman, 1936)

Bigenerina eocaena Sztrákos, 1979

Bigenerina oligocaena Sztrákos, 1979

Textularia pala Czjzek, 1848

Karrerotextularia concava (Karrer, 1868)

Lingulina glabra Hantken, 1875

Lenticulina budensis (Hantken, 1875)

Percultazonaria pseudodecorata (Hagn, 1952)

Vaginulinopsis schwageri (Hantken, 1875)

Planularia karolyi Cicha \& Rögl, 1998

Spirolingulina inflata (Sztrákos, 1979)

Bolivina beyrichi beyrichi Reuss, 1851

Bolivina beyrichi carinata Hantken, 1875

Bolivina oligocaenica Spandel, 1909

Cassidulina laevigata d'Orbigny, 1826

Cassidulina vitalisi Majzon, 1948

Cassidulinoides bodeni Hagn, 1952

Rectobolivina reticulosa (Cushman, 1936)

Bulimina sculptilis Cushman, 1923

Uvigerina hantkeni Cushman \& Edwards, 1937

Angulogerina angulosa (Williamson, 1858)

Angulogerina germanica Cushman \& Edwards, 1938

Trifarina bradyi Cushman, 1923

Cancris auriculus (Fichtel \& Moll, 1798)

Valvulineria palmarealensis (Nuttall, 1932)

Rosalina semiporata douvillei (Cushman, 1928)

Sphaeroidina bulloides d'Orbigny, 1826

Planulina renzi Cushman \& Stainforth, 1945

Cibicides boueanus (d'Orbigny, 1846)

Nonionella liebusi Hagn, 1952

Almaena abrardi (Poignant, 1965)

Anomalinoides granosa (Hantken, 1875)

Gyroidinoides mamillata (Andreae, 1884)

Hansenisca allani (Finlay, 1939)

Hansenisca elegans (d'Orbigny, 1846)

Elphidiella minuta (Reuss, 1865)

Planostegina costata (d'Orbigny, 1839)

Nummulites bouillei de la Harpe, 1879

Nummulites fichteli Michelotti, 1841

Nummulites vascus Joly \& Leymerie, 1848

Operculina complanata (Defrance, 1822)

Bullalveolina bulloides (d'Orbigny, 1826)

Bolivina liebusi Hofmann, 1967

Loxostomoides zsigmondii (Hantken, 1868)

Reussella byramensis Cushman \& Todd, 1946

Valvulineria sculpturata (Cushman, 1935)

Discorbina mira (Cushman, 1922)

Discorbina trocha (Römer, 1838)

Rosalina semiporata semiporata (Egger, 1857)

Falsocibicides aquitanicus Poignant, 1958

Halkyardia maxima Cimerman, 1969

Astrononion budense Sztrákos, 1979

Asterigerina dollfusi Cushman, 1928

Almaena escornebovensis (Sigal, 1950)

Pararotalia parva (Cushman, 1922)

Pararotalia verriculata (Howchin \& Parr, 1938)

Elphidiella cryptostoma (Egger, 1857)

Ceratobulimina contraria (Reuss, 1851)

Bolivina fastigia Cushman, 1936

Sigmavirgulina tortuosa (Brady, 1884)

\begin{tabular}{|c|c|c|c|c|c|c|}
\hline ÉOCENE & & & & & $\mathrm{CH} A$ & EN \\
\hline & P18 & P19 & P20 & P21a & P21b & P22 \\
\hline & & & & & & \\
\hline & & & & & & \\
\hline & & & & & & \\
\hline & & & $?$ & & & \\
\hline & & & & & & \\
\hline & & & & & & \\
\hline & & & & & & \\
\hline & & & & & & \\
\hline & & & & & & \\
\hline & & & & & & \\
\hline & & & & & & \\
\hline & & & & & & \\
\hline & & & & & & \\
\hline & & & & & & \\
\hline & & & & & & \\
\hline & & & & & & \\
\hline & & & & & & \\
\hline & & & & & & \\
\hline & & & & & & \\
\hline & & & & & & \\
\hline & & & & & & \\
\hline & & & & & & \\
\hline & & & & & & \\
\hline & & & & & & \\
\hline & & & & & & \\
\hline & & & & & & \\
\hline & & & & & & \\
\hline & & & & & & \\
\hline & & & & & & \\
\hline & & & & & & \\
\hline & & & & & & \\
\hline & & & & & & \\
\hline & ? & & & & & \\
\hline & & & & & & \\
\hline & & & & & & \\
\hline & & & & & & \\
\hline & & & & & & \\
\hline & & & & & & \\
\hline & & & & & & \\
\hline & & & & & & \\
\hline & & & & & & \\
\hline & & & & & & \\
\hline & & & & & & \\
\hline & & & & & & \\
\hline & & & & & & \\
\hline & & & & & & \\
\hline
\end{tabular}


TABLEAU 2. - Suite/continuation.

\begin{tabular}{|c|c|c|c|c|c|c|c|}
\hline & ÉOCENE & & & IEN & & $\mathrm{CH}$ & IEN \\
\hline & & P18 & P19 & P20 & P21a & $\mathrm{P} 21 \mathrm{~b}$ & P22 \\
\hline Siphonina reticulata Czjzek, 1848 & & & & & & & \\
\hline Sigmoilinita asperula (Karrer, 1868) & & & & & & & \\
\hline Lingulina seminuda Hantken, 1875 & & & & & & & \\
\hline Bolivina antiqua d'Orbigny, 1846 & & & & & & & \\
\hline Asterigerinoides guerichi (Franke, 1912) & & & & & & & \\
\hline Nephrolepidina praemarginata (R. Douvillé, 1908) & & & & & & & \\
\hline Eulepidina dilatata (Michelotti, 1861) & & & & & & & \\
\hline Eulepidina formosoides (H. Douvillé, 1924) & & & & & & & \\
\hline Almaena hieroglyphica (Sigal, 1950) & & & & & & & \\
\hline Almaena osnabrugensis (Römer, 1838) & & & & & & & \\
\hline Hansenisca soldanii (d'Orbigny, 1826) & & & & & & & \\
\hline Almaena delmasi (Rey, 1958) & & & & & & & \\
\hline Rectobolivina costifera (Cushman, 1936) & & & & & & & \\
\hline Reussella spinulosa spinulosa Reuss, 1850 & & & & & & & \\
\hline Marginulina hirsuta d'Orbigny, 1826 & & & & & & & \\
\hline Rectobolivina sanctipauli Hayward \& Poignant, 19 & & & & & & & \\
\hline Nephrolepidina morgani (Lemoine \& Douvillé, 190 & & & & & & & \\
\hline Elphidium crispum (Linnaeus, 1758) & & & & & & & \\
\hline Heterostegina heterostegina (Silvestri, 1907) & & & & & & & \\
\hline Grzybowskia assilinoides (Blanckenhorn, 1890) & & & & & & & \\
\hline Spiroclypeus blanckenhorni ornata Henson, 1937 & & & & & & & \\
\hline Cycloclypeus eidae Tan Sin Hok, 1932 & & & & & & & \\
\hline Alliatina nitida (Tollmann, 1957) & & & & & & & \\
\hline Alliatina tollmani Langer, 1969 & & & & & & & \\
\hline Pavonitina plana Loeblich \& Tappan, 1985 & & & & & & & \\
\hline Bolivina cookei Cushman, 1922 & & & & & & & \\
\hline Bolivina hebes Macfadyen, 1930 & & & & & & & \\
\hline Tubulogenerina lunata Gibson \& Poignant, 1991 & & & & & & & \\
\hline Amphistegina hauerina (d'Orbigny, 1846) & & & & & & & \\
\hline Astrononion stelligerum (d'Orbigny, 1939) & & & & & & & \\
\hline Almaena obesa (Sigal, 1950) & & & & & & & \\
\hline Buccella hannai (Phleger \& Parker, 1951) & & & & & & & \\
\hline Elphidium flexuosum (d'Orbigny, 1846) & & & & & & & \\
\hline Miogypsinoides borodinensis Hanzawa, 1940 & & & & & & & \\
\hline Miogypsinoides complanata (Schlumberger, 1900) & & & & & & & \\
\hline Miogypsinoides ubaghsi Tan Sin Hok, 1936 & & & & & & & \\
\hline Miogypsinoides formosensis Yabe \& Hanzawa, 19 & & & & & & & \\
\hline Miogypsinoides bantamensis Tan Sin Hok, 1936 & & & & & & & \\
\hline Miogypsinoides dehaartii (Van der Vlerk, 1924) & & & & & & & \\
\hline Miogypsinoides lateralis Hanzawa, 1940 & & & & & & & \\
\hline Miogypsinoides mauretanicus Brönnimann, 1940 & & & & & & & \\
\hline
\end{tabular}

\section{RÉPARTITION DES FORAMINIFÈRES BENTHIQUES}

\section{RÉPARTITION STRATIGRAPHIQUE}

La répartition stratigraphique des foraminifères benthiques (Annexe 1) est basée sur les résultats des sondages et sur les publications suivantes: Groupe français d'Étude du Néogène (1974), Cahuzac (1984), Cahuzac \& Poignant (1988, 1992, 1997, 2002), Poignant (1998, 1999) et Poignant \& Lorenz (1985).

D'importants changements faunistiques ont eu lieu à partir du Priabonien inférieur dans le Bassin d'Aquitaine qui se poursuivent au cours du Rupélien. Parmi les 523 espèces qui ont été répertoriées dans le Priabonien (Sztrákos 2000; Sztrákos et al. 2010), 315 disparaissent au cours de cet étage et à la limite Éocène/Oligocène. 233 espèces franchissent cette limite selon notre inventaire, plus d'un tiers de la faune totale de l'Oligocène, qui compte 587 espèces (voir Annexe 1). L'apparition et la disparition des espèces est progressive, ce qui permet d'en utiliser certaines comme marqueurs pour la stratigraphie du Bassin d'Aquitaine. Ces espèces sont indiquées dans les Tableaux 2 et 3.

RÉPARTITION EN FONCTION DE LA BATHYMÉTRIE Association du domaine infralittoral

(0-50 $m$ de tranche d'eau)

Les genres les plus fréquents sont les Sphaerogypsina, Halkyardia, Amphistegina, Neorotalia, Pararotalia, Miogypsinoides, Nummulites et Operculina sur la plateforme carbonatée. Cahuzac \& Poignant (1988) ont décrit une faune de cette tranche d'eau, mais vivant sur un fond sableux dans les affleurements d'Abesse et Estoti. Les Almaena étaient déjà présentes dans ce milieu. 
TABLEAU 3. - Disparition de quelques foraminifères d'importance stratigraphique.r, Apparition; - -1, Disparition/Disappearance of some stratigraphically important foraminifera. -1, Appearance; -1, Disappearance.

Palmula inglisiana (Puri, 1957)

Uvigerina acutocostata Hagn, 1956

Neorotalia lecalvezae (Boulanger \& Poignant, 1971)

Chapmanina gassinensis (A. Silvestri, 1905)

Quadrimorphinella incauta Vetrova, 1975

Textularia Iontensis Lalicker, 1935

Ceratocancris crassus (Halkyard, 1919)

Bolivina striatocarinata Cushman, 1936

Globocassidulina alpina Sztrákos \& Du Fornel, 2003

Cribroparella pteromphalia (Gümbel, 1870)

Hansenisca poignantae Sztrákos, 1993

Coleites cancellatus (Cushman \& Bermúdez, 1936)

Textularia neorugosa Thalmann, 1950

Valvulina limbata Terquem, 1882

Triloculina angularis d'Orbigny, 1905

Articulina nitida d'Orbigny, 1865

Tubulogenerina conica Heron-Allen \& Earland, 1909

Bulimina sculptilis Cushman, 1923

Rosalina parisiensis d'Orbigny, 1826

Epistomaria separans Le Calvez, 1949

Marginulina propinqua Hantken, 1883

Globocassidulina ornata Sztrákos, 2000

Almaena taurica Samoylova, 1940

Falsoplanulina ammophila (Gümbel, 1870)

Clavulinoides kruhelensis (Wojczik, 1913)

Valvulina triangularis d'Orbigny, 1826

Peneroplis orbicularis d'Orbigny, 1852

Bullalveolina bulloides (d'Orbigny, 1826)

Bolivina terquemi Lindenberg, 1965

Biapertorbis alteconicus Pokornỳ, 1956

Halkyardia minima (Liebus, 1911)

Epistomaria rimosa (Parker \& Jones, 1865)

Karreria fallax Rzehak, 1891

Nummulites vascus Joly \& Leymerie, 1848

Almaena epistominoides (Marie, 1950)

Nummulites fichteli Michelotti, 1841

Triplasia loeblichi Hagn, 1953

Cancris subconicus (Terquem, 1882)

Nonionella wemmelensis Kaasschieter, 1961

Elphidium latidorsatum (Reuss, 1864)

Halkyardia maxima Cimerman, 1969

Haddonia intermedia (Halkyard, 1919)

Karreriella hantkeniana Cushman, 1936

Clavulinoides szaboi (Hantken, 1868)

Percultazonaria fragaria (Gümbel, 1870)

Marginulina behmi (Reuss, 1866)

Bolivina crenulata Cushman, 1936

Bolivina elongata Hantken, 1875

Bolivina semistriata Hantken, 1868

Bulimina alsatica Cushman \& Parker, 1937

Uvigerina moravia Boersma, 1984

Kolesnikovella tubulifera (Kaasschieter, 1961)

Baggina dentata Hagn, 1956

Planulina costata (Hantken, 1875)

Stichocibicides moravicus Pokornỳ, 1956

Anomalinoides similis (Hantken, 1875)

Heterolepa eocaena (Gümbel, 1870)

Miogypsinoides complanata (Schlumberger, 1900)

Miogypsinoides formosensis Yabe \& Hanzawa, 1828

Nummulites bouillei de la Harpe, 1879

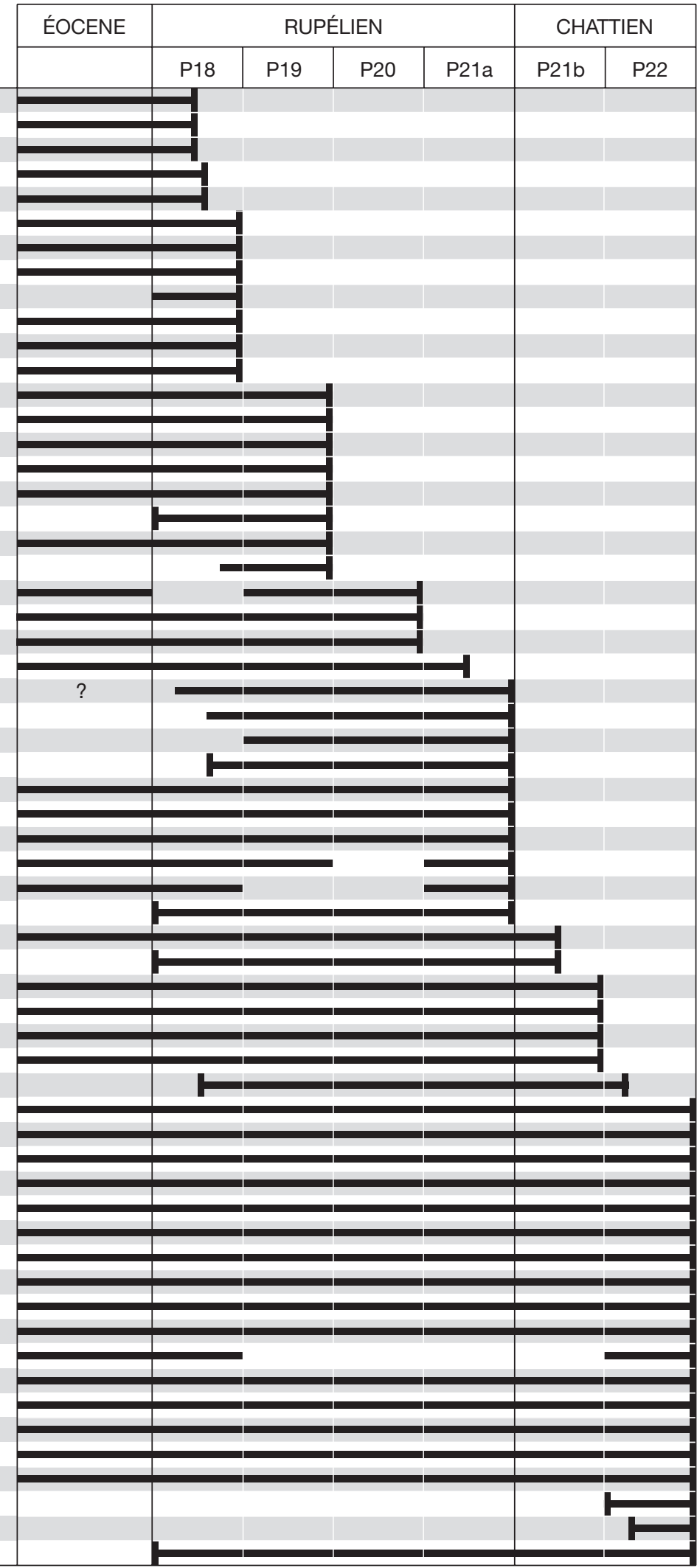




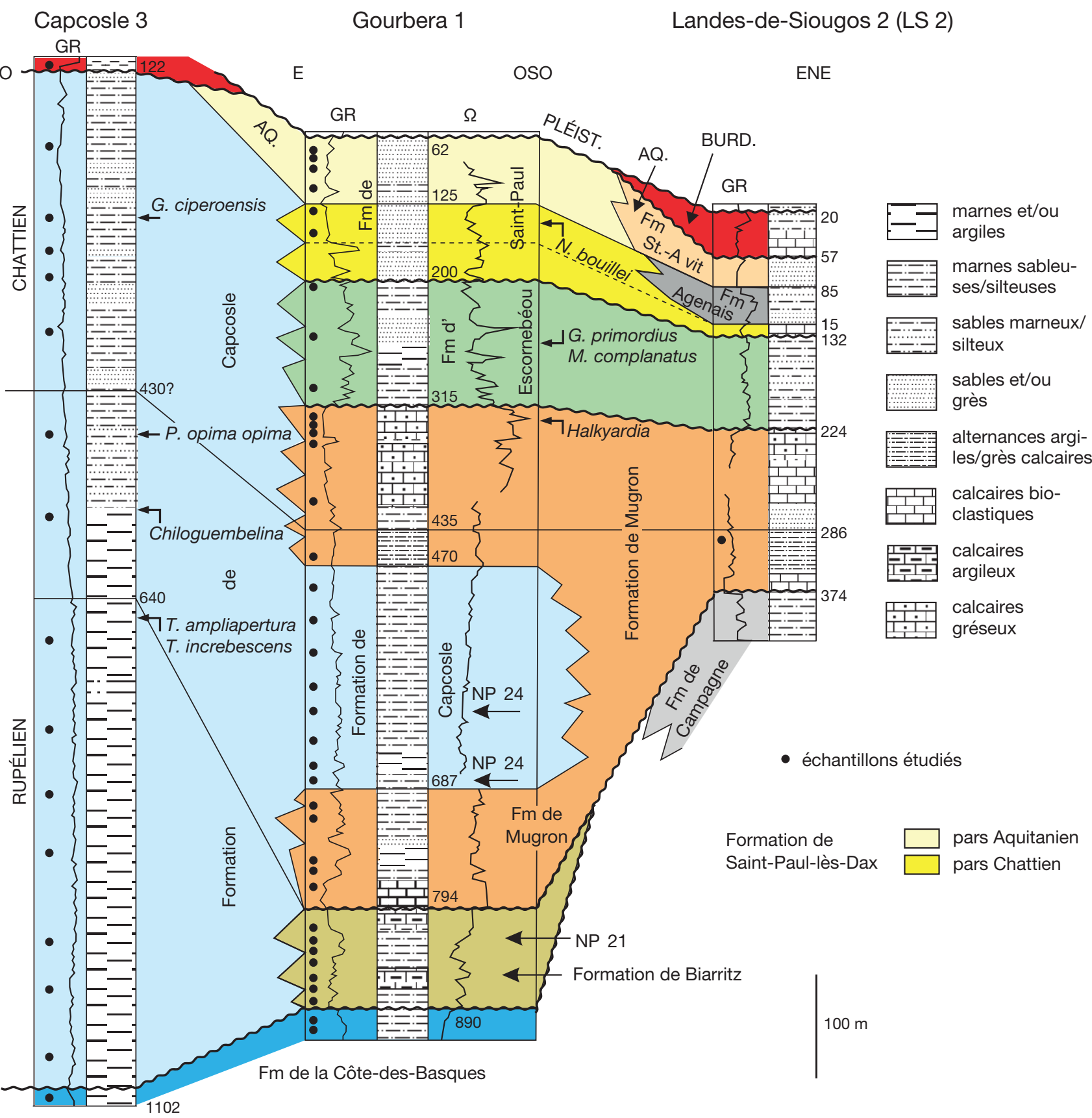

FIG. 2. - Corrélation de l'Oligocène entre les sondages Capcosle 3, Gourbera 1 et Landes-de-Siougos 2. Abréviations: AQ., Aquitanien; BURD., Burdigalien; PLEIST., Pléistocène; St-Paul, Formation de Saint-Paul-lès-Dax; GR, Gamma ray; $\Omega$, Résistivité/Correlation of the Oligocene between boreholes Capcosle 3, Gourbera 1 and Landes-de-Siougos 2. Abbreviations: AQ., Aquitanian; BURD., Burdigalian; PLEIST., Pleistocene; St-Paul, Saint-Paul-lès-Dax Formation; GR, Gamma ray; $\Omega$, Resistivity.

Association du domaine infralittoral

(50-100 $m$ de tranche d'eau)

Hoeglundina elegans (d'Orbigny, 1826), Sphaeroidina bulloides d'Orbigny, 1826 (Van Morkhoven et al. 1986), Uvigerina moravia Boersma, 1984, Praeglobobulimina pyrula (d'Orbigny, 1846), Planulina costata (Hantken, 1875), Heterolepa dutemplei (d'Orbigny, 1846), H. megomphala (Gümbel, 1870) et Melonis pompilioides (Fichtel \& Moll, 1798) (la variété comprimée, affinis de Reuss, 1851) apparaissent dans cette tranche d'eau.
Association du domaine circalittoral (100-200 $m$ de tranche d'eau)

Les genres Martinottiella et Karreriella apparaissent à partir de $100 \mathrm{~m}$ de profondeur d'eau (Murray 1973). Ces genres sont présents dans les argiles oligocènes d'Aquitaine. Martinottiella communis (d'Orbigny, 1846), Semivulvulina pectinata (Reuss, 1850), Pullenia quinqueloba (Reuss, 1851) et P. bulloides (d'Orbigny, 1826) ont été observées dans les marnes à Escornebéou qui se sont déposées entre 100 et $200 \mathrm{~m}$ de profondeur d'eau (Groupe français d'Étude du Néogène 1974). 
Heterolepa eocaena (Gümbel, 1870) et Falsoplanulina ammophila (Gümbel, 1870), présentes dans l'Oligocène d'Aquitaine, apparaissent à partir de $100 \mathrm{~m}$ de profondeur d'eau selon Van Morkhoven et al. 1986. Clavulinoides szaboi (Hantken, 1868) et Bulimina sculptilis Cushman, 1923 sont présentes dans cette association et également dans le milieu bathyal.

\section{Association du domaine bathyale}

(200-600 $m$ de tranche d'eau)

Les sondages situés sur la façade atlantique ont traversé des dépôts bathyaux. Ils sont caractérisés par la présence rare des espèces suivantes: Vulvulina haeringensis (Gümbel, 1870), V. flabelliformis (Gümbel, 1870), Reticulophragmium acuticostatum (Hantken, 1868), Pleurostomella alternans Schwager, 1866, P. incrassata Hantken, 1883, Ellipsoglandulina ellipsoides Seguenza, 1859, E. Labiata (Schwager, 1866), E. laevigata Silvestri, 1900, E. vasarhelyi (Hantken, 1868) et Cribroparella pteromphalia (Gümbel, 1870). Cette association appartient au milieu bathyal supérieur (Mathelin \& Sztrákos 1993). Labsence du genre Laticarinina laisse supposer des profondeurs inférieures à $300 \mathrm{~m}$ (Van Morkhoven et al. 1986).

\section{AFFINITÉS RÉGIONALES DE LA FAUNE}

La faune de foraminiferes du Bassin d'Aquitaine montre de nombreuses affinités avec celle de la Paratéthys centrale (Sztrákos 1979, 1982; Cicha et al. 1998). Ceci vient du fait que les deux sont en partie composées des survivants de la faune de la Téthys éocène, commune dans les deux régions, où l'on note également la présence de nombreuses espèces décrites dans le sud des EtatsUnis et en Amérique centrale. Ce fait a déjà été observé par Poignant \& Lorenz (1985) et par Poignant \& Sztrákos (1986).

La découverte d'espèces qui se limitent à l'Oligocène en Europe centrale montre que les liens n'ont pas cessé entre ces régions. Parmi les 549 espèces reconnues dans la faune benthique aquitaine, 348 ont été signalées de la Paratéthys centrale. Parmi les espèces spécifiques de l'Aquitaine, on dénombre de nombreux taxons infralittoraux.

Le cas d'une espèce rare, Thyromata curviseptum (Subbotina, 1936) illustre bien l'existence de cette communication marine. Cette forme a été décrite dans l'Oligocène inférieur du nord du Caucase. Rögl \& Hansen (2009) l'ont mentionné dans de nombreuses localités entre le Caucase et la Haute Savoie. L'étude des marnes épibathyales a permis de la découvrir en Aquitaine dans le Rupélien inférieur.

La découverte d'une autre espèce, Globocassidulina alpina Sztrákos \& Du Fornel, 2003, décrite du Priabonien et de l'Oligocène basal des Alpes Maritimes (SE de la France) montre également les liens qui ont perduré entre cette région et l'Aquitaine. Le contact des deux régions s'est effectué par le détroit de Gibraltar et la zone bétique, au sud de l'Espagne (Cahuzac et al. 1992; Rögl \& Hansen 2009).

\section{DESCRIPTION DES UNITÉS LITHOSTRATIGRAPHIQUES}

Pour des raisons historiques, on différencie deux régions en Aquitaine: les Bassins de l'Adour et de Parentis d'une part, où se développent tous les milieux de dépôt du bathyal à continental dans la direction ouest-est et la plate-forme nord-aquitaine d'autre part, où dominent les sédiments néritiques, carbonatés et les formations continentales. Les formations sont traitées dans ce qui suit d'abord selon leur position géographique (de l'ouest à l'est) et puis par ordre stratigraphique croissant.

\section{BASSINS DE L'ADOUR ET DE PARENTIS}

\section{Formation de Capcosle \\ (formation nouvellement proposée dans ce travail)} (Figs 2, 3-6)

LoCALitÉ-TYPe. - Sondage Capcosle 3, 122-1102 m. X=313,215; $\mathrm{Y}=3174,685 ; \mathrm{Z}$ réf. $=51,4 \mathrm{~m}$, foré en 1965 (Fig. 2). Les échantillons et le rapport de fin de sondage se trouvent au Bureau ExplorationProduction des Hydrocarbures du Ministère de l'Industrie (BEPH).

ORIGINE DU NOM. — Du nom du sondage-type.

DÉFINITION. - Formation à dominance argileuse, qui appartient majoritairement aux milieux circalittoral à épibathyal. Elle peut devenir infralittoral au sommet. Des niveaux sableux ou carbonatés, localement riches en macrofaune, peuvent être présents dans les niveaux turbiditiques.

CONTACTS. — La formation repose sur la surface érodée des Marnes de la Côte des Basques (Priabonien supérieur) et est surmontée par le Burdigalien dans le sondage type. Cependant, Vigneaux et al. (1970) ont observé que ces marnes passent en continuité dans l'Aquitanien à Globorotalia kugleri Bolli, 1957 dans un forage d'eau à Soustons. Le toit de la formation doit donc être défini par la discordance érosive régionale qui se situe entre l'Aquitanien et le Burdigalien.

EXTENSION GÉOGRAPHIQUE. — La formation occupe la façade atlantique du Bassin d'Aquitaine entre Labenne au sud et Biscarrosse au nord, sur une longueur de $100 \mathrm{~km}$ et une largeur de $30 \mathrm{~km}$ au maximum (Figs 3-6).

DESCRIPTION DE LA COUPE-TYPE. - 122-301 m : marne grise, sableuse, micacée, glauconieuse, passées de grès grossier, rouge à ciment ferrugineux. Galets de quartz et de roches éruptives. Présence de Nummulites. 301-681 m: marne grise, finement sableuse et glauconieuse, pyrite, débris coquilliers et de poissons. 681-925 m: marne calcaire grise, finement micacée et glauconieuse, intercalations décimétriques de silt et de grès fin, gris clair, glauconieux. Rares débris coquilliers. 925-1102 m: marne grise, très finement micacée, parfois sableux; argile calcaire verte, glauconieuse. Présence de pyrite, débris ligniteux abondants.

Milieu DE DÉPÔT. - La Formation de Capcosle appartient au milieu bathyal supérieur entre 430 et $1102 \mathrm{~m}$, au milieu circalittoral entre 215 et $430 \mathrm{~m}$ et représente le milieu infralittoral entre 122 et $215 \mathrm{~m}$ dans la coupe type. Elle passe latéralement dans les formations infralittorales vers l'est. Les niveaux sableux ou carbonatés d'origine turbiditique peuvent s'intercaler dans la partie bathyale. Ces intercalations sont peu épaisses en général. Cette lithologie, qui représente le milieu infralittoral, réapparaît dans sa partie sommitale, régressive, en relation avec le remplissage progressif du bassin.

ÂGE. — L'intervalle de 670 à $1070 \mathrm{~m}$ du sondage Capcosle 3 appartient à la zone P 18 avec Turborotalia increbescens (Bandy, 1949), T. ampliapertura (Bolli, 1957) et Subbotina linaperta utilisindex (Jenkins \& Orr, 1973); Pseudohastigerina barbadoensis Blow, 1969 a été observée à 1010 et $1070 \mathrm{~m}$. Les foraminiferes planctoniques sont rares et peu caractéristiques jusqu’à $370 \mathrm{~m}$, où $G$. angulisuturalis Bolli, 


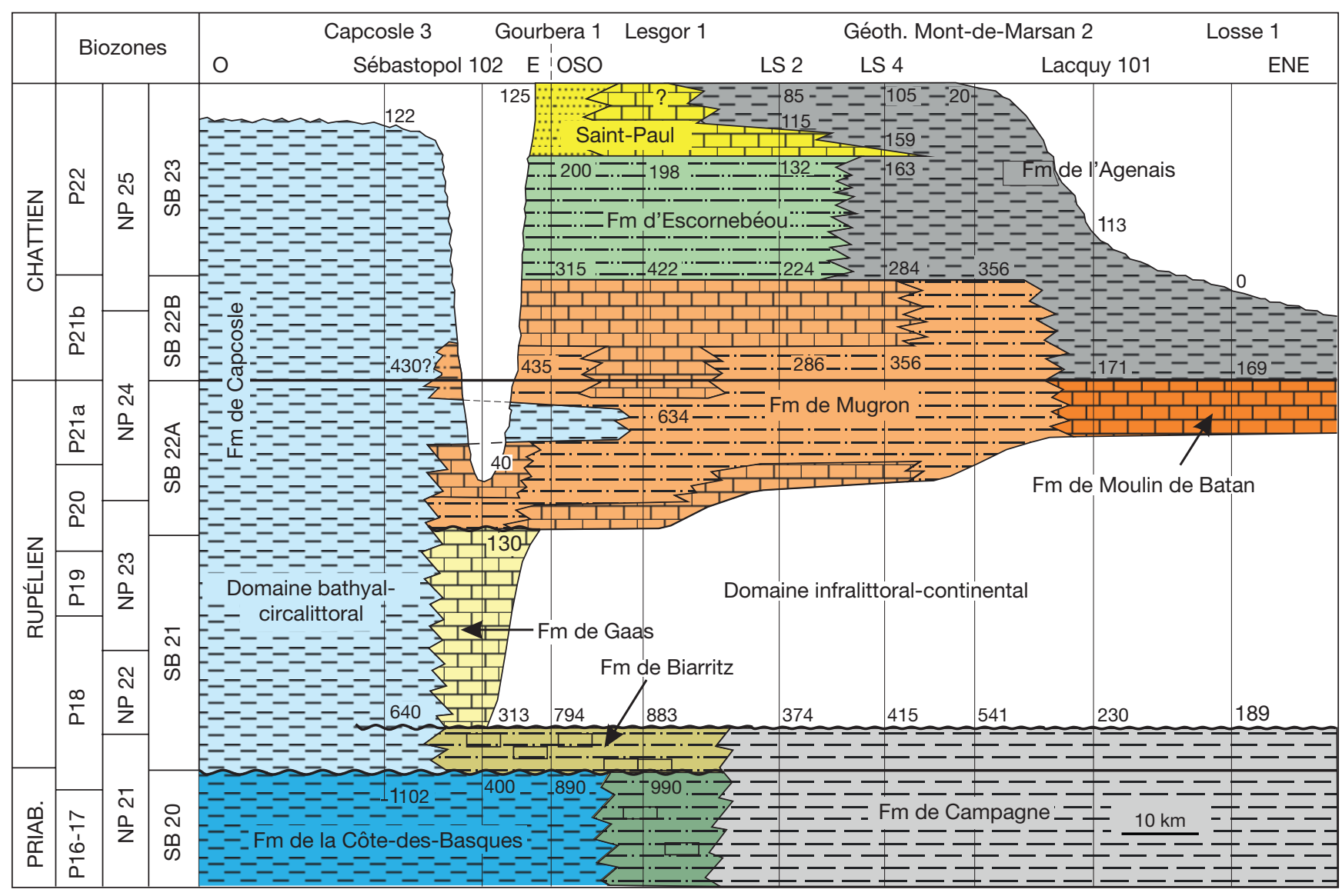

FIG. 3. - Corrélation de l'Oligocène entre les sondages Capcosle 3 et Losse 1. Abréviations: LS, Landes-de-Siougos; Saint-Paul, Formation de Saint-Paul-lèsDax; Ligne interrompue, limite des domaines reconnus/Correlation of the Oligocene between boreholes Capcosle 3 and Losse 1. Abbreviations: LS, Landesde-Siougos; Saint-Paul, Saint-Paul-lès-Dax Formation; Interrupted line, boundary between the identified domains.

1957 est présente (P 21-P 22). Paragloborotalia opima opima (Bolli, 1957) (zone P 21) a été observée à $470 \mathrm{~m}$ et Chiloguembelina cubensis (Palmer, 1934) à $550 \mathrm{~m}$ (zone P 21a). Le sommet de la formation appartient au Chattien probablement supérieur, avec une faune peu caractéristique à Victoriella abnormis (Hantken, 1875) et Operculina complanata (Defrance, 1822) à 190 m. Karreriella siphonella (Reuss, 1851) et Globigerina ciperoensis Bolli, 1957 coexistent à $260 \mathrm{~m}$. L'âge de la formation est Rupélien et Chattien (P 18-P 22) d'après les datations effectuées dans les autres puits pétroliers, pouvant monter jusqu'à l'Aquitanien (Vigneaux et al. 1970).

\section{Formation de Biarritz \\ (formation redéfinie ici) \\ (Figs 2, 3, 6)}

AuTEUR. — Eardley (1946: tableau 1) : Biarritz Sandstone, nom non valide (absence de définition).

SYNONYMES. - Calcaires sableux à Spatangus ornatus Defrance in Brongniart, 1827 du phare Saint-Martin au Vieux Port, calcaires sableux et marneux à Turritella imbricataria Lamarck, 1804 du phare, Thorent (1846); Calcaires à Euspatangus ornatus, Grès à Operculina, Delbos (1854); Calcaire sableux à Euspatangus ornatus, Grès et sables à Operculines, Pellat (1863); Grès à Euspatangus ornatus, Grès et calcaires à Operculines (Jacquot 1864); Couches de la Villa Belza, du Port Vieux et de l'Atalaye, Couches de la Villa Eugénie, du Phare et de la Chambre d'Amour (Boussac 1911); Sa- bles d'Yrieu (Poignant 1967, nom non valide parce que décrit dans une thèse; Hedberg 1979: 24). Le «Biarritz Sandstone" d'Eardley (1946) inclut les deux unités des anciens auteurs.

LOCALITÉ-TYPE. - Affleurements de la Côte des Basques à Biarritz entre les Rochers de Lou Cachaou et la commune de la Chambre d'Amour, répartis sur une distance de $3 \mathrm{~km}$ environ.

DÉFINITION. - Formation carbonatée, composée essentiellement de marnes sableuses à bancs de calcaire gréseux autour de Bayonne devenant plus carbonatée à l'est, où les calcaires sableux, bioclastiques à nummulites dominent.

CONTACTS. - Cette formation repose sur le sommet érodé de la Marne de la Côte des Basques, avec une discordance angulaire de $10^{\circ}$ environ à Biarritz, aux Rochers de Lou Cachaou (Mathelin \& Sztrákos 1993). Les affleurements sont probablement délimités par une faille entre la Chambre d'Amour et Labenne. Les formations qui composent son toit sont inconnues dans la région-type. Le sondage Labenne 1, qui se situe à $8 \mathrm{~km}$ au nord de la Chambre d'Amour, n’a traversé que les argiles bathyales.

EXTENSION GÉOGRAPHIQUE. - La formation a été observée au sud-ouest du Bassin d'Aquitaine, au sud d'une ligne Ondres-Dax.

ÂGE. — Mathelin \& Sztrákos (1993) ont placé dans la zone NP 21 la partie basale de la Formation de Biarritz de la Villa Belza à Biarritz et ont noté la présence de Nummulites bouillei de la Harpe, 1879, N. fichteli Michelotti, 1841, N. incrassatus de la Harpe, 1896 et $N$. vascus Joly \& Leymerie, 1848. Steurbaut (1983) a observé la 
zone NP 21 aux étangs d'Yrieu et d'Orx. Ces affleurements appartiennent à la zone SB 21 du Rupélien (Cahuzac \& Poignant 2002). Cahuzac \& Poignant (1997) ont situé l'affleurement de la Chambre d'Amour dans la zone SB 21 (Rupélien inférieur). Pujol (1970) a déterminé des foraminifères planctoniques appartenant à la zone P 18-P 19 dans cet affleurement: Turborotalia increbescens (Bandy, 1949), T. ampliapertura (Bolli, 1957), Globigerina ouachitaensis gnaucki Blow \& Banner, 1962, Subbotina angiporoides (Hornibrook, 1965) (Globigerina cf. angipora Stache, 1864 dans le texte).

\section{AfFleUREMENTS}

La coupe-type de Biarritz montre une succession qui commence par un poudingue à galets siliceux, auquel succède une marne calcaire très sableuse avec des bancs de calcaire gréseux à galets de chaille à la Villa Belza (Mathelin \& Sztrákos 1993). La série continue par des marnes sableuses à bancs de grès et lits de galets à nombreuses nummulites jusqu'au Port des Pêcheurs. La coupe se poursuit par des marnes sableuses à bancs gréseux à Operculina complanata (Defrance, 1822) au Phare et se termine par des marnes gréseuses à $O$. complanata, Nummulites fichteli Michelotti, 1841 et $N$. vascus Joly \& Leymerie, 1848 de la Villa Noailles à la Chambre d'Amour (Boussac 1911). Les sédiments à lithologie proche affleurent à l'ouest de SaintMartin-de-Seignanx et autour de l'étang d'Yrieu: calcaire peu gréseux à bancs marneux, calcaire à débris ligniteux (Kieken \& Thibault 1972); grès argileux, marne très sableuse, micacée à petits bancs de lignite (Boulanger \& Poignant 1964; Kieken \& Thibault 1975). Ducasse (1974) a observé la continuation des couches de la Chambre d'Amour en faciès circalittoral sur le plateau continental, au large de Bayonne.

\section{SONDAGES}

La formation a été reconnue dans le sondage Gourbera 1 entre 794 et $890 \mathrm{~m}$ de profondeur (Figs 2, 3). Elle est composée par l'alternance de calcaire argileux, grès et argile plus ou moins sableuse. Elle est délimitée par des surfaces d'érosion vers le mur et le toit. L'ensemble appartient au milieu infralittoral avec Operculina complanata (Defrance, 1822) (855 m) et Nummulites fichteli Michelotti, $1841(810 \mathrm{~m})$. La zone NP 21 a été déterminée à 823,7 m dans une carotte latérale à balle par C. Müller : assemblage à Cyclicargolithus floridanus (Roth \& Hay in Hay, Mohler, Roth, Schmidt \& Boudreaux, 1967), Coccolithus formosus (Kamptner, 1963), Reticulofenestra dictyoda (Deflandre in Deflandre \& Fert, 1954), Clausicoccus fenestratus (Deflandre \& Fert, 1954), Clausicoccus subdistichus (Roth \& Hay in Hay, Mohler, Roth, Schmidt \& Boudreaux, 1967), Helicosphaera compacta Bramlette \& Wilcoxon, 1967, H. reticulata Bramlette \& Wilcoxon, 1967, Lanternithus minutus Stradner, 1962, Reticulofenestra umbilica (Levin, 1965), Sphenolithus moriformis (Bronnimann \& Stradner, 1960) et Zygrhablithus bijugatus (Deflandre in Deflandre \& Fert, 1954). Les diagraphies électriques permettent de reconnaître cette formation dans les sondages Sébastopol 102 (313-400 m) et Lesgor 1 (883-990 m; Fig. 3). L'occurrence la plus orientale de la formation a été observée dans le puits Pouyarramon 1, représentée par un niveau gréseux, gris à Halkyardia maxima Cimerman, 1969 et Nummulites vascus Joly \& Leymerie, 1848 à $560 \mathrm{~m}$, en contact avec l'Éocène.

\section{Formation de Gaas}

(Figs 2, 3, 7)

Auteur. — Raulin (1897: 526) : Falun de Gaas et de Lahosse.

SYNONYMES. - Fahluns (sic) bleus à Natica maxima Risso, 1826, Fahlun bleu de Lesbarritz, Calcaire de Garans et de Lesperon, Delbos (1848); Calcaires récifaux de Tuc de Saumon, Platel (1990b).

LOCALITÉ TYPE. - Affleurements à l'ouest du village de Gaas, qui s'étendent depuis la ferme de Garanx jusqu'à celle de Castera selon Le Pochat \& Thibault (1977).

DÉFINITION. - La formation est composée par l'alternance de calcaires bioclastiques, marnes et argiles dans les coupes de référence. La rareté des sables quartzeux est caractéristique à la formation.

EXTENSION GÉOGRAPHIQUE. — La Formation de Gaas infralittorale est connue dans les affleurements à l'est des diapirs de Dax et de Bénesse-lès-Dax et dans les sondages de l'anticlinal de Clermont. Elle passe progressivement dans les molasses argileuses, continentales vers l'est, dans le Bassin d'Arzacq (Formation de Jurançon); sa disparition doit se situer entre les anticlinaux de Clermont et de Montfort. La formation est également connue entre la structure de Sébastopol, la ville de Dax et l'anticlinal de Louer. Sa limite se situe entre la structure de Sébastopol et le sondage Gourbera 1 vers le nord-est.

ÂGE. - Les coupes décrites dans la formation appartiennent à la zone SB 21 (Cahuzac \& Poignant 1997, 2002). Les échantillons du puits Pouyarramon 1 ne contiennent pas d'Eulepidina ou Nephrolepidina, ce qui laisse supposer que les $333 \mathrm{~m}$ de la Formation de Gaas appartiennent à la zone SB 21.

\section{AFFLEUREMENTS}

La Formation de Gaas surmonte directement les calcaires marneux à Nummulites variolarius (Lamarcq, 1804) dans le ruisseau Haubardin (Benoist 1884) et à N. striatus (Bruguière, 1792) à Loustanaou, près de Gaas (Boussac in Dollfus 1906). À Gaas, dans la coupe de Garanx, Tournouer (1863) a décrit un niveau de calcaire marneux, sans fossiles à la base, puis $1 \mathrm{~m}$ de marne blanche à coquilles brisées et à polypiers. Les 5-6 m suivants se composent d'une argile ocre à rognons calcaires avec nombreuses huîtres et à Nummulites intermedius d'Archiac, 1846 (= Nummulites fichteli Michelotti, 1841) puis une couche de calcaire dur à nummulites. Benoist (1884) a observé un niveau de lignite de 0,3-0,5 m d'épaisseur entre les fermes de Tartas et Laplace et des couches lacustres au sommet de la formation à Bis. Le Pochat \& Thibault (1977) ont décrit calcaires durs et marnes bleu verdâtre à rognons calcaires dans les coupes-types. La lithologie des affleurements de Gaas a été révisée par Janssen en 1985.

Dans la carrière de Lesperon à Bénesse-lès-Dax, Tournouer (1863) a observé une alternance de calcaire et marnes charbonneuses à Natica crassatina Deshaeyes, 1824 (actuellement Megatylotus crassatinus) à la base et calcaires à "Cerithium diaboli Brongniart, 1822" au sommet (Tympanotonos diaboli est restreint à l'Éocène selon Cavelier 1979). Les calcaires de la formation reposent sur l'Éocène dans cette coupe (Cahuzac 1980). S'observe également une intercalation de marne ligniteuse, épaisse de $0,25 \mathrm{~m}$.

À Lahosse et Lourquen, à l'est de Montfort-en-Chalosse, Tournouer (1863) a levé $1 \mathrm{~m}$ de marne blanchâtre, $4 \mathrm{~m}$ de calcaire argileux et $5 \mathrm{~m}$ de calcaire grossier à coquilles 


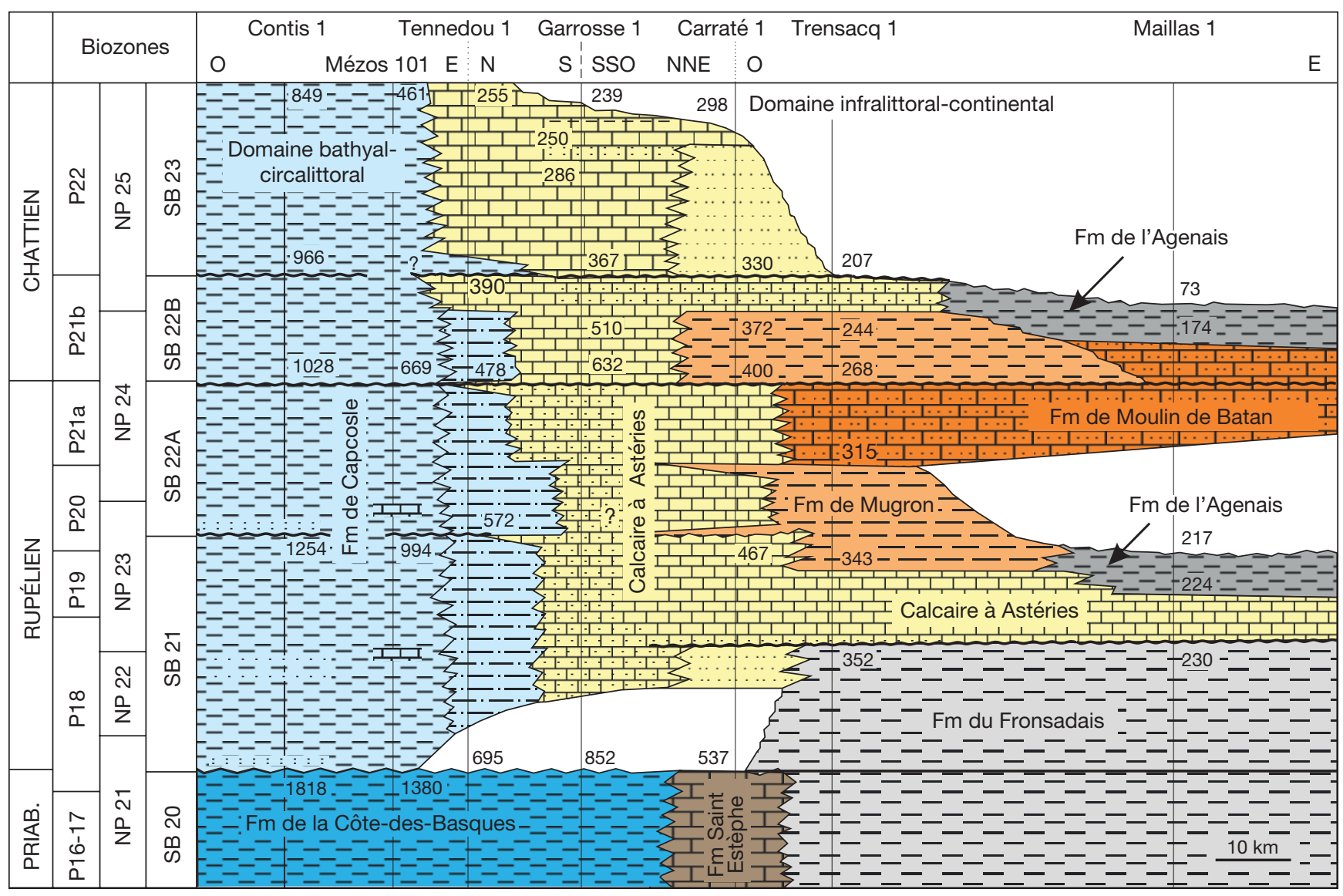

FIG. 4. - Corrélation de I'Oligocène entre les sondages Contis 1 et Maillas 1/Correlation of the Oligocene between boreholes Contis 1 and Maillas 1.

et polypiers. La formation est représentée par des calcaires gréseux dans le synclinal du Louts. La coupe de Lahosse a été publiée par Nolf et al. (2002: fig. 21). Elle est constituée par des marnes grises, coquillières, avec des rares et minces intercalations carbonatées. Le toit de la formation est une surface de ravinement. La Formation de Mugron sus-jacente commence par une marne sombre, ligniteuse et se poursuit par des sables à fragments de coraux.

Au Tuc de Saumon, à l'est de Gousse, Tournouer (1863) a observé 8-10 m de calcaire à "stratification confuse» avec polypiers et Megatylotus crassatinus (Deshaeyes, 1824) qu'il a corrélé avec des couches de Gaas, surmonté par des sables gris et fauves, azoïques, localement cimentés, qui correspondent à la Formation de Mugron. La coupe a été redécrite par Nolf et al. (2002: fig. 18): $5 \mathrm{~m}$ de calcaire crayeux, bioclastique est succédé par $4 \mathrm{~m}$ de calcaire caverneux à gros polypiers. Son contact avec des sables sus-jacents (Formation de Mugron) est irrégulier.

\section{SONDAGES}

Les sondages pétroliers de l'anticlinal de Clermont montrent une lithologie très variée avec une épaisseur qui peut atteindre $500 \mathrm{~m}$. Dans le puits Pouyarramon 1, les marnes jaunes, sableuses, continentales à intercalations de sable occupent l'intervalle entre 411 et $562 \mathrm{~m}$. Une faune marine était présente à $560 \mathrm{~m}$ dans un niveau gréseux, gris (Halkyardia maxima Cimerman, 1969, Nummulites vascus Joly \& Leymerie, 1848), équivalent de la
Formation de Biarritz. Les calcaires sableux, bioclastiques, qui correspondent à la Formation de Gaas, apparaissent à $411 \mathrm{~m}$ et alternent avec des sables moyens à grossiers et des marnes jaunes, sableuses jusqu'à $246 \mathrm{~m}$. Le faciès calcaire, bioclastique domine ensuite jusqu' $78 \mathrm{~m}$ de profondeur. La Formation de Gaas y est surmontée par des marnes grises ou ocre, sableuses qui contiennent des foraminiferes (Burdigalien). Ils n'ont pas été étudiés par manque d'échantillons.

Dans le puits Larrouy 1, $4 \mathrm{~km}$ plus à l'est, les marnes ocre, continentales dominent de 194 à $468 \mathrm{~m}$ de profondeur, où les intercalations de calcaires bioclastiques, marins sont rares et peu épaisses. Une alternance de calcaire bioclastique et de marne grise occupe l'intervalle de 154 à $194 \mathrm{~m}$ et les calcaires francs de 109 à 194 m (Formation de Gaas). La comparaison des deux puits montre l'augmentation de l'épaisseur des dépôts continentaux et l'amincissement des faciès marins vers l'est. Les calcaires sont surmontés par des marnes et calcaires probablement burdigaliens.

Le sondage Sébastopol 102 a reconnu la formation sur une hauteur de 183 m (130-313 m), constituée de calcaire blanc, crayeux, graveleux, peu sableux à Nummulites fichteli Michelotti, 1841, rupertiidés et mélobésiées (Fig. 3). Son épaisseur est de $110 \mathrm{~m}$ dans le puits Sébastopol 1bis (20-130 m). La lithologie y est représentée par un calcaire crayeux, blanc crème à gris, peu siliceux à Nummulites, Halkyardia, Sphaerogypsina et polypiers (Cahuzac 1980). 


\section{Formation de Mugron}

(Figs 2-4, 8, 9)

AuTEUR. — Platel 1990b.

Synonyme. — Grès de Donzacq, Le Pochat \& Thibault (1977). Le nom de cette unité n'est pas valide, pouvant être confondue avec celui des Marnes de Donzacq de Burger et al. (1945).

LoCAlitÉ-TYPE. — Affleurements entre Gousse, Mugron et Nerbis (Platel 1990b).

HISTORIQUE. - Les affleurements de cette formation ont été décrits par Delbos en 1854, puis étudiés par Tournouer en 1863. Le nom "grès de Mugron" apparaît dans une phrase d'une publication de Douvillé (1906), puis dans un article de Dollfus (1917), sans définition. La première description valide est de Platel (1990b).

DÉFINITION. - Ensemble dominé par des faciès gréseux (sable, grès, calcaire gréseux) qui contiennent grands foraminifères en général (Nummulites, Operculina, lépidocyclines).

ÂGE. - Cahuzac \& Poignant $(1997,2002)$ ont placé les grès de l'affleurement du Tuc de Saumon dans la zone SB 22A (Rupélien supérieur) à cause de la présence d'Eulepidina dilatata (Michelotti, 1861), E. formosoides (H. Douvillé, 1924), Nephrolepidina praemarginata (R. Douvillé, 1908) et Bullalveolina bulloides (d’Orbigny, 1826). L'affleurement de Haillets a été placé dans la partie chattienne de la zone NP 24 par Cahuzac et al. (1995). La Formation de Mugron a été datée dans le puits Mont-de-Marsan 1, à 6,5 km du sondage Landesde-Siougos 2, où elle occupe l'intervalle 348,5-431 m. La zone NP 24 a été déterminée à $430 \mathrm{~m}$ (Cyclicargolithus abisectus (Müller, 1970)) et à $350 \mathrm{~m}$ (C. abisectus, Sphenolithus predistentus Bramlette \& Wilcoxon, 1967, Helicosphaera recta (Haq, 1966) et H. perch-nielseniae (Haq, 1971); dét. C. Müller). Bullalveolina bulloides (d'Orbigny, 1826) indique le Rupélien à $370 \mathrm{~m}$. Les calcaires gréseux des sondages Gourbera 1, Lesgor 1 et Landes-de-Siougos 2 (LS 2), entre les dépôts rupéliens à Bullalveolina bulloides (d'Orbigny, 1826) et la Formation d'Escornebéou du Chattien supérieur, appartiennent probablement au Chattien inférieur.

\section{AfFleUREMENTS}

La formation est constituée de grès gris bleu, plus ou moins carbonaté de 20-30 m d'épaisseur dans les environs de Mugron. Elle est représentée par des calcaires marneux, gris à gris noir qui peuvent contenir jusqu'à $30 \%$ de sables à Haillets. On observe également des grès et sables jaunes à stratification entrecroisée, avec intercalations marneuses et niveaux sableux. Il y a très peu de macro- ou microfaune. Au voisinage de Mugron, on observe des calcaires marneux et des marnes à Nummulites fichteli Michelotti, 1841, Halkyardia, rupertiidés, gypsinidés et charophytes. Intercalations lacustres à charophytes sont connues à Poyanne et niveaux ligniteux à Mouliot (Poignant 1967; Platel 1990b). Les équivalents gréseux à nummulites et operculines de ces niveaux s'observent également à Thétieu et Pontonx.

Au Tuc de Saumon, Tournouer (1863) a observé que les calcaires à polypiers (Formation de Gaas) sont surmontés sans transition par des sables gris et fauves, azoïques, localement cimentés, qui correspondent à la Formation de Mugron. Les bancs compacts contiennent des nummulites. La section se poursuit par des grès à Nummulites fichteli Michelotti, 1841 et lépidocyclines (Douvillé 1906; Daguin 1947). La coupe se termine par une lumachelle à Ostrea multiplicata Cossmann \& Peyrot, 1919 (Daguin 1947). La coupe publiée par Nolf et al. (2002: fig. 18) correspond à cette description.
À Lahosse, la surface de ravinement de base est surmontée par un niveau décimétrique de marne ligniteuse, puis s'est déposée l'alternance de sables, calcaires sableux et argiles, riches en otolithes de poissons (Nolf \& Steurbaut 2002; Nolf et al. 2002: fig. 21). Ces couches correspondent à la Formation de Mugron.

À Bastennes, elle est décrite sous le nom de «Grès de Donzacq", constituée de grès gris clair, carbonaté, glauconieux à stratification oblique et avec des passées conglomératiques (Le Pochat \& Thibault 1977).

\section{SONDAGES}

La formation a été traversée par les sondages Sébastopol 102 et Lesgor 1 (Fig. 3). L'intervalle de 40 à 130 m, au-dessus des calcaires de la Formation de Gaas, correspond à la Formation de Mugron dans le puits Sébastopol 102. Le contact est franc entre les deux, selon le log de résistivité. La coupe est la suivante (Cahuzac 1980) : 40 à 60 m - calcaires bioclastiques, grumeleux, graveleux peu sableux à lépidocyclines, operculines et milioles, puis de 60 à $130 \mathrm{~m}$ - alternance de grès calcaire, grès et sable argileux à operculines, Nummulites fichteli Michelotti, 1841et Almaena escornebovensis (Sigal, 1950).

La formation est plus complète dans le forage Lesgor 1, où elle repose sur la Formation de Biarritz et commence par $35 \mathrm{~m}$ de calcaire gréseux (883-848 m), que suit un intervalle de $214 \mathrm{~m}$ dominé par les sables. Le passage argileux entre 761 et $785 \mathrm{~m}$ contient du lignite. Des calcaires gréseux apparaissent entre 422 et $634 \mathrm{~m}$, surmontés par la Formation d'Escornebéou (Fig. 3).

Dans le sondage Gourbera 1 (Figs 2, 3) la Formation de Mugron transgresse sur la Formation de Biarritz. Elle commence par $25 \mathrm{~m}$ de calcaire bioclastique (769-794 m) et continue avec argiles silteuses à petites intercalations de grès fin jusqu'à $435 \mathrm{~m}$. L'intervalle entre 315 et 405 m est formé de calcaire gréseux que surmonte la Formation d'Escornebéou. Le milieu de dépôt était infralittoral entre 769 et 794 m d'une épaisseur de tranche d'eau inférieur à 30-50 m, avec des genres Halkyardia, Neorotalia, Nummulites, etc. Lapparition de Karreriella hantkeniana Cushman, 1936, Uvigerina moravia Boersma, 1984, Melonis pompilioides (Fichtel \& Moll, 1798) et Pullenia quinqueloba (Reuss, 1851) à $670 \mathrm{~m}$ indique une subsidence rapide (de l'ordre de $100 \mathrm{~m}$ ) et l'apparition du milieu circalittoral. Karreriella cf. siphonella (Reuss, 1851) a été observée à $650 \mathrm{~m}$, qui indique le même environnement. L'apparition des dépôts circalittoraux est interprétée comme une pénétration de la Formation de Capcosle dans celle de Mugron (Fig. 2). La présence d'Uvigerina moravia Boersma, 1984, sans les Karreriella entre 635 et $500 \mathrm{~m}$ indique le milieu infralittoral profond (>50 m). L'épaisseur de la tranche d'eau diminue au-dessus de $500 \mathrm{~m}(<50 \mathrm{~m})$. Les foraminiferes rencontrés dans l'intervalle 794-430 m ne permettent pas de donner un âge précis. Quelques exemplaires de Miogypsinoides complanatus (Schlumberger, 1900) sont présents au-dessus de $430 \mathrm{~m}$, qui définissent la zone SB 23. Cependant, ces exemplaires pourront être des retombées des niveaux supérieurs. Les nannofossiles calcaires ont été déterminés dans les carottes latérales à balle à 619 et $679 \mathrm{~m}$ par C. Müller dans ce forage. Ils caractérisent la zone NP 24: Coccolithus pelagicus (Wallich, 1877), Cyclicargolithus abisectus (Müller, 1970), C. floridanus (Bronnimann \& Stradner, 1960), Reticulofenestra dictyoda 


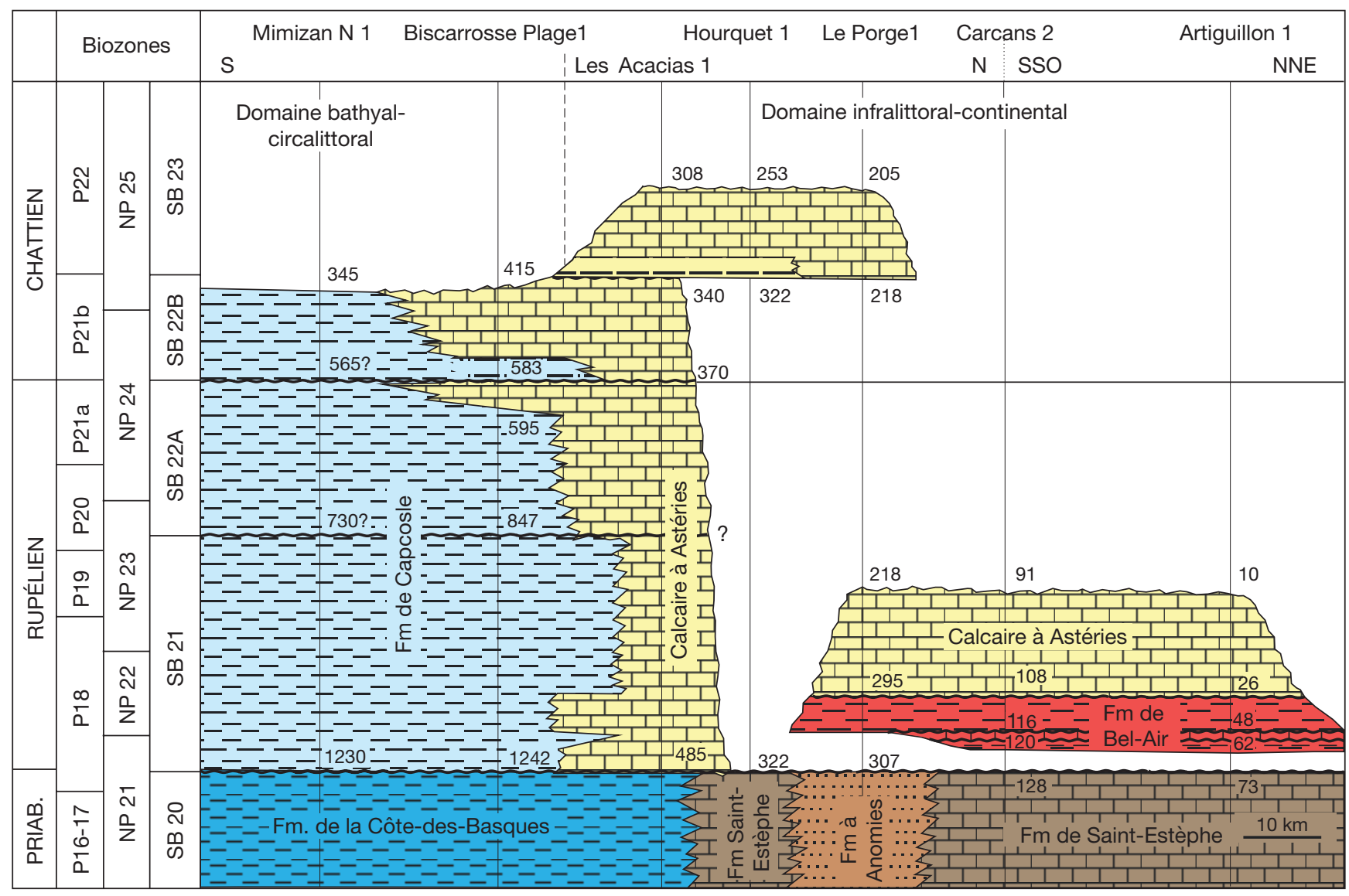

FIG. 5. - Corrélation de I'Oligocène entre les sondages Mimizan Nord 1 et Artiguillon 1/Correlation of the Oligocene between boreholes Mimizan Nord 1 and Artiguillon 1.

(Deflandre in Deflandre \& Fert, 1954), Helicosphaera bramlettei (Müller, 1970), H. euphratis Haq, 1966, H. perch-nielseniae (Haq, 1971), H. recta (Haq, 1966), Sphenolithus moriformis (Bronnimann \& Stradner, 1960), S. predistentus Bramlette \& Wilcoxon, 1967 et Zygrhablithus bijugatus (Deflandre in Deflandre \& Fert, 1954) .

La formation est réduite à $150 \mathrm{~m}$ dans le forage Landes-deSiougos 2 (LS 2; 224-374 m; Figs 2, 3), où elle surmonte la Formation de Campagne continentale d'âge Priabonien-Rupélien inférieur (?). Elle commence par $12 \mathrm{~m}$ de calcaire bioclastique et continue par une alternance d'argile et grès calcaire jusqu'à $286 \mathrm{~m}$ et se termine par des calcaires gréseux à $224 \mathrm{~m}$. Ces derniers sont surmontés par la Formation d'Escornebéou. L'âge Chattien inférieur, zone SB 22B, paraît probable pour l'intervalle 224$286 \mathrm{~m}$ à cause de sa position stratigraphique entre le Rupélien à Bullalveolina bulloides (d'Orbigny, 1826) et le Chattien, zone SB 23 à Miogypsinoides.

La même unité, de faciès argilo-gréseux a été reconnue dans les sondages du synclinal de Tartas (Grenade 1, Maurrin 1, Le Vigneau 1, Géothermie Mont-de-Marsan 2 ou GMM 2; Fig. 3) et au nord de l'axe des anticlinaux de Campagne et RoquefortCréon (Villenave 1 et 2, Garein 1, Labrit 2, Brocas Franks 1, Magenta 1 et 2, Trensacq 1 ; Fig. 4). Elle surmonte la Formation de Campagne dans la première zone, cette formation ou diverses formations marines de l'Éocène dans la seconde.

\section{Formation de Moulin de Batan}

(Figs 2-4, 8, 9)

AUTEUR. — Fallot \& Reyt (1891: 355): Couches de Moulin de Batan.

SynONYME. - Calcaires gréseux à Nummulites du Moulin de Batan, Platel (1990a).

DÉFINITION. - Les calcaires gréseux, bioclastiques dominent dans la formation avec des intercalations de sable et de grès.

Localité-TyPe. - Berges de la Doulouze (Moulin de Batan), à l'est de Roquefort.

ÂGE. - Rupélien supérieur (zone NP 24); la formation peut monter localement dans le Chattien inférieur (sondage Maillas 1). La zone NP 23 n'a pas été reconnue dans la formation, cependant, sa présence est possible dans la partie occidentale de son aire d'extension (Figs 2-4).

\section{AFFLEUREMENTS}

Raulin (1862) a levé la coupe suivante: poudingue à galets de craie et Nummulites fichteli Michelotti, 1841 à la base, puis $8 \mathrm{~m}$ de sable fin, grisâtre avec des plaquettes de grès à nummulites. La section se termine par des calcaires grossiers. Selon Platel (1990a) l'unité repose sur le Crétacé; sa base est constituée d'un niveau conglomératique à galets perforés et le reste est constitué de calcaires gréseux, bioclastiques avec des intercalations de marnes sableuses. Leur épaisseur 
peut atteindre $70 \mathrm{~m}$. La faune contient Nummulites fichteli Michelotti, 1841, Operculina complanata (Defrance, 1822), Neorotalia lithothamnica (Uhlig, 1866) etc., qui ne permet pas de donner un âge précis.

\section{SONDAGES}

Ces calcaires s'observent dans les puits au nord de l'anticlinal de Roquefort (Magenta 1 et 2, Losse 1, Maillas 1) et dans le synclinal de Tartas (Lacquy 101, Villeneuve-de-Marsan 1, Le Vigneau 1; Fig. 3). Les calcaires sont surmontés par la Formation de l'Agenais continentale, qui commence ici dans le Chattien inférieur et non dans le Rupélien supérieur, comme dans les environs de Bordeaux.

La formation a été traversée par le piézomètre de Montaut qui a été entièrement carotté (BRGM, Banque de Données du Sous-Sol, $\mathrm{N}^{\circ}$ 09515X0038), où elle correspond à sables et grès à ciment calcaire et Operculina complanata (Defrance, 1822) entre 68,5 et $82 \mathrm{~m}$, puis à des calcaires graveleux, gréseux à O. complanata et Nummulites fichteli Michelotti, 1841 entre 82 et $89,4 \mathrm{~m}$. Un niveau argileux à $90 \mathrm{~m}$, qui surmonte un calcaire caverneux, a livré des nannofossiles de la zone NP 24 (dét. C. Müller).

Le forage Maillas 1 (Fig. 4) montre la superposition de deux niveaux de calcaire gréseux. L'inférieur, entre 224 et $230 \mathrm{~m}$, est séparé du deuxième $(172-217 \mathrm{~m})$ par $7 \mathrm{~m}$ d'argile continentale. Il est probable que le premier corresponde à la Formation à Astéries typique et que le second soit l'équivalent de la Formation de Moulin de Batan. Ce dernier horizon contenait Nummulites vascus Joly $\&$ Leymerie, 1848 et $N$. fichteli Michelotti, 1841 à $218 \mathrm{~m}$ (Rupélien) et $N$. fichteli, Operculina complanata (Defrance, 1822) et Nephrolepidina morgani (Lemoine \& Douvillé, 1904) à 176 m. La dernière association indique l'âge Chattien inférieur, zone SB 22B.

Il est probable, que la Formation de Moulin de Batan de l'anticlinal de Roquefort corresponde à la transgression et à l'apparition des dépôts circalittoraux qui occupent la partie inférieure de la zone NP 24 dans le sondage de Gourbera 1. L'apparition du Rupélien marin sur l'anticlinal de Campagne est liée au même événement.

\section{Formation d'Escornebéou \\ (formation redéfinie ici)}

(Figs 2, 3, 10)

AUTEUR. — Steurbaut (1984: 10-11) : Falun d'Escornebéou.

SynONYMES. - Argile de Saint-Étienne-d'Orthe (Steurbaut 1984: 11); Formation de Saint-Étienne-d'Orthe (Cahuzac \& Janssen 2010). Steurbaut 1984 et Cahuzac \& Janssen 2010 n'ont pas défini et décrit la formation de façon formelle, leurs noms ne sont donc pas valides selon les règles de la nomenclature stratigraphique (Hedberg 1979: 24).

LOCALITÉ-TYPE. - Affleurements autour du moulin d'Escornebéou, à $15 \mathrm{~km}$ à l'ouest de Dax (Groupe français du Néogène 1974).

DÉFINITION. - Ensemble à dominance marneuse où les niveaux de calcaire gréseux ou sableux à caractère turbiditique sont également présents.
COnTACTS. - Dans le secteur de Saint-Étienne-d'Orthe, la formation comble le canyon de Saubrigues et surmonte des formations éocènes et paléocènes. Près d'Escornebéou, elle se développe à partir d'un Oligocène plus ancien (Kieken \& Thibault 1975). Les sondages Géothermie-Dax 1, Lesgor 1et Gourbera 1 montrent que la Formation d'Escornebéou repose sur la Formation de Mugron. Les calcaires gréseux de la Formation de Saint-Paul-lès-Dax constituent son toit. La sédimentation est continue entre les trois unités.

EXTENSION GÉOGRAPHIQUE. — La formation a été observée entre Escornebéou et Dax, dans les sondages Gourbera 1, Lesgor 1 et dans les forages de la partie occidentale de l'anticlinal de Campagne (Landes-de-Siougos 1, 2, 3, 8). Elle passe dans les argiles continentales (Formation de l'Agenais) plus à l'est (Landes-de-Siougos 4, 7, Mont-de-Marsan 1 et GMM 2) et dans les argiles marines transgressives, rattachées à la Formation de Capcosle vers le nord (sondage de Tennedou 1, entre 350 et $390 \mathrm{~m}$ avec maximum de la transgression entre 350 et $360 \mathrm{~m}$; Fig. 3) . Elle évolue latéralement dans une formation carbonatée à Miogypsinoides (Calcaire à Astéries) plus au nord et le nord-est (Garrosse 1, Pontenx-Village 1, Bernon 1, Argenteyres 1 et 2, Le Porge 1, Carcans 2). Elle se confond avec la Formation de Capcosle vers le nord-ouest qui représente un milieu moins profond, infralittoral pendant cette période.

ÂGE. — La localité-type appartient à la Zone NP 25, comme l'indique la présence de Sphenolithus ciperoensis Bramlette \& Wilcoxon, 1967. Celle de Miogypsinoides formosensis Yabe \& Hanzawa, 1928 et M. complanatus (Schlumberger, 1900) (zone SB 23) confirme cette datation (Groupe français d'Étude du Néogène 1974). Les affleurements de Saint-Étienne-d'Orthe appartiennent aux zones NP 25, P 22 et SB 23 (Müller \& Pujol 1979; Cahuzac 1980; Cahuzac et al. 1995; Cahuzac \& Poignant 2002).

\section{AfFLEUREMENTS}

La formation est constituée de marnes et argiles plus ou moins sableuses, grises autour du moulin d'Escornebéou, dans lesquelles s'intercalent des niveaux centimétriques de grès et des bancs décimétriques de calcaire gréseux (Groupe français d'Étude du Néogène 1974). Cahuzac (1980) et Cahuzac \& Poignant (2002) ont décrit des marnes grises, plus ou moins sableuses entre Saint-Étienne-d'Orthe et Cauneille. Elles contiennent des intercalations de calcaire bioclastique, des niveaux de graviers, du sable et lentilles de grès d'origine turbiditique. S'observent également des foraminifères remaniés de l'Éocène. Cahuzac \& Janssen (2010) la décrivent comme marne grise, homogène du milieu circalittoral autour de Saint-Étienne-d'Orthe, avec une intercalation sableuse dans l'affleurement de Verdun.

\section{SONDAGES}

La base de la Formation d'Escornebéou est facilement reconnaissable dans les sondages grâce à l'augmentation brusque du volume d'argile. Ceci se manifeste par une radioactivité naturelle plus élevée et par la diminution de la résistivité.

Le sondage Géothermie Dax 1 l'a traversé entre 82 et $187 \mathrm{~m}$. Les déblais montrent la forte proportion d'une argile beige puis verdâtre, autour de $80-90 \%$ et la présence de sables fins. Un niveau de grès à ciment calcaire se trouve entre 126 et $142 \mathrm{~m}$. Le passage dans les grès calcaires, coquilliers à interlits argileux de la Formation de Saint-Paul-lès-Dax est rapide.

Dans le sondage Gourbera 1 (Figs 2, 3), elle occupe l'intervalle entre 200 et 315 m et est représentée par des argiles ocre avec 
des intercalations de grès argileux. La microfaune contient Miogypsinoides complanatus (Schlumberger, 1900) entre 250 et $130 \mathrm{~m}$ et Globigerinoides primordius Blow \& Banner, 1962 à $250 \mathrm{~m}$. L'épaisseur de la tranche d'eau était moins de $50 \mathrm{~m}$.

La formation était traversée entre 198 et $422 \mathrm{~m}$ dans le forage Lesgor 1 et entre 132 et $224 \mathrm{~m}$ dans Landes-de-Siougos 2 (Figs 2,3).

\section{Formation de Saint-Paul-lès-Dax}

(Figs 2, 3, 10)

Auteur. - Delbos (1854: 57) : Falun de Saint-Paul-lès-Dax et Saint-Avit.

LoCAlité-TYPE. - Affleurements autour de Saint-Paul-lès-Dax (Abesse, Bezoye, Cabanes, Christus, Estoti, Lestrilles et Mainot).

DÉFINITION. - La formation est composée de calcaire sableux, bioclastique, sables et grès à nombreux débris coquilliers (Cahuzac 1980; Cahuzac \& Janssen 2010).

CONTACTS. - Elle surmonte la Formation d'Escornebéou en continuité et la formation du toit n'est pas connue dans les affleurements et dans les forages voisins. Elle passe vers l'est dans la Formation de l'Agenais. Les «Faluns de Saint-Avit» de l'Aquitanien, qui transgressent sur ces molasses continentales de l'Agenais entre Saint-Sever et Toulouzette dans le synclinal de Tartas (Platel 1990b), sont exclus de cette formation. La formation passe latéralement dans un ensemble carbonaté (Calcaire à Astéries) vers le nord et le nord-est: Tennedou 1, Pontenx Village 1, Cabeil 1, Le Terme 1 et Sanguinet 1.

EXTENSION GÉOGRAPHIQUE. — Les données actuelles montrent sa présence entre la commune de La Pince, à l'ouest de Dax et le sommet de l'anticlinal de Campagne, où commence sa transition dans les dépôts continentaux de la Formation de l'Agenais.

ÂGE. - Chattien supérieur, zones NP 25, P 22 et SB 23 et Aquitanien (Cahuzac 1980; Cahuzac et al. 1995, 1997; Cahuzac \& Poignant 1988, 1997; Cahuzac \& Janssen 2010). Les affleurements ne montrent pas le contact de l'Aquitanien et le Burdigalien, mais les sondages indiquent une discordance majeure entre les deux.

\section{AFFLEUREMENTS}

Tournouer (1863) a mentionné des faluns jaunes à SaintPaul-lès-Dax, entre les sondages d'Abesse et Mées-sur-l'Adour. Cahuzac (1980) a décrit une série d'affleurements entre La Pince et Saint-Paul-lès-Dax: calcaire sableux, bioclastique et sable à Miogypsinoides et lépidocyclines. Il a observé le contact du Chattien et l'Aquitanien dans la coupe du Moulin de Poustagnac, près du lac de Christus: une couche de poudingue à galets calcaires sépare les calcaires sableux du Chattien à Miogypsinoides formosensis Yabe \& Hanzawa, 1928 de ceux de l'Aquitanien à Miogypsina gunteri Cole, 1938.

\section{SONDAGES}

Dans le sondage Géothermie Dax 1 (GDX 1), les calcaires gréseux, bioclastiques entre 20 et $82 \mathrm{~m}$ représentent cette formation. Dans le puits Gourbera 1 (Figs 2, 3), elle a été reconnue entre 62 et $200 \mathrm{~m}$, représentée par des grès argileux à lumachelles entre 125 et $200 \mathrm{~m}$, puis par des faluns sableux non consolidés jusqu'au toit. Nummulites bouillei de la Harpe, 1879 (Oligocène) disparait à 130 m, l'âge aquitanien est indiqué par Globigerinoides cf. immatura Le Roy, 1939 dans l'échantillon de 100 m et par Paragloborotalia cf. continuosa (Blow, 1959) et Globoquadrina cf. altispira (Cushman \& Jarvis, 1936) à 90 et $80 \mathrm{~m}$. La sédimentation est continue entre le Chattien et l'Aquitanien dans ce sondage.

La formation est homogène, composée de calcaire gréseux dans le forage Lesgor 1 entre 18 et $198 \mathrm{~m}$ (Fig. 3). Le puits Landes-de-Siougos 2 montre des dépôts plus proximaux entre 57 et $132 \mathrm{~m}$ : la formation commence par $17 \mathrm{~m}$ de calcaire (Formation de St-Paul-lès-Dax), continue par environ $30 \mathrm{~m}$ d'argile sableuse, continentale (entre 85 ? et $115 \mathrm{~m}$ : Formation de l'Agenais, équivalente du poudingue du Moulin de Poustagnac ?) et se termine par $28 \mathrm{~m}$ de sable coquillier, équivalent du Falun de Saint-Avit (Figs 2, 3).

\section{PLATE-FORME NORD AQUITAINE}

\section{Formation de Bel-Air (Figs 5, 6)}

AuTEURS. — Dubreuilh \& Marionnaud (1973) : Marnes blanches de Faciès Bel-Air.

SYNONYMES. - Molasse et argile à Melobesia (appelées Molasse du Médoc à la page 112, Benoist 1885). Formation du Fronsadais (partim) : Fallot 1880, 1894. Marnes et calcaires à faciès sannoisien: Dubreuilh \& Marionnaud 1973.

LOCALITÉ-TYPE. - Civrac, à la base de la colline de Bel-Air (X = $345,5 ; Y=3343)$.

DÉFINITION. - Ensemble marneux marin ou saumâtre avec des intercalations plus ou moins importantes de calcaire bioclastique.

CONTACTS. - Une discordance avec érosion a été observée entre la Formation des Calcaires et marnes à Anomies de l'Éocène et les premiers dépôts marins ou saumâtres de l'Oligocène (Benoist 1885; Andreieff \& Marionnaud 1972). La sédimentation est continue vers la Marne à Echilus duchasteli Nyst, 1836 (actuellement Nystia duchasteli) de Benoist (1885) ou la Formation de Castillon lacustres. La Formation de Bel-Air est surmontée par le Calcaire à Astéries dans les sondages Carcans 2, Le Porge 1 et Maubuisson 1.

ÂGE. - Les foraminiferes ne permettent pas de donner un âge précis à la Formation de Bel-Air. Les nannofossiles calcaires sont absents (communication de C. Müller). La corrélation avec la Formation du Fronsadais laisse supposer son appartenance au Rupélien inférieur, zone à Stephanochara pinguis (Feist \& Ringeade 1977; = zone P 18, NP 21-22 d'après Hardenbol et al. 1998).

\section{AFFLEUREMENTS}

Dans la localité-type à Bel-Air, la formation est constituée par la succession de marnes blanches à jaunâtres-grisâtres avec des bancs dolomitiques et nodules calcaires à la base. Des intercalations de calcaire argileux à Peneroplis sp. et à petites huîtres apparaissent localement. Les marnes à Mélobésiées ont également été observées. Les marnes passent latéralement dans les «Marnes et calcaires à faciès sannoisien" de Dubreuilh \& Marionnaud (1973), qui sont constitués de marnes vertes et blanches avec nodules et lentilles carbonatées et contiennent une faune infralittorale à lagunaire (Ammonia, Elphidium). Ils sont réduits à un horizon de galets perforés à l'est de Vertheuil. Nous proposons d'inclure ces faciès dans la Formation de Bel-Air. 
Dans les environs de Vertheuil-Saint-Estèphe, Benoist (1885) a différencié deux unités à la base de l'Oligocène: Molasse et argile à Melobesia (qui correspond à la Formation de Bel-Air) et Marne à Echilus duchasteli au-dessus. La première consiste en deux niveaux marneux à concrétions calcaires et Melobesia, séparés par une argile verte à taches de couleur lie-de-vin d'une épaisseur de $10 \mathrm{~m}$. La seconde commence par 0,2 m de marne jaune à concrétions calcaires, puis viennent $0,8 \mathrm{~m}$ de calcaire bréchique à Nystia duchasteli (Nyst, 1836) et $1 \mathrm{~m}$ de marne blanche-verte. Il a noté en 1887, qu'une couche de marne gypseuse à débris végétaux et aux ossements roulés s'intercalait entre les couches à Melobesia et les Calcaires à Astéries à Cubzac.

À Trembleaux, la base de l'Oligocène montre des faciès saumâtres avec Ammonia propinqua (Reuss, 1856), Discorbis kiliani (Andreae, 1884) et Elphidium subnodosum (Roemer, 1838) que surmontent les marnes de type Bel-Air.

Sur la feuille Bordeaux (Alvinerie et al. 1977), l'Oligocène commence par des calcaires argileux, marins ou saumâtres (équivalents de la Formation de Bel-Air) et il continue par des sables arkosiques à intercalations graveleuses et ligniteuses, fluviatiles de la Formation du Fronsadais de Jouannet (1830). Les marnes et calcaires lacustres de la Formation de Castillon (Matheron 1867) à limnées et planorbes, surmontent cette unité.

Sur la feuille de Podensac (Capdeville et al. 1996), la Formation de Bel-Air est absente et la Formation du Fronsadais équivalente est entièrement continentale, composée d'argile sableuse, verdâtre, de grès et de sables. Cette formation contient une association de charophytes qui indique la zone à Stephanochara pinguis de Riveline et al. (1996) avec Harrisichara tuberculata (Lyell, 1826), Nitellopsis meriani (A. Braun ex Unger, 1850), N. aemula (Grambast, 1972), Rhabdochara major Grambast \& Paul, 1965 (Feist \& Ringeade 1977) et des mammifères du niveau de Ronzon (Cavelier 1979; Ringeade 1987). La présence de Rhabdochara major indique la partie supérieure de la zone. La Formation du Fronsadais est surmontée par la Formation de Castillon, représentée par des argiles vertes, marnes et calcaires blancs. Cette formation lacustre peut être absente localement.

\section{SONDAGES}

Les sondages Maubuisson 1, Artiguillon 1, Carcans 2 et Le Porge 1 montrent des affinités avec les coupes décrites sur les feuilles Saint-Vivien-de-Médoc-Soulac-sur-Mer (Dubreuilh \& Marionnaud 1972) et Lesparre-Médoc-Forêt-de-Junca (Dubreuilh \& Marionnaud 1973).

Le sondage Artiguillon 1 a reconnu deux horizons argilosableux dans la Formation de Bel-Air (26-48 m et 62-73 m; Fig. 5), séparés par un banc de calcaire. Arenagula globula Bourdon \& Lys, 1955 a été déterminée à $60 \mathrm{~m}$ et Bullalveolina bulloides (d'Orbigny, 1826) à $50 \mathrm{~m}$. L'intervalle entre 30 et 40 m est constitué de marne dolomitique et dolomie, qui est probablement l'équivalent de la Formation de Castillon lacustre. La partie supérieure du sondage est formée de calcaires bioclastiques du Calcaire à Astéries.
Dans le forage Carcans 2 (Fig. 5), on retrouve les deux horizons argileux du puits Artiguillon 1 puis les calcaires de la Formation à Astéries: 91-108 m calcaire microbréchique (Formation à Astéries) ; 108-116 m marnes vertes, bancs de grès ; 116-120 m calcaire gréseux; 120-128 m marnes grises et vertes. La microfaune contient Halkyardia maxima Cimerman, 1969, Operculina complanata (Defrance, 1822) (108 et 126 m), Nummulites sp. (108 m) et Arenagula globula Bourdon \& Lys, 1955 (126 m).

Dans le sondage Le Porge 1 (Fig. 5), les argiles sableuses entre 295-307 m, surmontées par la Formation à Astéries correspondent à la Formation de Bel-Air. Dans celui de Maubuisson 1, l'Oligocène commence par marnes blanches et glauconieuses, vertes (Formation de Bel-Air; 128-130 m) et se poursuit par des calcaires crayeux (Calcaire à Astéries; 114-128 m), avec Arenagula globula Bourdon \& Lys, 1955 et Operculina complanata (Defrance, 1822) à $121 \mathrm{~m}$.

\section{Formation de Calcaire à Astéries}

(Figs 4-10)

\section{Auteur. — Delbos (1847: 274).}

SYNONYMES. - Calcaire de Bourg (Jouannet 1830; Des Moulins 1832); Calcaire grossier du Bourg et Calcaire de Saint-Macaire (Raulin 1848); Calcaire à Ampullina crassatina (Benoist 1885); noms non utilisés.

RÉGION-TYPE. - Affleurements de Saint-Aubin de Blagnac, SainteColombe, Sainte-Foy-la-Grande, à l'ouest de Bergerac (Delbos 1847).

DÉFINITION. - Ensemble dominant calcaire, bioclastique à mélobésiées, foraminifères, bryozoaires, échinodermes (Asteria) et polypiers. Des niveaux carbonatés ou argileux à huîtres sont connus à sa base qui correspondent au Membre à Crassostrea longirostris (Dépôt d'Ostrea longirostris, Delbos 1847: 271).

CONTACTS. - Le Calcaire à Astéries repose sur les dépôts continentaux de la Formation du Fronsadais, de la Formation de Castillon ou sur la Formation de Bel-Air dans les sondages au nord-ouest de la plateforme nord-aquitaine (Delbos 1847; Benoist \& Billiot 1889). Le Calcaire à Astéries est surmonté par la Formation de l'Agenais continentale dans la partie nord orientale de cette plateforme.

EXTENSION GÉOGRAPHIQUE. - Tournouer (1862) a mentionné l'horizon à Crassostrea longirostris (Lamarck, 1806) à Rions, Cadillac, Labrède et Saint-Morillon. La Formation du Calcaire à Astéries est connue dans les affleurements isolés entre Lesparre et Bordeaux, plus étendus dans la région de l'Entre-Deux-Mers, jusqu'aux communes de Sainte-Foy-la-Grande et Saint-Pey-de-Castets (Delbos 1847). Les sondages permettent de la suivre jusqu'au nord du Bassin de l'Adour (Maillas 1, Trensacq 1). Elle passe latéralement dans la Formation de Gaas infralittorale plus au sud.

\section{AFFLEUREMENTS}

Delbos (1847) a décrit le Membre à Crassostrea longirostris comme une accumulation d'huîtres dans un ciment de calcaire marneux, très dur. Fallot $(1880,1894)$ mentionne un ciment argileux (Argile à Ostrea longirostris). Son passage est progressif vers le Calcaire à Astéries.

Benoist (1887) a décrit la coupe complète de la Formation à Astéries à Cenon, près de Bordeaux (de la base au sommet) : 
a) Calcaire argileux, bleu à Archiacina (= Peneroplis), Ampullina; b) Marne schisteuse, brune avec un banc de calcaire à Nummulites intermedius d'Archiac, 1846 (= N. fichteli Michelotti, 1841); c) Calcaire blanc à Astéries, algues calcaires et Nummulites; d) Calcaire plus dur avec parties terreuses à Nummulites, dont $N$. vascus Joly \& Leymerie, 1848 ; et e) Calcaire compact à polypiers. Il a observé l'absence des couches a et b à Bourg et dans le Médoc et leur passage latéral dans les argiles à Crassostrea longirostris (Lamarck, 1806) entre Libourne et Sainte-Foy-la-Grande.

Sur les feuilles de Saint-Vivien-de-Médoc et Lesparre (Dubreuilh \& Marionnaud 1972, 1973), la formation débute par des marnes et calcaires à petits foraminifères et rares charophytes qui passent dans les calcaires localement argileux, où les Peneroplis sont très fréquents ("Calcaire à Archiacina"). À Prignac, Dubreuilh \& Marionnaud (1973) ont observé un horizon perforé au toit de cette unité. Sur la feuille de Bordeaux, Alvinerie et al. (1977) ont décrit un niveau de calcaire azoïque, probablement lacustre dans la même position stratigraphique. La partie médiane du Calcaire à Astéries représente une nouvelle transgression dans les environs de Bordeaux, constituée de calcaire bioclastique à mélobésiées, foraminifères, bryozoaires et polypiers. Cette unité se termine par un épisode d'émersion, marqué par un tapis d'algues avec des traces de dessiccation.

La partie supérieure du Calcaire à Astéries constitue la transgression majeure de la région selon Alvinerie et al. (1977). Ses dépôts sont des calcaires type packstone à grainstone, bioclastiques, localement sableux. Un horizon à «algal balls» s'observe au toit de la formation. Elle est surmontée par des marnes vertes à blanches ou par des calcaires à Microcodium, continentaux (Formation de l'Agenais). Deux niveaux particuliers ont été observés dans le Calcaire à Astéries à Bordeaux et dans ses environs: les Couches de Terre-Nègre (Benoist 1883; Fallot 1894), composées de sables argileux de couleur bleu noirâtre, très fossilifères et les Couches de Madère-Sarcignan, qui sont des argiles fossilifères (Fallot 1894).

Sur la feuille Podensac, Capdeville et al. (1996) ont observé deux ensembles transgressifs dans le Calcaire à Astéries, séparés par une faible régression. Ferrand et al. (1970) ont placé la partie supérieure de cette formation dans l'Oligocène supérieur, à cause de la présence de l'ostracode Cnestocythere reticulata Moyes, 1965.

Une intercalation de calcaire marin à lacustre, épais de 0,25 à 2 m (que Capdeville et al. 1996 corrèlent avec le Calcaire de Monbazillac lacustre), divise ici la Formation de l'Agenais continentale en deux parties. La partie inférieure montre des influences marines et appartient à la zone de mammifères MP 22, équivalente des zones P 19/20 et NP 23 (Rupélien moyen) selon Riveline et al. (1996). Ceci est en contradiction avec l'âge Chattien déterminé par Ferrand et al. (1970). Le "Calcaire de Monbazillac» contient Halkyardia minima (Liebus, 1911) et Neorotalia lithothamnica (Uhlig, 1886) et appartiennent au Rupélien. Feist \& Ringeade (1977) ont observé des charophytes stampiennes dans la Formation de l'Agenais, qui appartiennent à la Zone Chara microcera de Riveline et al. (1996), équivalent de la zone P 21a selon Hard-

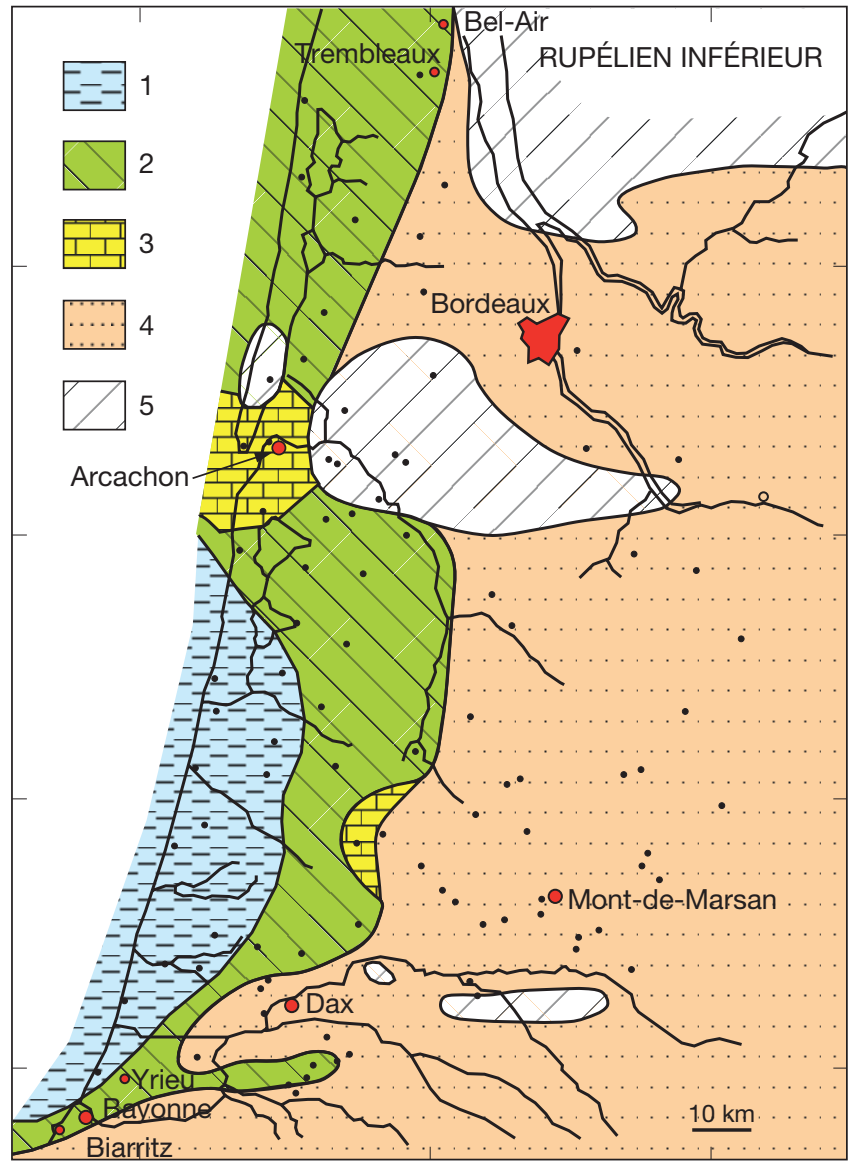

FIG. 6. - Schéma paléogéographique du Rupélien inférieur (zone P 18). Symboles: 1 , bathyal à circalittoral; 2 , plate-forme détritique; 3 , plateforme carbonatée; $\mathbf{4}$, continental; $\mathbf{5}$, érosion ou non dépôt/Paleogeographic scheme of the Lower Rupelian (Zone P18). Symbols: 1, bathyal to outer neritic; 2, detrital platform; 3, carbonate platform; 4, continental; 5, erosion or non-deposition.

enbol et al. (1998): Chara microcera Grambast \& Paul, 1965, Rhabdochara major Grambast \& Paul, 1965, R. praelangeri Castel, 1977, R. langeri Feist \& Ringeade, 1977, Nitellopsis meriani (A. Braun ex Unger, 1850).

\section{FORAGES D'EAU}

L'Oligocène marin des forages d'eau d'Arcachon, Cabanac, Le Porge, Pessac et Bordeaux-Bastide a été étudié par Veillon (1964). Cet auteur a noté la présence de (haut en bas) : 3) marnes sableuses et sables à charophytes à Bordeaux-Bastide; 2) calcaires marneux à Nummulites cf. vascus Joly \& Leymerie, 1848 ; et 1) marnes à Halkyardia minima (Liebus, 1911) dans la partie inférieure de l'Oligocène ("Calcaire à Anomies»). Mais, en réalité, l'unité inférieure appartient à l'Éocène (Cavelier 1979; Sztrákos et al. 2010). Sa deuxième unité est marine partout dans les régions que Veillon a étudiées, avec grès argileux avec des globigérinidés à Arcachon, calcaire marneux et marne à Nummulites incrassatus de la Harpe, 1896, N. intermedius d'Archiac, 1846 (= N. fichteli Michelotti, 1841), N. vascus Joly \& Leymerie, 1848, Bullalveolina sp. et Halkyardia minima (Liebus, 1911) ailleurs (Oligocène). Son "Oligocène supérieur» (3) se divise en deux parties à Arcachon, calcaire à Nummulites incrassatus et $N$. intermedius à la base 


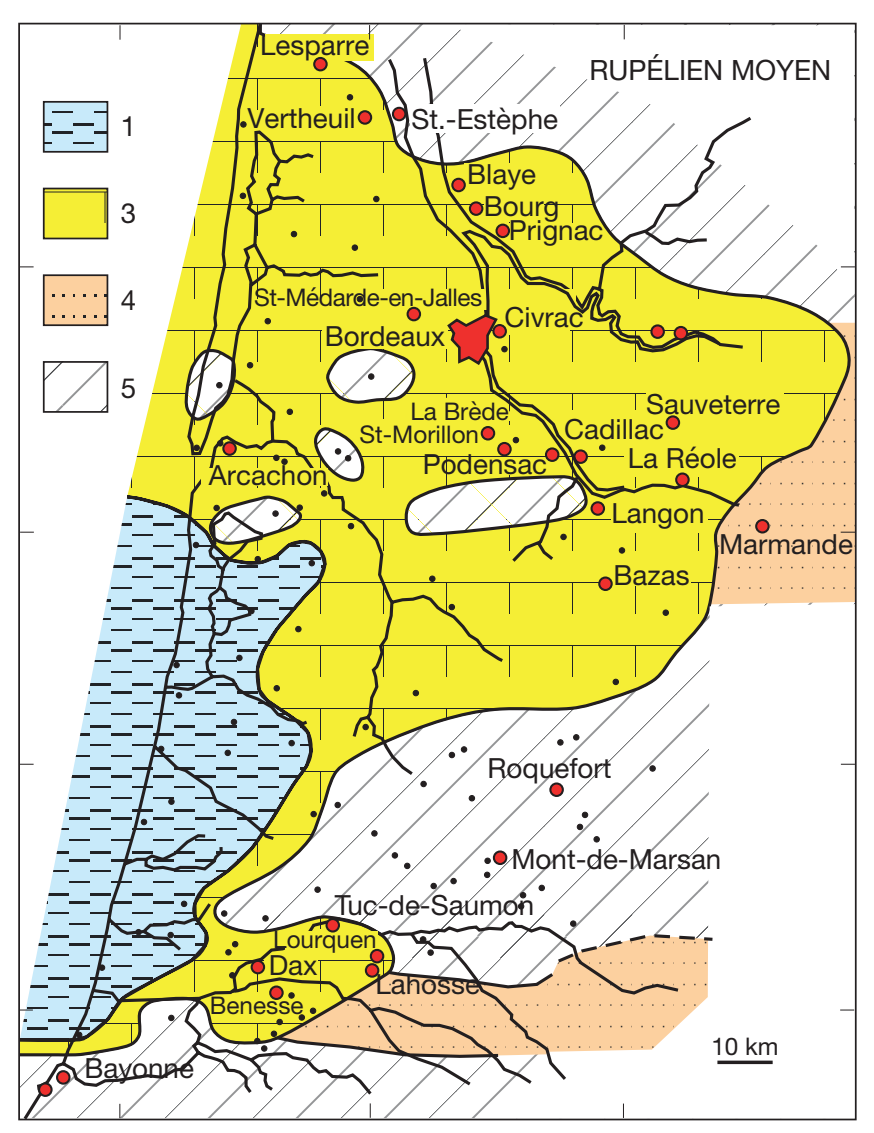

FIG. 7. - Schéma paléogéographique du Rupélien moyen (zones P 19-P 20 inf.). Symboles: $\mathbf{1}$, bathyal à circalittoral; $\mathbf{3}$, plateforme carbonatée; $\mathbf{4}$, continental; 5 , érosion ou non dépôt/Paleogeographic scheme of the middle Rupelian (Zones P19-lower P 20). Symbols: 1, bathyal to outer neritic; 3, carbonate platform; 4, continental; 5, erosion or non-deposition.

et marnocalcaire au sommet. Calcaires et calcaires argileux avec les mêmes Nummulites occupent le restant de la région. Elle a signalé la présence de Lepidocyclina et Miogypsinoides au sommet de l'Oligocène, sans préciser le nom du sondage.

D’après Veillon (1964), ces trois unités correspondent à trois transgressions, séparées par des faciès continentaux. La première et la deuxième sont séparées par la Formation du Fronsadais et la deuxième et troisième seraient séparées par la Formation de Castillon. Par conséquent, la troisième unité devrait inclure l'intervalle correspondant à l'intervalle Rupélien moyen-Chattien, tenant compte des observations développées ci-dessus et de la présence de Miogypsinoides.

\section{PUITS PÉTROLIERS}

La lithostratigraphie de l'Oligocène montre des affinités avec les coupes décrites sur la feuille de Podensac (Capdeville et al. 1996) dans les puits de Sore 1, Baloze 1, Noaillan 1, Bazas 1, Heulies 1, Cadillac 1, Saucats 1 et Bouliac 1, situés à l'est et le nord-est du Bassin d'Aquitaine. La série se caractérise par la présence de la Formation du Fronsadais à la base, les Calcaires à Astéries au milieu et la Formation de l'Agenais au sommet. Les deux dernières formations peuvent être plus ou moins érodées, en fonction de l'intensité de l'érosion qui a précédé le dépôt du Burdigalien.

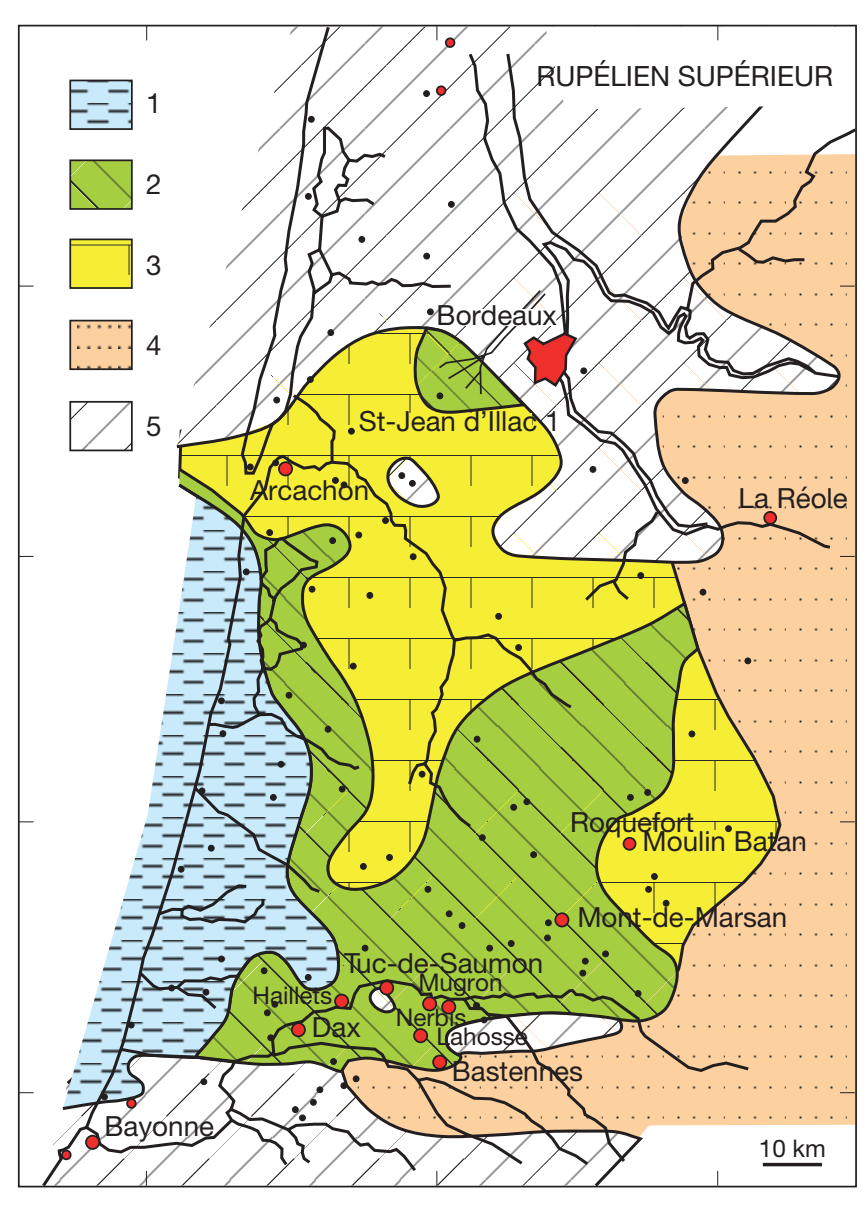

FIG. 8. - Schéma paléogéographique du Rupélien supérieur (zones $\mathrm{P} 20$ sup.$P$ 21a). Symboles: 1, bathyal à circalittoral; 2 , plate-forme détritique; 3 , plateforme carbonatée; $\mathbf{4}$, continental; $\mathbf{5}$, érosion ou non dépôt/Paleogeographic scheme of the upper Rupelian (Zones upper P 20-P 21a). Symbols: 1, bathyal to outer neritic; 2, detrital platform; 3, carbonate platform; 4, continental; 5, erosion or non-deposition.

Le Rupélien et le Chattien inférieur sont peu développés dans les forages Le Teich 1, Lenan 1, Caudos 1 et Le Porge 1. Les corrélations diagraphiques suggèrent que la base de l'Oligocène soit absente et que la sédimentation commence avec les Calcaires à Astéries d'âge correspondant probablement aux zones P 19-P 21 dans Caudos 1. En revanche, la base de l'Oligocène est argileuse dans les puits Le Teich 1, Lenan 1 et le Porge 1, horizon qui pourrait correspondre à la partie supérieure de la Formation de Bel-Air (Fig. 5). Les calcaires de ces sondages contiennent Halkyardia maxima Cimerman, 1969 et Nummulites vascus Joly \& Leymerie, 1848. L'Oligocène supérieur sommital est également carbonaté dans ces trois puits, avec Miogypsinoides complanatus (Schlumberger, 1900) dans Le Porge 1 (210 m) et Planolinderina escornebovensis Freudenthal, 1969 dans Caudos 1 (191 m). La base de cette partie est représentée par une lumachelle dans le puits Le Teich 1. Miogypsinoides complanatus a été observée dans les calcaires sommitaux, à $190 \mathrm{~m}$ de profondeur. Les calcaires rupéliens à Nummulites fichteli Michelotti, 1841 (150 m) sont en contact avec les calcaires burdigaliens dans le forage Courchade 1 .

Le Rupélien est présent dans le puits Argenteyres 2 et absent dans Hourquet 1 (Fig. 5). Cet étage commence avec un intervalle argileux avec Nummulites vascus Joly \& Leymerie, 1848 dans 


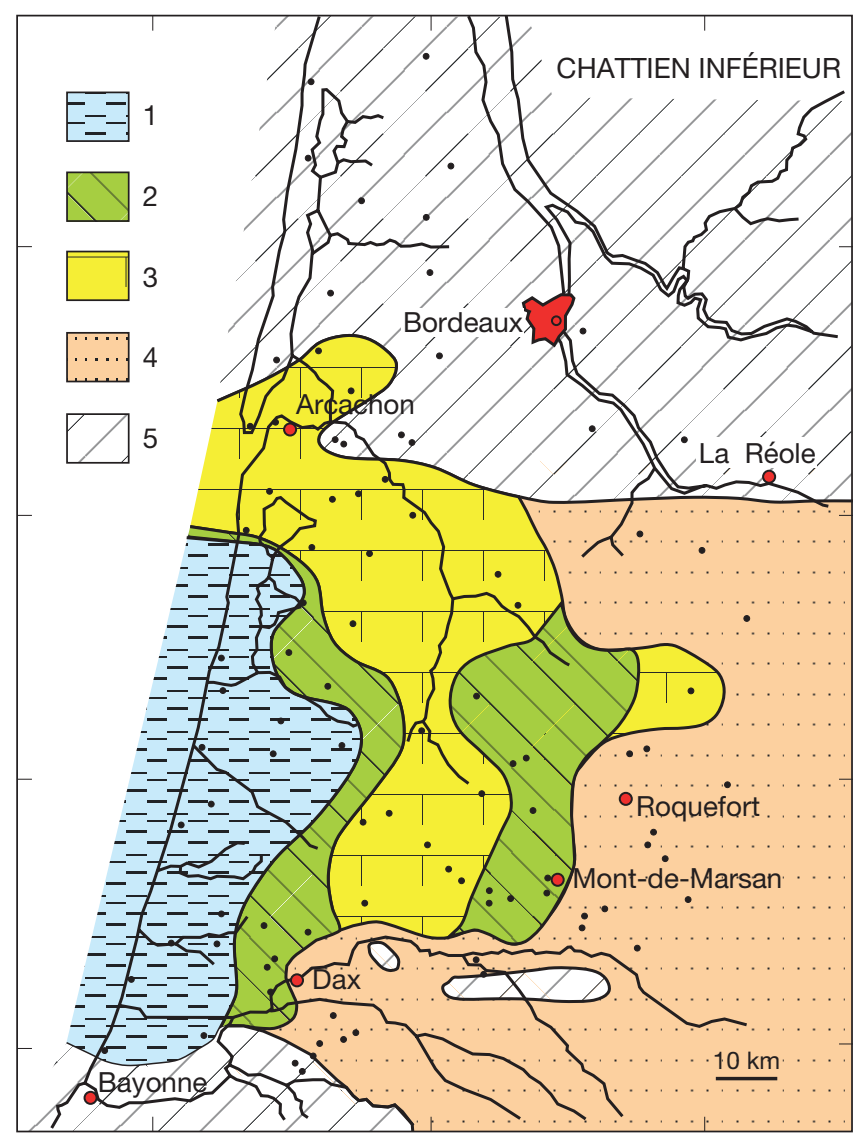

FIG. 9. - Schéma paléogéographique du Chattien inférieur (zone P 21b). Symboles: 1, bathyal à circalittoral; 2 , plate-forme détritique; 3 , plateforme carbonatée; 4 , continental; $\mathbf{5}$, érosion ou non dépôt/Paleogeographic scheme of the lower Chattian (Zone P 21b). Symbols: 1, bathyal to outer neritic; 2, detrital platform; 3, carbonate platform; 4, continental; 5, erosion or non-deposition.

Argenteyres $2(145 \mathrm{~m})$ qui surmonte des calcaires de l'Éocène et continue avec des calcaires bioclastiques qui contiennent $\mathrm{Mio}-$ gypsinoides complanatus (Schlumberger, 1900) (Argenteyres 2, 95, 107 et $124 \mathrm{~m}$; Hourquet $1,300 \mathrm{~m}$ ).

Les sondages Tennedou 1, Les Acacias 1, Lavergne-la-Teste 1, Carraté 1 (Figs 4, 5) montrent la transition entre les faciès argileux de la Formation Capcosle et les calcaires de la Formation du Calcaire à Astéries. Cinq périodes transgressives ont été identifiées à partir des forages Tennedou 1 et Carraté 1 pendant l'Oligocène. Les trois premières sont d'âge rupélien, vu la présence de Nummulites vascus Joly \& Leymerie, 1848 (Tennedou 1, $505 \mathrm{~m}$; Carraté 1, $415 \mathrm{~m}$ ). L'âge de la quatrième ne peut être déterminé précisément avec la microfaune rencontrée dans le forage Tennedou 1 (Chattien inférieur ?; Fig. 4), mais l'intercalation argileuse à sa base, entre 412 et $480 \mathrm{~m}$, montre que la profondeur maximale de la mer, entre 100 et $200 \mathrm{~m}$, a été atteinte dans cet intervalle. La dernière séquence appartient au Chattien supérieur, avec Miogypsinoides complanatus (Schlumberger, 1900) à 295 et 345 m. La même espèce a été déterminée dans le forage Lavergne-la-Teste 1 à $344 \mathrm{~m}$.

Le sondage Les Acacias 1 (Fig. 5) est globalement plus carbonaté, excepté la base de la cinquième séquence, qui est argileuse. Nummulites vascus Joly \& Leymerie, 1848 et Chapmanina gassinensis

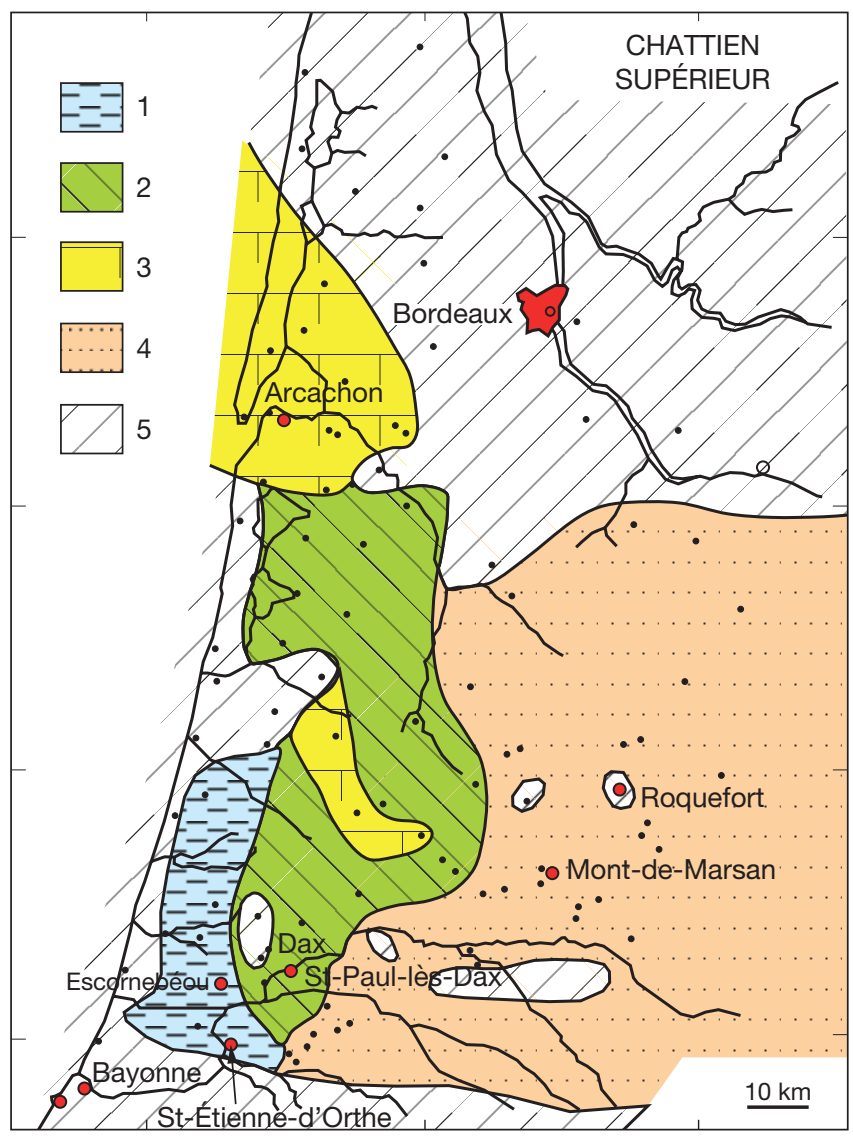

FIG. 10. - Schéma paléogéographique du Chattien supérieur (zone P 22). Symboles: 1 , bathyal à circalittoral; 2 , plate-forme détritique; 3 , plateforme carbonatée; 4 , continental; 5 , érosion ou non dépôt/Paleogeographic scheme of the upper Chattian (zone P 22). Symbols: 1, bathyal to outer neritic; 2, detrital platform; 3, carbonate platform; 4, continental; 5, erosion or non-deposition.

(A. Silvestri, 1905) indiquent le Rupélien inférieur à $448 \mathrm{~m}$, dans la deuxième séquence. Nummulites bouillei de la Harpe, 1879 et Planolinderina escornebovensis Freudenthal, 1969 étaient présents dans la quatrième séquence, à $366 \mathrm{~m}$ (Chattien inférieur). Les diagraphies ne permettent pas d'identifier des séquences dans le puits Sanguinet 1, les calcaires et calcaires gréseux dominent dans toute la coupe (320-747 m). Arenagula globula Bourdon \& Lys, 1955 et Nummulites vascus Joly \& Leymerie, 1848 ont été déterminés à $520 \mathrm{~m}$ (Rupélien) et Nummulites bouillei de la Harpe, 1879 et Miogypsinoides formosensis Yabe \& Hanzawa, 1928 à 350,35 m (Chattien supérieur).

Le sondage Garrosse 1 a traversé une série rupéliennechattienne monotone, carbonatée entre 286 et $852 \mathrm{~m}$, avec Miogypsinoides sp. au sommet (286-367 m; Fig. 4).

Les coupes des sondages Le Brain 1 et Saint-Jean-d'Illac 1 sont spécifiques et ne s'apparentent pas avec les sections décrites précédemment. L'Oligocène du forage Le Brain 1 commence par un ensemble argileux de milieu néritique interne (180$215 \mathrm{~m}$ ) et se poursuit par des Calcaires à Astéries (165-180 m). La partie supérieure (96-165 m) est argilo-sableuse d'âge chattien en tenant compte de la présence de Miogypsinoides? sp. et Halkyardia maxima Cimerman, 1969 à $110 \mathrm{~m}$. L'Oligocène du sondage Saint-Jean-d'Illac 1 est argilo-sableux; marne 
et sable fin à moyen, glauconieux entre 227 et $254 \mathrm{~m}$. Les sables à grain fin à moyen, coquilliers et calcaires sableux, bioclastiques dominent entre 146 et $227 \mathrm{~m}$. La présence de Bullalveolina bulloides (d'Orbigny, 1826) à 185 m montre que ces niveaux appartiennent au Rupélien. Il est possible que ce forage indique la partie externe d'un delta.

\section{ÉVOLUTION SÉDIMENTAIRE DE L'OLIGOCÈNE AQUITAIN}

Trois grandes aires sédimentaires se différencient en Aquitaine occidentale au cours de l'Oligocène. La première, qui occupe la façade atlantique entre Labenne, près de Bayonne et Cazaux, au sud d'Arcachon, se caractérise par les dépôts à dominance argileuse, bathyaux, avec un taux de sédimentation très important, près de $1700 \mathrm{~m}$ à Contis et à Mimizan. La sédimentation y est continue, à l'exception de quelques structures anticlinales actives, où les lacunes sédimentaires et réductions de série peuvent être observées. Les éléments détritiques arrivent dans ce bassin de l'est et l'on constate leur progradation vers l'ouest en montant dans les coupes. Ceci s'accompagne par la diminution de la tranche d'eau vers le haut, jusqu'au remplissage complet du bassin.

La deuxième aire qui forme un arc de cercle autour de la première, appartient à la plate-forme et présente des sédiments plus variés: calcaires bioclastiques, argiles et sables souvent glauconieux, coquilliers. Les lacunes de sédimentation sont plus fréquentes et les épaisseurs ne dépassent pas de 400$500 \mathrm{~m}$. La zone de transition entre les deux est étroite et suit les grands accidents tectoniques connus depuis le Crétacé inférieur (Mathieu 1986). Les dépôts continentaux de type molasse constituent le troisième aire et occupent la partie sud et orientale du Bassin d'Aquitaine.

Une compression nord-sud, liée à la tectonique pyrénéenne, influence la sédimentation et définit le taux de remplissage dans les différentes parties du bassin. Elle se manifeste par les ondulations de grande longueur d'onde. Nous pensons que les cycles eustatiques ont une influence très faible sur la sédimentation dans la région aquitaine par rapport aux signaux tectoniques, tenant compte des données de Miller et al. (2005).

\section{RUPÉLIEN INFÉRIEUR, ZONE P 18 (FIG. 6)}

La fin du Priabonien est marquée par des mouvements tectoniques compressifs dans le Bassin d'Aquitaine. Ceci se manifeste par l'apparition des faciès infralittoraux, carbonatés du Membre du Cachaou au sommet des Marnes de la Côte des Basques, comme à Biarritz et dans les sondages de Soustons 1 et Contis 1, ou par la présence des sables, comme dans les secteurs de Mézos, Pontenx et Parentis. À Biarritz, une discordance angulaire de $10^{\circ}$ sépare ces marnes des Grès de Biarritz rupéliens (Mathelin \& Sztrákos 1993). Cette discordance est soulignée par l'apparition d'un banc de grès ou de calcaire gréseux à la base du Rupélien, dépôts vite envahis par des pélites (Soustons 1, Saint-Girons-en-Marensin 1, Contis 1, Mimizan Nord 1, Marlenx 1, Le Terme 1).

Dans d'autres sondages, comme à Montagnottes 1 et Capcosle 3, il n'y a pas de changement lithologique notable à la limite Priabonien/Rupélien, laissant supposer la continuité de la sédimentation. Dans quelques cas, la lithologie est proche de part et d'autre de cette limite, mais les diagraphies montrent une rupture, liée à l'augmentation du volume d'argile dans le Rupélien (Laborde 1, Soustons 2). La pendagemétrie ne montre pas de différence d'angle entre ces deux étages dans les synclinaux (Gourbera 1).

La sédimentation argileuse, épibathyale à circalittorale domine sur la façade atlantique (Formation de Capcosle). Des niveaux détritiques apparaissent localement pendant la séquence. Ils sont localisés à l'intérieur d'un polygone délimité par les forages Saint-Girons-en-Marensin 1, Biscarrosse-Plage 1, Mézos 3 et Parentis 1. On observe localement des remaniements des foraminifères éocènes bathyaux (Contis 1).

Le domaine épibathyal-circalittoral est entouré par une ceinture de formations infralittorales, carbonatées. Elles sont parfois marneuses, nummulitiques à la base (Tennedou 1, Carraté 1, Sanguinet 1, Sore 1), rarement carbonatées (Les Acacias 1) ou lagunaires-saumâtres comme dans le Médoc (Formation de Bel-Air; Artiguillon 1). Elles passent latéralement dans la Formation du Fronsadais continentale.

L'extension maximale des faciès marins est marquée par les sondages Pouyarramon 1, Sébastopol 102 et Lesgor 1 dans le Bassin de l'Adour. Les formations infralittorales passent dans les dépôts continentaux au sud, à l'est et au nord. Ces derniers sont des argiles versicolores à intercalations de conglomérats dans le Bassin d'Arzacq (Formation de Jurançon), des argiles continentales dans le synclinal de Tartas (Formation de Campagne) ou des argiles continentales avec calcaires lacustres au sommet au nord-est de la plateforme nord-aquitaine (Formation du Fronsadais supérieure et Formation de Castillon). Les intercalations de calcaire gréseux, bioclastique apparaissent localement dans cet ensemble (autour de l'anticlinal de Clermont au SE de Dax et dans les sondages de Heulies 1, Noaillan 1 au sud de Langon). Les dépôts continentaux de la Formation du Fronsadais sont bien développés dans la région de l'Entre-Deux-Mers. La limite entre les formations du Fronsadais et de Castillon est une discordance régionale.

FIG. 11. - Foraminifères d'intérêt stratigraphique dans l'Oligocène d'Aquitaine occidentale. Pars 1/Foraminifera of stratigraphic interest in the Oligocene of western Aquitaine. Pars 1: A. Haplophragmoides latidorsatum (Bornemann, 1855). Mimizan-Plage 1, 1375 m; B, Vulvulina flabelliformis (Gümbel, 1870). Montagnottes 1, 600 m; C, Dorothia asiphonia (Andreae, 1884). Mimizan-Plage 1, 1065 m; D, Karreriella siphonella (Reuss, 1851). Capcosle 3, 310 m; E, Bigenerina eocaena Sztrákos, 1979. Saint-Girons-en-Marensin 1, 1150 m; F, Bigenerina oligocaena Sztrákos, 1979. Lit-et-Mixe 1, 1025 m; G, Semivulvulina pectinata (Reuss, 1850). Montagnottes 1, 430 m; H, Karrerotextularia concava (Karrer, 1868). Contis 1, 1505 m; I, Tritaxilina hantkeni Cushman, 1936. Mimizan-Plage 1, 855 m; J, Clavulinoides kruhelensis (Wojczik, 1913). Montagnottes 1, 600 m; K. Triloculinella sp. Capcosle 3, 310 m; L, Sigmoilinita asperula (Karrer, 1868). Capcosle 3, $370 \mathrm{~m} ; \mathbf{M}$, Lingulina seminuda Hantken, 1875. Mimizan-Plage 1, 950 m; N, Lenticulina budensis (Hantken, 1875). Montagnottes 1, 650 m; O, Percultazonaria pseudodecorata (Hagn, 1952). Mimizan-Plage 1, 1065 m; P, Vaginulinopsis schwageri (Hantken, 1875). Mimizan-Nord 1, 772 m; Q, Planularia karolyi Cicha \& Rögl, 1998. Mimizan-Nord 1, 717 m; R, Spirolingulina inflata (Sztrákos, 1979). Mimizan-Nord 1, 600 m; S, Planularia moravica (Karrer, 1865). Mimizan-Nord 1, 827 m; T, Lagena strumosa Reuss, 1858. Saint-Girons-en-Marensin 1, 815 m; U, Lagena sp. 1. Montagnottes 1, 600 m; V, Buchnerina orbignyana orbignyana 


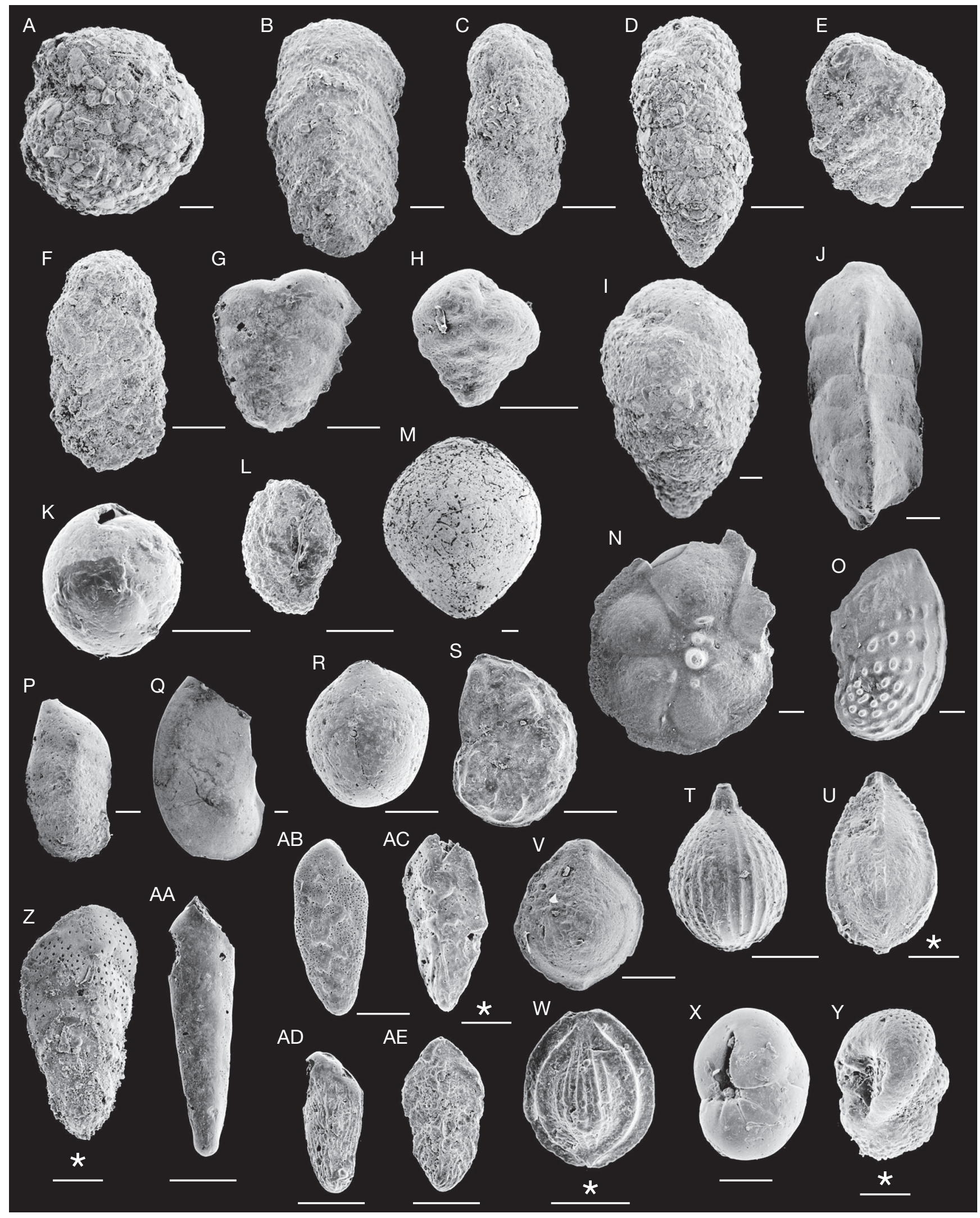

(Seguenza, 1862). Saint-Girons-en-Marensin 1, $1010 \mathrm{~m}$; W, Fissurina cf. praeclara Cushman \& Renz, 1946. Montagnottes 1, $490 \mathrm{~m} ; \mathbf{X}$, Ceratobulimina contraria (Reuss, 1851). Montagnottes 1, $600 \mathrm{~m}$; Y, Roglicia ? egerensis (Sztrákos, 1982). Lit-et-Mixe 1, $820 \mathrm{~m} ; \mathbf{Z}$, Bolivina beyrichi Reuss, 1851. Gourbera 1, 250 m; AA, Bolivina elongata Hantken, 1875. Mimizan-Nord 1, 500 m; AB, Bolivina liebusi Hofmann, 1967. Mimizan-Plage 1, 1130 m; AC, Bolivina fastigia Cushman, 1936. Capcosle 3, 470 m; AD, Bolivina vaceki bavarica Lühr, 1962. Lit-et-Mixe 1, 1010 m; AE, Bolivina cf. reticulata Hantken, 1875. Lit-et-Mixe 1, 960 m. Échelles: sans * ${ }^{*}, 1 \mathrm{~mm}$; avec *, $0,05 \mathrm{~mm} / \mathrm{Scale}$ bars: without ${ }^{*}, 0.1 \mathrm{~mm}$; with *, $0.05 \mathrm{~mm}$. 
Les sondages pétroliers indiquent, que les dépôts continentaux avancent jusqu'aux puits Artiguillon 1, Le Brain 1, Carraté 1, Landes-de-Siougos 2, Toulouzette 1 et Pouyarramon 1 vers l'ouest pendant le Rupélien inférieur.

Les variations des épaisseurs du Rupélien inférieur montrent l'importance de la tectonique synsédimentaire. Une forte subsidence caractérise la région entre Contis et Mimizan, avec des épaisseurs de 500-600 m. L'épaisseur est très faible sur la plate-forme nord-aquitaine, pouvant se réduire jusqu'à quelques dizaines de mètres (Artiguillon 1, Lavergnela-Teste 1). Les deux transgressions observées dans le Médoc (celle de la Formation de Bel-Air et celle du Membre à Crassostrea longirostris, qui constitue la base du Calcaire à Astéries en sédimentation continue) pourront se superposer aux deux séquences eustatiques observées par Miller et al. (2005) à la base de l'Oligocène.

\section{RupÉLIEN MOYEN, ZONES P 19-P 20 INFÉRIEURE (Fig. 7)}

Le dépôt du Calcaire à Astéries et de la Formation de Gaas représente la transgression majeure en Aquitaine, que l'on peut placer dans les zones P 19 et SB 21 supérieure. La mer du Calcaire à Astéries avance de l'ordre de $90 \mathrm{~km}$ vers l'est, jusqu'aux environs de Marmande, au nord d'une ligne TrensacqMaillas. Cette avancée est plus modeste, environ 30-40 km dans le Bassin de l'Adour (Formation de Gaas; Figs 6, 7).

La Formation de Gaas transgresse sur différents niveaux de l'Éocène dans sa localité-type, à Bénesse-lès-Dax et dans le puits Géothermie Dax 1. La sédimentation continentale domine pendant cette période dans le Bassin d'Arzacq (Formation de Jurançon).

La nouvelle transgression est marquée par l'apparition d'un horizon argileux dans les forages en bordure du Bassin de Parentis qui est surmonté par une série de calcaire gréseux, monotone avec Nummulites vascus Joly \& Leymerie, 1848 et $N$. fichteli Michelotti, 1841 (Marlenx 1, Les Acacias 1, Tennedou 1, Le Teich 1 , Courchade 1 , Caudos 1 ). Les faciès bathyaux avancent de 10-15 km vers l'est.

La séquence repose sur les différents termes de l'Éocène ou de l'Oligocène basal sur la plate-forme nord-aquitaine. La sédimentation nettement marine de l'Oligocène commence ici par le Calcaire à Astéries, après un épisode d'émersion observée au toit de la Formation de Castillon lacustre. Les dolomies du sondage Artiguillon 1, sous le Calcaire à Astéries à Bullalveolina bulloides (d'Orbigny, 1826) correspondent à cet épisode lacustre. Les trois transgressions décrites dans le Calcaire à Astéries du Bordelais (Alvinerie et al. 1977) ne sont pas des événements eustatiques, mais sédimentaires et tectoniques (remplissage du bassin suivi par une subsidence), qui n'existent pas sur la courbe de Miller et al. (2005). La transgression du Calcaire à Astéries suit la dépression qu'a empruntée la Formation de Saint-Palais-sur-Mer au Bartonien inférieur (anciennement Calcaire de Blaye; Gély \& Sztrákos 2000; Sztrákos et al. 2010). Le Calcaire à Astéries passe latéralement dans la "Molasse inférieure de l'Agenais", continentale vers l'est.

RUPÉLIEN SUPÉRIEUR, ZONES P 20 SUPÉRIEURE-P 21A (FIG. 8) Un événement tectonique majeur, lié à la dernière étape de la mise en place des nappes nord-pyrénéennes, a eu lieu entre les zones SB 21 et SB 22, dans la zone P 20 des foraminifères planctoniques. Cet événement modifie la paléogéographie du bassin. Premièrement, les dépôts continentaux envahissent le sud-est du Bassin de l'Adour. Plus à l'ouest, ceci se manifeste par le creusement du canyon de Saubrigues (Gély \& Sztrákos 2001) et par l'érosion partielle des formations éocènes dans les environs de Dax (ride de Tercis; cependant, elles ont été conservées autour de l'anticlinal de Clermont et plus à l'est, à l'écart de la poussée principale). Une autre conséquence de cet événement est l'invasion de la plate-forme par des éléments sableux de la Formation de Mugron dans le synclinal de Tartas, qui progradent vers l'ouest. La mer avance jusqu'à l'anticlinal de RoquefortCréon à l'est dans cette région subsidente, avancée que l'on peut estimer à 50-60 km. À cette subsidence répond une région émergente plus au nord, où les Calcaires à Astéries sont surmontés par la "Molasse supérieure de l'Agenais". L'ampleur de cette régression est de l'ordre de $30 \mathrm{~km}$. On observe également le rétrécissement du domaine bathyal. Les faciès carbonatés dominent au nord et les argilo-sableux au sud dans le domaine néritique.

Il n'y a pas de changement lithologique lié à cet événement dans les sondages Labenne 1, Soustons 1, Capcosle 3, Montagnottes 1, Lit-et-Mixe 1, Mimizan-Plage 1, Mimizan-Nord 1, à cause d'un milieu de dépôt profond. En revanche, des niveaux carbonatés ou gréseux apparaissent dans les autres sondages du Bassin de Contis et de Parentis (Contis 1, Mézos 3 et 101, Biscarrosse-Plage 1). Ce passage est bien visible dans le sondage Saint-Gironsen-Marensin 1 (1010-1055 m), où il est encadré par des dépôts appartenant à la zone P 20 (absence de Turborotalia ampliapertura (Bolli, 1957) à 1070 et à $1030 \mathrm{~m}$, présence de Paragloborotalia opima opima (Bolli, 1957) à $1010 \mathrm{~m}$ ). Ce sondage permet donc de caler l'événement tectonique mentionné dans l'échelle des biozones.

FIG. 12. - Foraminifères d'intérêt stratigraphique dans l'Oligocène d'Aquitaine occidentale. Pars 2/Foraminifera of stratigraphic interest in the Oligocene of western Aquitaine. Pars 2: A, Bolivina reticulata Hantken, 1875. Lit-et-Mixe 1, 1025 m; B, Bolivina terquemi Lindenberg, 1965. Mézos 101,780 m; C, Loxostomoides zsigmondii (Hantken, 1868). Mimizan-Plage 1, 950 m; D, Bolivinita concavomoeninia Poag, 1966. Capcosle 3, 1070 m; E, Cassidulina laevigata d'Orbigny, 1826. Biscarrosse-Plage 1. 862 m; F, Cassidulina vitalisi Majzon, 1948. Contis 1, 1730 m; G, Cassidulinoides bodeni Hagn, 1952. Capcosle 3 , 370 m; H, Globocassidulina alpina Sztrákos \& Du Fornel, 2003. Capcosle 3, 310 m; I, Globocassidulina ornata Sztrákos, 2000. Montagnottes 1, 600 m; J, Caucasina coprolithoides (Andreae, 1884). Labenne 1, 570 m; K, Bulimina sculptilis Cushman, 1923. Mimizan-Nord 1, 1102 m.; L, Uvigerina hantkeni Cushman, 1937. Lit-et-Mixe 1, 1078 m; M, Uvigerina moravia Boersma, 1984. Gourbera 1, 655 m; N, Angulogerina angulosa (Williamson, 1858). Capcosle 3, 880 m; O, Angulogerina muralis (Terquem, 1882). Mimizan-Nord 1, $653 \mathrm{~m} ; \mathbf{P}$, Angulogerina germanica Cushman \& Edwards, 1938. Mimizan-Nord 1, $717 \mathrm{~m} ; \mathbf{Q}$, Angulogerina germanica/tenuistriata transition. Mézos 3, 440 m; R, Angulogerina tenuistriata (Reuss, 1870). Capcosle 3, 550 m; S, Kolesnikovella tubulifera (Kaasschieter, 1961 ). Mézos 3, 1000 m; T-U, Drepaniota lorifera (Halkyard, 1919). Capcosle 3, 550 m; V, Pleurostomella acuta Hantken, 1875. Lit-et-Mixe 1, 730 m; W, Valvulineria palmarealensis (Nuttall, 1932). Mézos 3, 1076 m; X, Siphonina subreticulata Myatlyuk, 1953. Capcosle 3, 1070 m; Y, Cibicidoides pachyderma (Rzehak, 1886). Mimizan-Plage 1, 


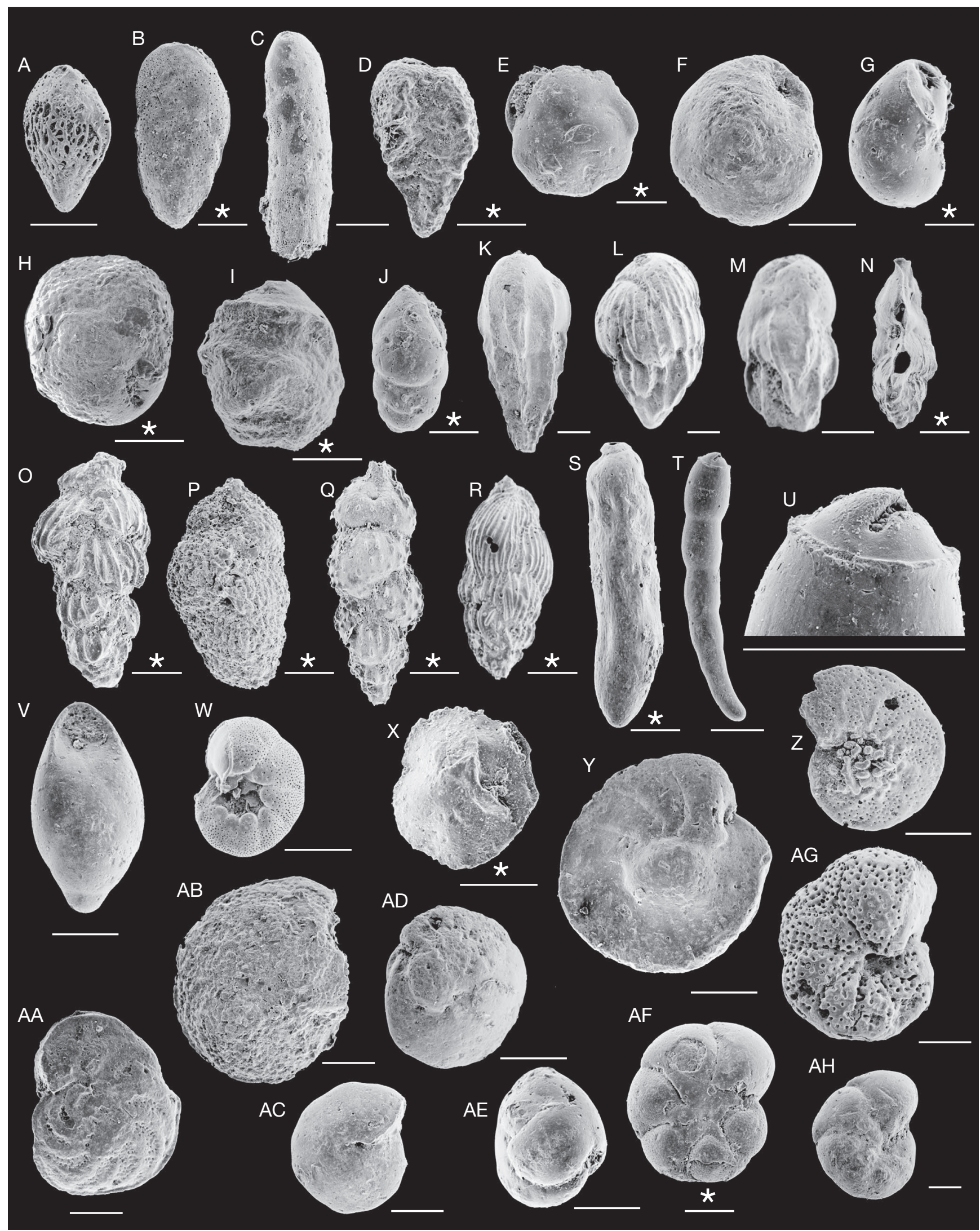

1065 m; Z, Cibicidoides ungerianus (d'Orbigny, 1846). Capcosle 3, 290 m; AA, Planulina costata (Hantken, 1875). Saint-Girons-en-Marensin 1, 1010 m; AB, Planulina costata (Hantken, 1875). Lit-et-Mixe 1, 1078 m; AC, Thyromata curvisepta (Subbotina, 1936). Mimizan-Nord 1, 717 m; AD, Nonion durhami Mallory, 1959. Contis 1, 1730 m; AE, Nonionella liebusi Hagn, 1952. Contis 1, 910 m; AF, Astrononion budense Sztrákos, 1979. Mézos 3, 640 m; AG, Anomalinoides granosa (Hantken, 1875). Capcosle 3, $550 \mathrm{~m} ; \mathbf{A H}$, Anomalinoides similis (Hantken, 1875). Montagnottes 1, $650 \mathrm{~m}$. Échelles: sans *, 0,1 mm; avec *, 0,05 mm/Scale bars: without *, $0.1 \mathrm{~mm}$; with *, $0.05 \mathrm{~mm}$. 
ChATTIEN InfÉRIEUR, ZONE P 21B (Fig. 9)

Une régression générale s'observe au cours du Chattien inférieur dans les parties occidentale et septentrionale du Bassin d'Aquitaine, indiquée par la diminution de la tranche d'eau dans les sondages et l'avancée de la Formation de l'Agenais à Noaillan, ainsi que dans les secteurs de l'anticlinal de Roquefort-Créon et du synclinal de Tartas. Cependant, l'apparition d'une intercalation argileuse à la base de cet étage, dans les forages situés dans la partie centrale du Bassin d'Aquitaine, laisse supposer une subsidence locale observée dans les sondages Tennedou 1, Carraté 1, Trensacq 1, Biscarrosse Plage 1 (Figs 4, 5).

Cet intervalle correspond à une période de non-dépôt dans certaines parties d'Aquitaine septentrionale. Ceci est démontré par l'absence du Chattien inférieur dans quelques sondages. Par exemple, les calcaires à Miogypsinoides et Planolinderina escornebovensis Freudenthal, 1969 reposent sur la craie sénonienne dans le sondage Argenteyres 2, sur le Rupélien supérieur dans Le Teich 1. Les dépôts carbonatés dominent dans la zone située entre les anticlinaux de Louer-Audignon et Carcans. Une deuxième région carbonatée se situe entre Villeneuve-de-Marsan et Maillas. Le restant de la plate-forme est couvert par des sédiments argilo-sableux.

\section{ChatTien Supérieur, ZONE P 22 (Fig. 10)}

La sédimentation reste argileuse, monotone entre les zones P 21 et P 22 sur la façade atlantique au sud de Biscarrosse. C'est dans la zone de transition entre le bassin et la plate-forme carbonatée et sur cette dernière que l'on voit l'importance de la dernière transgression de l'Oligocène. Elle se manifeste par l'apparition massive des faciès argileux (Formation d'Escornebéou) dans le canyon de Saubrigues et près de Dax et Tartas (Gourbera 1, Lesgor 1, Landes-de-Siougos 2), audessus des calcaires de la séquence précédente. La base de cette transgression qui avance jusqu'aux environs du Porge vers le nord, est argileuse dans les sondages Tennedou 1, Biscarrosse Plage 1, Les Acacias 1, Hourquet 1. La phase régressive est représentée par des sables argileux de la Formation de SaintPaul-lès-Dax ou par des Calcaires à Astéries. L'épaisseur de la Formation d'Escornebéou atteint plus de $100 \mathrm{~m}$ près de Dax et diminue progressivement vers l'est et le nord.

La Formation de l'Agenais avance de 50-60 km vers l'ouest en même temps sur la ligne Maillas-Trensacq-Marlenx, montrant le caractère local et l'origine tectonique de la transgression mentionnée. Cette formation continentale surmonte les calcaires infralittoraux de la Formation de Moulin de Batan dans le forage Maillas 1 et recouvre les anticlinaux de
Roquefort-Créon, Magenta et Losse. Le passage latéral de la Formation d'Escornebéou dans la Formation de l'Agenais s'observe à l'est du sommet de l'anticlinal de Campagne (Landes-de-Siougos 7, Mont-de-Marsan 1 et GMM 2).

La plate-forme carbonatée est réduite à la région qui se situe au nord des forages Cazaux 1 et Bernon 1 d'une part et à la zone entre les forages de Tennedou 1 et Villenave 1 d'autre part. Le restant du domaine néritique est occupé par des dépôts dominant argilo-sableux. D’après les données actuellement disponibles, la sédimentation pourrait être continue entre le Chattien et l'Aquitanien dans les environs de Dax (Gourbera 1), où les sables argileux monotones franchissent cette limite. Vigneaux et al. (1970) ont prouvé l'existence de l'Aquitanien dans un forage d'eau à Soustons, dans une série argileuse monotone, grâce à la présence de Globorotalia kugleri (Bolli, 1957), au-dessus des sédiments chattiens.

Le fait, que le Falun de Saint-Avit repose sur la Formation de l'Agenais dans le synclinal de Tartas (Platel 1990b) et la présence d'un poudingue entre le Chattien et l'Aquitanien à Saint-Paul-lès-Dax (Cahuzac 1980), montre que l'Aquitanien représente une nouvelle transgression dans de nombreuses régions.

Le Chattien supérieur est fortement érodé sur la façade atlantique et sur la plate-forme nord-aquitaine, où l'Oligocène est surmonté par les dépôts du Burdigalien. Ce fait montre l'existence d'une période d'érosion intense entre l'Aquitanien et le Burdigalien.

\section{CONCLUSIONS}

La stratigraphie de l'Oligocène d'Aquitaine occidentale a été revue en synthétisant les données bibliographiques et en réexaminant 93 sondages, dont 60 ont été datés à l'aide de foraminifères ou nannofossiles calcaires.

Les Tableaux 2, 3 et l'Annexe 1 mettent en évidence la modification progressive de la faune de petits foraminifères benthiques, les disparitions et apparitions des espèces donnant une indication complémentaire sur l'âge des couches qui les enferment. Ce groupe a permis d'estimer les variations de la tranche d'eau dans les coupes, entre les domaines épibathyal et saumâtre. La faune montre de fortes affinités avec celle de l'Europe centrale, contact qui s'est établi à travers du détroit de Gibraltar et la zone bétique, au sud de l'Espagne.

Les définitions des formations marines de l'Oligocène de l'Aquitaine occidentale ont été revues. L'extension latérale,

FIG. 13. - Foraminifères d'intérêt stratigraphique dans l'Oligocène d'Aquitaine occidentale. Pars 3/Foraminifera of stratigraphic interest in the Oligocene of western Aquitaine. Pars 3: A, Heterolepa megomphala (Gümbel, 1870); Montagnottes 1, 490 m; B, Nuttallides sp. Contis 1, 1195 m; C, Gyroidinoides mamillata (Andreae, 1884). Mimizan-Nord 1, 653 m; D, Rotaliatina sp. Capcosle 3, 880 m; E, Escornebovina leganyii (Kenawy \& Nyirő, 1967). Montagnottes 1, 430 m; F, Chiloguembelina cubensis (Palmer, 1934). Capcosle 3, 750 m; G, Chiloguembelina cubensis (Palmer, 1934). Capcosle 3, 880 m; H, Paragloborotalia mendacis (Blow, 1969). Gourbera 1, 150 m; I, Paragloborotalia opima nana (Bolli, 1957). Lit-et-Mixe 1, 1110 m; J, Paragloborotalia opima opima (Bolli, 1957). Mimizan-Plage 1, 855 m; K, Turborotalia increbescens (Bandy, 1949). Gourbera 1, 670 m; L, Turborotalia ampliapertura (Bolli, 1957). Capcosle 3, 750 m; M, Tenuitella brevispira (Subbotina, 1960). Mimizan-Plage 1, 862 m; N, Tenuitella brevispira (Subbotina, 1960). Capcosle 3, 750 m; O, Tenuitella liverovskae (Bykova, 1960). Contis 1, 910 m; P, Catapsydrax dissimilis (Cushman \& Bermúdez, 1937). Montagnottes 1, 650 m; Q, Catapsydrax martini scandretti (Blow \& Banner, 1962 ). Capcosle 3, 880 m; R, Subbotina gortanii (Borsetti, 1959). Contis 1, $1730 \mathrm{~m} ; \mathbf{S}$, Globoquadrina tripartita (Koch, 1926). Mimizan-Plage 1, $1065 \mathrm{~m} ;$ T, Globoquadrina tapuriensis (Blow \& Banner, 1962). Mimizan-Nord 1, 827 m; U, Globoquadrina sellii (Borsetti, 1959). Montagnottes 1, 490 m; V, Subbotina angiporoides (Hornibrook, 1965). Montagnottes 1, 650 m; W, Subbotina linaperta utilisindex (Jenkins \& Orr, 1973). Mimizan-Nord 1, 1005 m; X, Dentoglobigerina pseudovenezuelana (Blow \& Banner, 1962). Mimizan-Nord 1, 600 m; Y, Dentoglobigerina pseudovenezuelana (Blow \& Banner, 1962). Capcosle 3, 370 m; Z, Pseudohastigerina barbadoensis Blow, 1969. Capcosle 3, 880 m; AA, Cassigerinella chipolensis (Cushman \& Ponton, 1932). Capcosle 3, 750 m; AB, Bolliella sp. Mimizan-Nord 1, 563 m; AC, Turboro- 


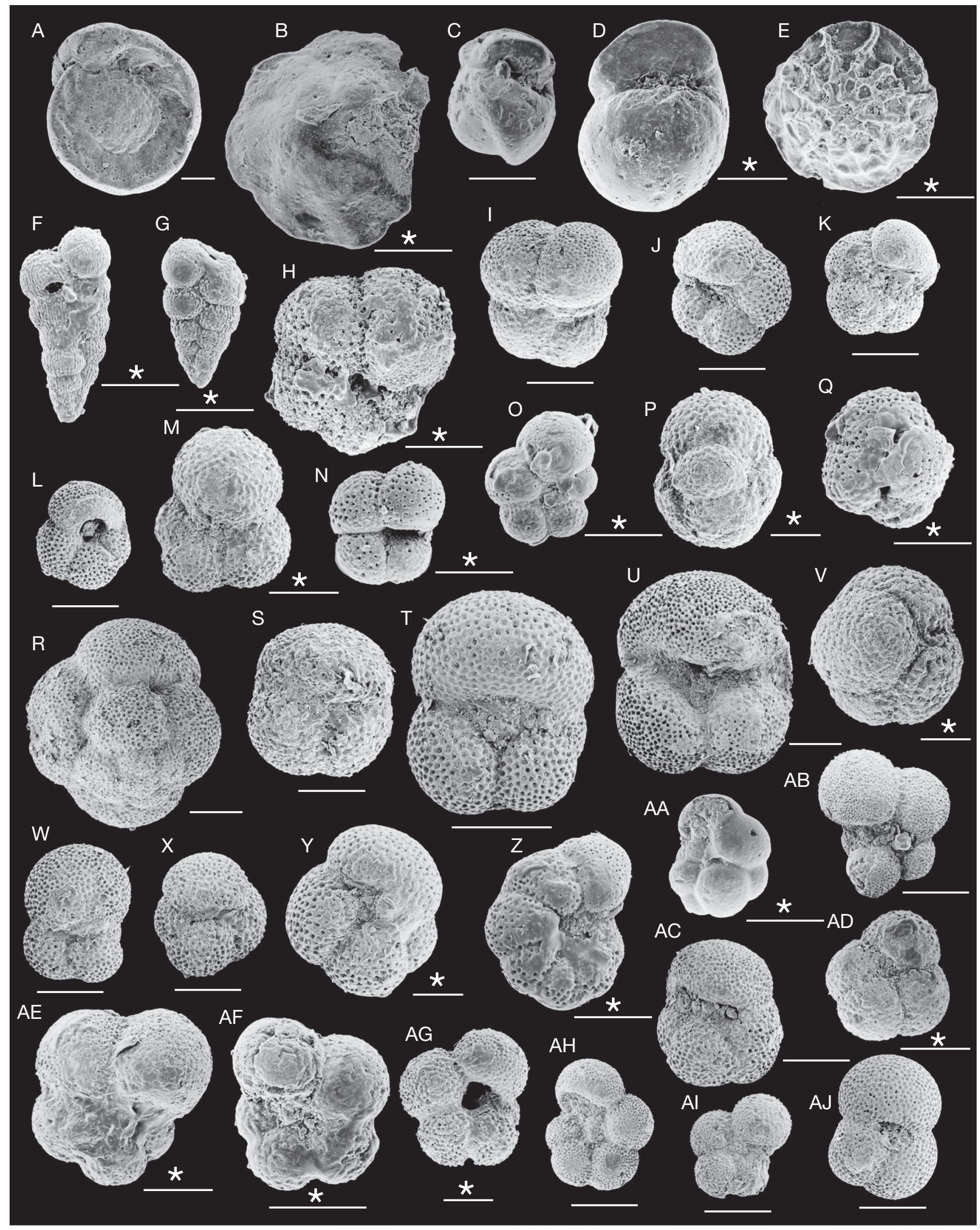

talia euapertura (Jenkins, 1960). Biscarrosse-Plage 1. 862 m; AD, Globigerina officinalis Subbotina, 1953. Capcosle 3, $1070 \mathrm{~m}$; AE, Globigerina anguliofficinalis Blow, 1969. Contis 1, 1275 m; AF, Globigerina anguliofficinalis Blow, 1969. Mimizan-Nord 1, 1102 m; AG, Globigerina angulisuturalis Bolli, 1957. Mimizan-Nord 1, $350 \mathrm{~m}$; AH, Globigerina ciperoensis Bolli, 1957. Mézos 3, $640 \mathrm{~m}$; Al, Globoturborotalita ouachitaensis gnaucki (Blow \& Banner, 1962$)$. Mézos 3, $786 \mathrm{~m} ;$ AJ, Globigerinoides primordius Blow \& Banner, 1962. Gourbera 1, $250 \mathrm{~m}$. Échelles: sans * ${ }^{*}, 0,1 \mathrm{~mm}$; avec *, $0,05 \mathrm{~mm} / \mathrm{Scale}$ bars: without ${ }^{*}, 0.1 \mathrm{~mm} ;$ with *, $0.05 \mathrm{~mm}$. 
la nature des contacts et les variations lithologiques des formations ont été clarifiées grâce aux sondages (Figs 2-5). Les formations suivantes sont retenues dans l'Oligocène de l'Aquitaine occidentale:

\section{BASSIN DE L'ADOUR}

\section{Domaine marin}

Formation de Capcosle. Ici nouvellement introduite: présentant une dominance argileuse, bathyale-circalittorale devenant infralittorale au sommet, d'âge Rupélien-Aquitanien.

Formation de Biarritz. Infralittorale, Rupélien inférieur, redéfinie.

Formation de Gaas. Infralittorale, Rupélien moyen.

Formation de Mugron. Infralittorale, Rupélien supérieurChattien inférieur.

Formation de Moulin de Batan. Infralittorale, Rupélien supérieur-Chattien inférieur.

Formation d'Escornebéou. Circalittorale, Chattien supérieur, redéfinie.

Formation de Saint-Paul-lès-Dax. Infralittorale, Chattien supérieur-Aquitanien

\section{Domaine continental}

Formation de Jurançon. Éocène supérieur-Miocène

Formation de Campagne. Éocène supérieur-Rupélien inférieur? Formation de l'Agenais. Chattien.

\section{PLATE-FORME NORD-AQUITAINE}

Domaine marin

Formation de Bel-Air. Infralittorale-saumâtre, Rupélien inférieur.

Formation du Calcaire à Astéries avec le Membre à Crassostrea longirostris à la base. Infralittorale, Rupélien-Chattien.

\section{Domaine continental}

Formation du Fronsadais. Éocène supérieur-Rupélien inférieur. Formation de Castillon. Lacustre, Rupélien inférieur. Formation de l'Agenais. Rupélien moyen-Chattien.

\section{ÉVOLUTION PALÉOGÉOGRAPHIQUE}

L'évolution paléogéographique de la région aquitaine a été retracée (Figs 6-10). Trois grandes aires sédimentaires se différencient au cours de l'Oligocène. La première, entre Labenne et Arcachon, se caractérise par les dépôts à dominant argileux, bathyaux à circalittoraux, avec un taux de sédimentation très important. La deuxième aire forme un arc de cercle autour de la première, et représente la plate-forme avec des sédiments plus variés: calcaires bioclastiques, argiles et sables coquilliers. Le troisième est représenté par des dépôts continentaux, qui entourent la précédente à l'est et au sud.

Cinq transgressions s'observent dans l'Oligocène du Bassin d'Aquitaine: au Rupélien inférieur (Formation de Biarritz, Formation de Bel-Air); Rupélien moyen (Formations de Gaas et Calcaire à Astéries s.s.); Rupélien supérieur (Formation de Mugron, Formation de Moulin de Batan); Chattien inférieur et Chattien supérieur (Formation d'Escornebéou, Calcaire à Astéries avec Miogypsinoides). La transgression du Chattien inférieur ne s'observe que dans la partie centrale du Bassin d'Aquitaine, grâce à l'apparition d'un horizon argileux au sein des formations carbonatées (Tennedou-Trensacq-Biscarrosse Plage 1; Figs 4, 5). Le Chattien inférieur est régressif au sud, dans le Bassin de l'Adour.

Les événements tectoniques pyrénéens (compression N-S) influencent la sédimentation. Au cours du Rupélien moyen, l'avancée de la Formation du Calcaire à Astéries au nord est plus importante que celle de la Formation de Gaas au sud. En revanche, la transgression des formations de Mugron et Moulin de Batan au sud (Rupélien supérieur) est contemporaine de la régression marquée par la Formation de l'Agenais continentale au nord. La transgression du Chattien inférieur correspond à la subsidence de la partie centrale du Bassin d'Aquitaine. L'impact de la tectonique reste important au Chattien supérieur vu que la transgression de la Formation d'Escornebéou est orientée par la réactivation du synclinal de Tartas.

Un échantillonnage serré des sondages avec plus de matériel permettra de compléter nos connaissances sur la faune de foraminifères, de préciser la limite des biozones et des variations des milieux de dépôt. L'étude d'autres sondages, particulièrement dans le Bassin de Parentis pourra préciser la transition entre les domaines bathyal et néritique, tandis que l'étude détaillée des forages d'eau donnera plus d'informations sur la transition entre les dépôts marins et continentaux au nord-est du Bassin d'Aquitaine. La réinterprétation des sections sismiques précisera l'extension des corps sédimentaires, la localisation des discordances et l'amplitude des érosions entre et au sein des unités lithostratigraphiques.

\section{Remerciements}

Nous remercions les responsables du Bureau Exploration-Production des Hydrocarbures du Ministère de l'Industrie (BEPH) et de Gaz de France pour nous avoir prêté les échantillons des sondages. Messieurs Thierry Hubin et Adriano Vandersypen de l'Institut royal des Sciences naturelles de Belgique (Bruxelles) ont fortement contribué à la finalisation des versions électroniques des figures. Les nummulites ont été déterminées par Monsieur Alphonse Blondeau (†). Nous remercions également Madame Carla Müller pour la détermination des nannofossiles calcaires ainsi que Messieurs Bruno Cahuzac et Jean-Pierre Gély pour leurs conseils. Madame Armelle Poignant mérite notre plus grand respect et notre reconnaissance la plus profonde pour ses conseils et pour l'ensemble de ses travaux sur l'Oligocène aquitain.

\section{RÉFÉRENCES}

Alvinerie J., Pratviel L., Gayet J., Dubreuilh J., Moisan J. L., Wilbert J., Astié H. \& DuverGÉ J. 1977. - Notice explicative, carte géologique de la France (1/50000) feuille Bordeaux (803). Bureau de Recherches géologiques et minières, Orléans, 40 p.

ANDREIEFF P. \& MARIONNAUD J.-M. 1972. — Observations préliminaires sur la limite Éocène/Oligocène dans la série classique du Médoc (Gironde). La position stratigraphique des "grès et calcaires à Anomies». Comptes Rendus de l'Académie des Sciences (Paris) 274: 1637 1640. http://gallica.bnf.fr/ark:/12148/bpt6k58080984/f223.item 
BenOist E. 1883. - Communications sur les sables coquilliers dits de Terre-Nègre (Bordeaux). Comptes Rendus de la Société linnéenne de Bordeaux: 25, 26.

BENOIST E. 1884. - L'étage Oligocène moyen dans la commune de Gaas (Landes). Bulletin de la Société Borda 9: 53-61. http:// gallica.bnf.fr/ark:/12148/bpt6k34175q/f157.item

BENOIST E. 1885. - Description géologique et paléontologique des communes de Saint-Estèphe et de Vertheuil. Actes de la Société linnéenne de Bordeaux 39: 79-15, 301-352. https://biodiversitylibrary.org/page/26424146

BENOIST E. 1887. - Esquisse géologique des terrains tertiaires du Sud-Ouest de la France. Journal d'Histoire naturelle du Sud-Ouest (2) 6: 55-58, 69-71, 79-83.

Benoist E. \& Billiot J. T. 1889. - Coupe géologique des terrains tertiaires sur la rive droite de la Gironde et de la Dordogne. Actes de la Société linnéenne de Bordeaux 43: 209-249. https:// biodiversitylibrary.org/page/31868904

Berggren W. A., Kent D. V., Swisher III C. C. \& Aubry M.-P. 1995. - A revised Cenozoic geochronology and chronostratigraphy. SEPM Special Publication 54: 129-212. https://doi. org/10.7916/D8XD1B1H

Berggren W. A. \& Pearson P. N. 2005. - A revised tropical to subtropical Paleogene planktonic foraminiferal zonation. Journal of Foraminiferal Research 35: 279-298. https://doi. org/10.2113/35.4.279

Boulanger D. \& Poignant A. 1964. — Le passage Éocène supérieur-Oligocène en Aquitaine occidentale. Compte Rendu sommaire des Séances de la Société géologique de France 2: 85-86.

BOUSSAC J. 1911. - Études stratigraphiques et paléontologiques sur le Nummulitique de Biarritz. Annales Hébert (Lab. Géol. Sorbonne), Paris, vol. 5, 96 p. https://doi.org/10.5962/bhl.title.139027

Burger J. J., Cuvillier J. \& Schoeffler J. 1945. - Stratigraphie du Nummulitique de la Chalosse de Montfort. Bulletin de la Société géologique de France (5) 15: 207-220. https://doi. org/10.2113/gssgfbull.S5-XV.4-6.207

CAHUZAC B. 1980. - Stratigraphie et paléogéographie de l'Oligocène an Miocène moyen en Aquitaine sud-occidentale. Thèse de l'Université de Bordeaux, 2 tomes, $586 \mathrm{p}$.

CAHUZAC B. 1984. - Les faunes de Miogypsinidae d'Aquitaine méridionale (France), in Benthos '83, 2nd International Symposium on Benthic Foraminifera (Pau, April 1983): 117-129.

Cahuzac B., Alvinerie J., Lauriat-Rage A., Montenat C. \& Pujol C. 1992. - Paleogeographic maps of the Northeastern Atlantic Neogene and relation with the Mediterranean sea. Paleontologia $i$ Evolució 1: 279-293.

Cahuzac B., Janin M. C. \& Steurbaut E. 1995. - Biostratigraphie de l'Oligo-Miocène du bassin d'Aquitaine fondée sur les nannofossiles calcaires. Implications paléogéographiques. Géologie de la France 2: 57-82.

Cahuzac B. \& Janssen A. W. 2010. - Eocene to Miocene holoplanktonic Mollusca (Gastropoda) of the Aquitaine Basin, Southwest France. Scripta Geologica 141: 1-193.

CAHUZAC B. \& POIGNANT A. 1988. - Les foraminiferes benthiques de l'Oligocène terminal du vallon de Poustagnac (Landes, Bassin d'Aquitaine, SO de la France). Découverte de Cycloclypeus et de Pararotalia à loges équatoriales supplémentaires. Benthos'86, Revue de Paléobiologie, volume spécial 2: 633-642.

CAHUZAC B. \& POIGNANT A. 1992. - Les foraminifères benthiques intéressant la limite Oligocène-Miocène en Aquitaine (sud-ouest de la France) - Comparaisons avec la Mésogée occidentale. Paleontologia y Evolució 24-25: 15-28.

CahuZaC B. \& Poignant A. 1997. — Essai de biozonation de l'OligoMiocène dans les bassins européens à l'aide de grands foraminiferes benthiques. Bulletin de la Société géologique de France 168 (2): 155-169.

CAHUZAC B. \& Poignant A. 2002. - Associations de foraminiferes benthiques dans quelques gisements de l'Oligo-Miocène du SudAquitain. Revue de Micropaléontologie 45 (3): 221-256. https:// doi.org/10.1016/S0035-1598(02)90027-9
CaHUZAC B., Turpin L. \& Bonhomme P. 1997. — Sr isotope record in the area of the Lower Miocene historical stratotypes of the Aquitaine Basin (France), in MONTANARI A., ODIN G. S. \& COCCIONI R. (eds), Miocene Stratigraphy: an Integrated Approach. Elsevier Science, coll. Developments in Paleontology and Stratigraphy, vol. 15: 33-56. https://doi.org/10.1016/S0920-5446(06)80008-7

Capdeville J. P., Charnet F. \& LenOIR M. 1996. - Notice explicative de la feuille Podensac à 1/50000 (828). Bureau de Recherches géologiques et minières, Orléans, $60 \mathrm{p}$.

CAVEliER C. 1979. — La limite Éocène/Oligocène en Europe occidentale. Institut de géologie, Strasbourg, vol. 54, 280 p. (coll. Sciences géologiques)

Cicha I., RÖGl F., Rupp CH. \& CTyroka J. 1998. — OligoceneMiocene of the Central Paratethys. Fritz F. Steininger, coll. Abhandlungen der Senckenbergischen Naturforschenden Gesellschaft, vol. 549,325 p.

DaGuin F. 1947. - Observations sur la partie supérieure de la coupe du Tuc de Saumon (Landes). Compte Rendu sommaire de la Société géologique de France 6: 109-111.

Delbos J. 1847. - Recherches sur l'âge de la formation d'eau douce de la partie orientale du bassin de la Gironde. Mémoires de la Société géologique de France, série 2, 2: 241-289. https:// biodiversitylibrary.org/page/42373689

Delbos J. 1848. - Notice sur les fahluns du sud-ouest de la France. Bulletin de la Société géologique de France 5: 417-428.

Delbos J. 1854. - Essai d'une description géologique du Bassin de l'Adour suivi de considérations sur l'âge et classement des terrains nummulitiques. Thèse de doctorat, Imp. des Ouvriers associés, Bordeaux, $162 \mathrm{p}$.

Des Moulins CH. 1832. - Lettre à M. Desnoyers. Bulletin de la Société géologique de France 2: 440-442. https://biodiversitylibrary. org/page/53829561

DollfuS G. F. 1906. - Considérations sur la classification du Tertiaire. Bulletin de la Société géologique de France, série 4, 6: 478-480. https://biodiversitylibrary.org/page/30559362

Dollfus G. F. 1917. - L'Oligocène supérieur marin dans le bassin de l'Adour. Bulletin de la Société géologique de France 17 (4): 89-102.

Douvillé H. 1906. - Stratigraphie des couches de Gaas. Bulletin de la Société géologique de France, série 4, 6: 500. https://biodiversitylibrary.org/page/30559396

Dubreuilh J. \& MarionNAUd J.-M. 1972. - Notice explicative, carte géologique de la France (1/50000) feuille Saint-Vivien-deMédoc-Soulac-sur-Mer (730). Bureau de Recherches géologiques et minières, Orléans, $45 \mathrm{p}$.

Dubreuilh J. \& MARIONNAUd J.-M. 1973. - Notice explicative, carte géologique de la France (1/50000) feuille Lesparre-MédocForêt-de-Junca (754). Bureau de Recherches géologiques et minières, Orléans, $47 \mathrm{p}$.

DuCASSE O. 1974. - Sur l'extension probable des formations oligocènes de Biarritz dans la partie méridionale du Golfe de Gascogne. Compte Rendu sommaire de la Société géologique de France 4: 76.

EARdLEY A. J. 1946. - Petroleum geology of Aquitaine Basin, France. Bulletin of the American Association of Petroleum Geologists 30 (9): 1517-1545.

Fallot E. 1880. - Esquisse géologique du département de la Gironde. Feuille des jeunes naturalistes 19: 1-27.

FALlOT E. 1894. - Contribution à l'étude de l'étage Tongrien dans le département de la Gironde. Mémoires de la Société des Sciences physiques et naturelles 5 (4): 146-192.

Fallot E \& ReYT L. 1891. - Observations sur le Crétacé de Roquefort et ses relations avec quelques assises tertiaires affleurant dans cette localité. Actes de la Société linnéenne de Bordeaux 44: 353-360. https://biodiversitylibrary.org/page/27383782

FeIsT M. \& RingeAde M. 1977. — Étude biostratigraphique et paléobotanique (charophytes) des formations continentales d'Aquitaine, de l'Éocène supérieur au Miocène inférieur. Bulletin de la Société géologique de France, série 7, 19 (2): 341-354. https://doi.org/10.2113/gssgfbull.S7-XIX.2.341 
Ferrand J. M., Kuingebiel A. \& Moyes J. 1970. — Contribution à l'étude de l'Oligocène du Réolais. Bulletin de l'Institut géologique du Bassin d'Aquitaine 9: 87-92.

GÉLY J.-P. \& SZTRÁKOS K. 2000. — L'évolution paléogéographique et géodynamique du Bassin aquitain au Paléogène: enregistrement de la tectonique pyrénéenne. Géologie de la France 2: 31-57.

GÉLY J.-P. \& SZTRÁKOS K. 2001. — La tectonique pyrénéenne à l'Oligocène: une phase majeure de la déformation en compression méconnue du Bassin aquitain (France). Comptes Rendus de l'Académie des Sciences - Series IIA - Earth and Planetary Science 332 (8): 507-512. https://doi.org/10.1016/S1251-8050(01)01564-6

Groupe FRANÇAIS D'ÉTUdE DU NÉOGÈne 1974. - Étude biostratigraphique des gisements d'Escornebéou (Aquitaine méridionale, France). Documents des Laboratoires de Géologie de la Faculté des Sciences de Lyon 59: 1-86.

Hardenbol J., Thierry J., Farley M. B., Jacquin T., DE GraCIANSKY P. C. \& VAIL P. R. 1998. - Mesozoic and Cenozoic Sequence Chronostratigraphic Framework of European Basins, in De Graciansky P. C., Hardenbol J., JacQuin T. \& Vail P. R. (eds), Mesozoic and Cenozoic Sequence Stratigraphy of European Basins. SEPM, Society for Sedimentary Geology, Special Publication 60, Charts 1-5, 786 p. https://doi.org/10.2110/pec.98.02

HEDBERG H. D. 1979. - Guide stratigraphique international. Classification, terminologie et règles de procédures. Doin, Paris, 233 p.

Henry J., Zolnaï G., Le Pochat G. \& Mondeilh C. 1989. Notice explicative de la feuille à 1/50000 Orthez (1003). Bureau de Recherches géologiques et minières, Orléans, $55 \mathrm{p}$.

JACQUOT M. E. 1864. - Description géologique des falaises de Biarritz, Bidart, Guetary et Saint-Jean-de-Luz (Basses Pyrénées). Actes de la Société linnéenne de Bordeaux 25: 1-58. https://biodiversitylibrary.org/page/34075870

JANSSEN A. W. 1985. - Ontsluitingen in het Bekken van Aquitaine. Afzettingen van de Werkgroep voor Tertiaire en Kwartaire Geologie 6: 74-97, 104-129.

JOUANNET F. 1830. - Considérations générales sur les terrains tertiaires du département de la Gironde. Actes de la Société linnéenne de Bordeaux: 171-226.

Kieken M. \& Thibault CL. 1972. - Notice explicative de la feuille Hasparren à 1/50000 (1002). Bureau de Recherches Géologiques et Minières, Orléans, $26 \mathrm{p}$

KIEKEN M. \& Thibault CL. 1975. - Notice explicative de la feuille St-Vincent-de-Tyrosse à 1/50000 (975-976). Bureau de Recherches Géologiques et Minières, Orléans, $46 \mathrm{p}$.

Le Pochat G. \& Thibault Cl. 1977. - Notice explicative de la feuille Dax à 1/50000 (977). Bureau de Recherches Géologiques et Minières, Orléans, $24 \mathrm{p}$.

Magné J. \& Malmoustier G. 1964. — Contribution à l'étude des associations microfauniques du Paléogène nord-aquitain. Colloque sur le Paléogène, 1962. Mémoires du Bureau de Recherches Géologiques et Minières 28: 269-282.

MARTINI E. 1971. - Standard Tertiary and Quaternary Calcareous Nannoplankton Zonation, in Proceedings 2nd Planctonic Conference (Roma, 1970). Tecnoscienza, Roma 2: 739-785.

Mathelin J. C. \& SzTrÁKOS K. 1993. - L'Éocène de Biarritz (Pyrénées atlantiques, SW de la France). Stratigraphie et paléoenvironnement. Monographie des foraminifères. Cahiers de Micropaléontologie, n.s. 8 (1): 5-85.

Matheron Ph. 1867. - Note sur les dépôts tertiaires du Médoc et des environs de Blaye et sur leurs rapports avec les couches fluvio-lacustres du nord-est de l'Aquitaine et avec les lambeaux tertiaires des environs de Nantes. Bulletin de la Société géologique de France, série 2, 24: 197-228.

Mathieu C. 1986. - Histoire géologique du sous-bassin de Parentis. Bulletin des Centres de Recherches Exploration-Production Elf-Aquitaine 10 (1): 33-47.

Miller K. G., Kominz M. A., Browning J. V., Wright J. D., Mountain G. S., Katz M. E., Sugarman P. J., Cramer B. S., Christie-Blick N. \& Pekar S. F. 2005. — The Phanerozoic reward of global sea-level change. Science 350: 1293-1298. https:// doi.org/10.1126/science.1116412

Müller C. \& PUjOl C. 1979. — Étude du nannoplancton calcaire et des foraminifères planctoniques dans l'Oligocène et Miocène en Aquitaine (France). Géologie Méditerranéenne 6 (2): 357-368. MurraY J. W. 1973. - Distribution and Palaeoecology of Benthic Foraminifera. Heinemann Educational Books, London, 274 p.

Nolf D. \& Steurbaut E. 2002. - Compléments à l'étude des otolithes de poissons rupéliens d'Aquitaine méridionale (Sud Ouest de la France). Revue de Micropaléontologie 45 (4): 297-312. https://doi.org/10.1016/S0035-1598(02)90058-9

Nolf D., Steurbaut E. \& Cahuzac B. 2002. - Progrès récents dans la connaissance des gisements cénozö̈ques en Aquitaine méridionale (France S-O). Revue de Micropaléontologie 45 (3): 169-194. https://doi.org/10.1016/S0035-1598(02)90017-6

OgG J. G., OgG G. \& Gradstein F. M. 2008. - The Concise Geologic Time Scale. Cambridge University Press, New York, 177 p.

Pellat E. 1863. - Note sur les falaises de Biarritz. Bulletin de la Société géologique de France, série 2, 20: 670-677. https://biodiversitylibrary.org/page/54668288

Platel J.-P. 1990a. - Notice explicative. Carte géologique de la France (1/50000). Feuille Cazaubon (926). Bureau de Recherche géologique et minière, Orléans, 66 p.

Platel J.-P. 1990b. - Notice explicative. Carte géologique de la France (1/50000). Feuille Tartas (950). Bureau de Recherche géologique et minière, Orléans, $51 \mathrm{p}$.

Poignant A. 1967. - L'Oligo-Miocène de l'Aquitaine méridionale. Thèse de doctorat, Paris, 3 vol., $381 \mathrm{p}$.

POIGNANT A. 1998. — Révision des espèces de foraminiferes signalées par d'Orbigny en Aquitaine (SO de la France) dans le "Tableau méthodique de la classe des Céphalopodes" (1826). Revue de Micropaléontologie 41 (2): 107-149. https://doi.org/10.1016/ S0035-1598(98)90055-1

Poignant A. 1999. - Révision des taxons de petits foraminifères benthiques décrits dans l'Oligocène et le Miocène d'Aquitaine (SO de la France) postérieurement à ceux cités par d'Orbigny en 1826. Description d'une nouvelle espèce et d'une nouvelle sous-espèce. Revue de Micropaléontologie 42 (2): 133-159. https:// doi.org/10.1016/S0035-1598(99)90116-2

POIGNANT A. \& LORENZ CL. 1985. — Répartition biogéographique de foraminiferes benthiques à l'Oligocène et au Miocène inférieur dans la Téthys. Bulletin de la Société géologique de France 5: 771779. https://doi.org/10.2113/gssgfbull.I.5.771

PoignANT A. \& SzTRÁKOS K. 1986. — Les foraminifères de l'Oligocène supérieur de la Formation de Ciudad Granada (coupe de Barranco Blanco, province d'Almeria, Espagne). Revista española de Micropaleontologia 18 (1): 115-129.

Pujol C. 1970. - Contribution à l'étude des foraminifères planctoniques néogènes dans le bassin aquitain. Bulletin de l'Institut Géologique du Bassin d'Aquitaine 9: 201-219.

PujOl C. \& CAHUZAC B. 1984. - Contribution à la connaissance des dépôts tertiaires d'Aquitaine méridionale. Résumés de la 10e Réunion annuelle des Sciences de la Terre, Bordeaux: 463.

RaUlin V. 1848. - Nouvel essai d'une classification des terrains tertiaires de l'Aquitaine. Thèse de Doctorat, Bordeaux, $58 \mathrm{p}$.

RAULIN V. 1862. - Sur quelques protubérances crétacées de la partie occidentale de l'Aquitaine. Actes de l'Académie de Bordeaux, série 3, 24: 199-222.

RAULIN V. 1897. — Statistique géologique et agronomique du département des Landes. $3 e$ partie. Laurent imp., Verdun: 239-406.

RINGEADE M. 1987. — Séquences mammaliennes en Aquitaine: corrélations des zones à mammiferes classiques, zones à charophytes et à ostracodes. Münchner geowissenschaftliche Abhandlungen, $A$, Geologie und Paläontologie 10: 189-197.

Riveline J., Berger J.-P., Feist M., Martin-Closas C., SchuDACK M. \& SOUlí́-MÄrSCHE I. 1996. — European MesozoicCenozoic charophyte biozonation. Bulletin de la Société géologique de France 167: 453-468. 
RÖGL F. \& HansEN H.-J. 2009. — Thyromata nov. gen., a benthic foraminifer from the Late Eocene-Early Oligocene of the Paratethys. Annalen des Naturhistorischen Museums in Wien, Geologie und Paläontologie 111A: 15-32.

STEURBAUT E. 1983. - The stratigraphic position of the Lower Oligocene Yrieu Sands (Southwestern France), based on calcareous nannofossils and a new Helicosphaera species. Eclogae Geologiae Helvetiae 76 (2): 327-331. https://doi.org/10.5169/seals-165365

Steurbaut E. 1984. — Les otolithes de Téléostéens de l'OligoMiocène d'Aquitaine (Sud-ouest de la France). Palaeontographica Abt. A, 186 (1-6): 1-162.

SzÖts E., Malmoustier G. \& Magné J. 1964. — Observations sur le passage oligo-miocène en Aquitaine et sur les zones de foraminiferes planctoniques de l'Oligocène. Mémoires du Bureau de Recherche géologique et minière 28: 433-454.

SZTRÁKOS K. 1979. — La stratigraphie, paléoécologie, paléogéographie et les foraminiferes de l'Oligocène du nord-est de la Hongrie. Cahiers de Micropaléontologie 3: 1-95.

SZTRÁKOS K. 1982. — Les foraminiferes de la Marne de Buda et la limite Éocène-Oligocène en Hongrie. Cahiers de Micropaléontologie 4: 1-48.

SZTRÁKOS K. 2000. - Les foraminiferes de l'Éocène du Bassin de l'Adour (Aquitaine, France) : biostratigraphie et taxinomie. Revue de Micropaléontologie 43 (1): 71-172. https://doi.org/10.1016/ S0035-1598(00)90096-5

SZTrákOs K., BlONDEAU A. \& HotTinger L. 2010. — Lithostratigraphie et biostratigraphie des formations marines paléocènes et éocènes nord-aquitaines (bassins de Contis et Parentis, seuil et plate-forme nord-aquitains). Géologie de la France 2: 3-52.

Sztrákos K., Gély J.-P., Blondeau A. \& Müller C. 1998. L'Éocène du Bassin sud-aquitain: lithostratigraphie, biostratigraphie et analyse séquentielle. Géologie de la France 4: 57-105.
SZTrÁKOS K. \& Du Fornel E. 2003. - Stratigraphie, paléoécologie et foraminiferes du Paléogène des Alpes Maritimes et des Alpes de Haute Provence (Sud-Est, France). Revue de Micropaléontologie 46 (4): 229-267. https://doi.org/10.1016/j.revmic.2003.09.003

Thorent M. 1846. - Mémoire sur la constitution géologique des environs de Bayonne. Mémoires de la Société géologique de France, série 2, 1: 181-191. https://biodiversitylibrary.org/page/42314844

TOURNOUER R. 1862. - Note stratigraphique et paléontologique sur les faluns du département de la Gironde. Bulletin de la Société géologique de France, série 2, 19: 1035-1088.

TOURNOUER R. 1863. - Note sur la présence des nummulites dans l'étage de Natica crassatina du bassin de l'Adour. Bulletin de la Société géologique de France, série 2, 20: 649-670.

Van Simaeys S., De Man E., Vandenberghe N., Brinkhuis H. \& STEURBAUT E. 2004. - Stratigraphic and paleoenvironmental analysis of the Rupelian-Chattian transition in the type region: evidence from dinoflagellate cysts, foraminifera and calcareous nannofossils. Palaeogeography, Palaeoclimatology, Palaeoecology 208: 1-58. https://doi.org/10.1016/j.palaeo.2004.02.029

Van Morkhoven F. P. C. M., BergGren W. A. \& Edwards A. S. 1986. - Cenozoic cosmopolitan deep-water benthic foraminifera. Bulletin des Centres de Recherches Exploration-Production ElfAquitaine, Mémoire 11, $421 \mathrm{p}$.

VeILLON M. 1964. — Les zones de foraminifères du Paléogène nord-aquitain et leur valeur stratigraphique. Colloque sur le Paléogène, 1962. Mémoires du Bureau de Recherches géologiques et minières 28: 227-241.

Vigneaux M., Moyes J. \& Pujol C. 1970. — Les foraminifères planctoniques et leur intérêt dans l'interprétation de la zone de transition oligo-miocène définie à Soustons (Aquitaine méridionale). Bulletin de l'Institut de Géologie du Bassin d'Aquitaine 9: 153-156. 


\begin{tabular}{|c|c|c|c|c|c|c|c|}
\hline \multirow{2}{*}{$\begin{array}{r}\text { Étages/séries } \\
\text { Zones de foraminifères planctoniques }\end{array}$} & \multirow[t]{2}{*}{ ÉOCENE } & \multicolumn{4}{|c|}{ RUPÉLIEN } & \multicolumn{2}{|c|}{ CHATTIEN } \\
\hline & & P18 & P19 & P20 & P21a & P21b & P22 \\
\hline \multicolumn{8}{|l|}{ Sous-ordre TEXTULARIINA } \\
\hline \multicolumn{8}{|l|}{ Bathysiphon cf. taurinensis Sacco, 1893} \\
\hline \multicolumn{8}{|l|}{ Psammosiphonella cylindrica (Glaessner, 1937) } \\
\hline \multicolumn{8}{|l|}{ Rhizammina cf. indivisa Brady, 1884} \\
\hline \multicolumn{8}{|l|}{ Ammodiscus grzybowskii Emiliani, 1954} \\
\hline \multicolumn{8}{|l|}{ Repmanina charoides (Jones \& Parker, 1860) } \\
\hline \multirow{2}{*}{\multicolumn{8}{|c|}{ Haplophragmoides latidorsatum (Bornemann, 1855) }} \\
\hline \multicolumn{3}{|l|}{ Ammobaculites agglutinans (d'Orbigny, 1846) } & & & & & \\
\hline \multicolumn{8}{|l|}{ Flabellammina sp. } \\
\hline Triplasia loeblichi Hagn, 1953 & & & & & & & \\
\hline Haddonia intermedia (Halkyard, 1919) & & & & & & & \\
\hline Reticulophragmium cf. acutidorsatum (Hantken, 1868) & & & & & & & \\
\hline Spirorutilis carinatus (d'Orbigny, 1846) & & & & & & & \\
\hline Vulvulina haeringensis (Gümbel, 1870) & & & & & & & \\
\hline V. flabelliformis (Gümbel, 1870) & & & & & & & \\
\hline V. pennatula (Batsch, 1791) & & & & & & & \\
\hline Pavonitina kiscelliana (Sztrákos, 1979) & & & & & & & \\
\hline P. plana Loeblich \& Tappan, 1985 & & & & & & & \\
\hline Plectina dalmatina (Schubert, 1911) & & & & & & & $\mathrm{R}$ ? \\
\hline Dorothia asiphonia (Andreae, 1884) & & & & & & & \\
\hline D. fallax Hagn, 1954 & & & & & & & \\
\hline D. traubi (Hagn,1956) & & & & & & & \\
\hline Karreriella siphonella (Reuss, 1851) & & & & & & & \\
\hline K. hantkeniana Cushman, 1936 & & & & & & & \\
\hline K. subglabra (Gümbel, 1870) & & & & & & & \\
\hline Martinottiella communis (d'Orbigny, 1846) & & & & & & & \\
\hline M. rhumbleri (Cushman, 1936) & & & & & & & \\
\hline Bigenerina eocaena Sztrákos, 1979 & & & & $?$ & & & \\
\hline Bigenerina oligocaena Sztrákos, 1979 & & & & & & & \\
\hline Semivulvulina deperdita (d'Orbigny, 1846) & & & & & & & \\
\hline S. pectinata (Reuss, 1850) & & & & & & & \\
\hline Textularia agglutinans d'Orbigny, 1846 & & & & & & & \\
\hline T. elongata (Hantken, 1875) & & & & & ? & & \\
\hline T. gramen d’Orbigny, 1846 & & & & & & & \\
\hline T. lontensis Lalicker, 1935 & & & & & & & \\
\hline T. neorugosa Thalmann, 1950 & & & & & & & \\
\hline T. pala Czjzek, 1848 & & & & & & & \\
\hline T. sagittula Defrance, 1824 & & & & & & & \\
\hline Karrerotextularia concava (Karrer, 1868) & & & & & & & \\
\hline Siphotextularia finlayi Hornibrook, 1961 & & & & & & & \\
\hline Clavulinoides kruhelensis (Wojczik, 1913) & ? & & & & & & \\
\hline C. szaboi (Hantken, 1868) & & & & & & & \\
\hline Pseudogaudryina ? gardnerae (Cushman, 1926) & & & & & & & \\
\hline P.? glabrata (Cushman, 1922) & & & & & & & \\
\hline Tritaxia triquetra (Reuss, 1864) & & & & & & & \\
\hline Arenagula globula Bourdon \& Lys, 1955 & & & & & & & \\
\hline Cylindroclavulina rudislosta (Hantken, 1889) & & & & & & & $?$ \\
\hline Valvulina irregularis Terquem, 1882 & & & & & & & \\
\hline V. limbata Terquem, 1882 & & & & & & & \\
\hline V. pupa d'Orbigny, 1850 & & & & & & & \\
\hline V. terquemi Le Calvez, 1952 & & & & & & & \\
\hline V. triangularis d'Orbigny, 1826 & & & & & & & \\
\hline V. triedra Le Calvez, 1952 & & & & & & & \\
\hline Tritaxilina hantkeni Cushman, 1936 & & & & & & & \\
\hline Sous-ordre SPIRILLININA & & & & & & & \\
\hline Spirillina vivipara Ehrenberg, 1843 & & & & & & & \\
\hline & & & & & & & \\
\hline Sous-ordre MILIOLINA & & & & & & & \\
\hline Vertebralina turbiformis (Cuvillier \& Sacal, 1949) & & & & & & & \\
\hline Adelosina longirostra (d'Orbigny, 1846) & & & & & & & \\
\hline Spiroloculina cf. angulosa Terquem, 1878 & & & & & & & \\
\hline Spiroloculina cf. bidentata Hadley, 1935 & & & & & & & \\
\hline S. canaliculata d'Orbigny, 1846 & & & & & & & \\
\hline
\end{tabular}


ANNEXE 1. - Suite/Continuation

\begin{tabular}{|c|c|c|c|c|c|c|c|}
\hline \multirow{2}{*}{$\begin{array}{r}\text { Étages/séries } \\
\text { Zones de foraminifères planctoniques }\end{array}$} & \multirow[t]{2}{*}{ ÉOCENE } & \multicolumn{4}{|c|}{ RUPÉLIEN } & \multicolumn{2}{|c|}{ CHATTIEN } \\
\hline & & P18 & P19 & P20 & P21a & P21b & P22 \\
\hline \multicolumn{8}{|l|}{ Sous-ordre MILIOLINA (suite) } \\
\hline \multicolumn{8}{|l|}{ S. carinata Le Calvez, 1947} \\
\hline \multicolumn{8}{|l|}{ S. costigera Terquem, 1882} \\
\hline \multicolumn{8}{|l|}{ S. grateloupi d'Orbigny, 1826} \\
\hline \multicolumn{8}{|l|}{ S. tricarinata Terquem, 1882} \\
\hline \multicolumn{8}{|l|}{ Cycloforina badenensis (d'Orbigny, 1846) } \\
\hline \multicolumn{8}{|l|}{ C. bicarinella Reuss, 1869} \\
\hline \multicolumn{8}{|l|}{ C. gr. contorta (d'Orbigny, 1846) } \\
\hline \multicolumn{8}{|l|}{ C. costata (d'Orbigny, 1826) } \\
\hline C. ludwigi (Reuss, 1866) & & & & & & & \\
\hline C. parisiensis (d'Orbigny, 1826) & & & & & & & \\
\hline Heterillina bella (Le Calvez, 1947) & & & & & & & \\
\hline H. carinata Schlumberger, 1905 & & & & & & & \\
\hline Quinqueloculina bicarinella Reuss, 1868 & & & & & & & \\
\hline Q. crassa d'Orbigny, 1826 & & & & & & & \\
\hline Q. eos Reuss, 1868 & & & & & & & \\
\hline Q. ermani Bornemann, 1855 & & & & & & & \\
\hline Q. ? lucida Karrer, 1868 & & & & & & & \\
\hline Q. seminuda Reuss, 1866 & & & & & & & \\
\hline Miliolinella enoplostoma (d'Orbigny, 1839) & & & & & & & \\
\hline Flintina serratula Cuvillier \& Sacal, 1949 & & & & & & & \\
\hline F. variolaria Cuvillier \& Sacal, 1949 & & & & & & & \\
\hline Pseudotriloculina consobrina (d'Orbigny, 1846) & & & & & & & \\
\hline P. cyclostoma (Reuss, 1850) & & & & & & & \\
\hline P. cylindrica (d'Orbigny, 1826) & & & & & & & \\
\hline Pyrgo alata (d'Orbigny, 1852) & & & & & & & \\
\hline Pyrgo bulloides (d'Orbigny, 1826) & & & & & & & \\
\hline P. lunula (d'Orbigny, 1846) & & & & & & & \\
\hline P. oblonga (d'Orbigny, 1839) & & & & & & & \\
\hline P. simplex (d'Orbigny, 1846) & & & & & & & \\
\hline P. subsphaerica (d'Orbigny, 1839) & & & & & & & \\
\hline Triloculina angularis d'Orbigny, 1905 & & & & & & & \\
\hline T. exilis Reuss, 1869 & & & & & & & \\
\hline T. gibba d'Orbigny, 1826 & & & & & & & \\
\hline T. hemisphaerica Terquem, 1882 & & & & & & & \\
\hline T. inflata d'Orbigny, 1846 & & & & & & & \\
\hline T. cf. intermedia Karrer, 1868 & & & & & & & \\
\hline T. trigonula (Lamarck, 1804) & & & & & & & \\
\hline T. cf. turgida inflata Andreae, 1884 & & & & & & & \\
\hline Triloculinella sp. & & & & & & & \\
\hline Sigmoilina celata (Costa, 1855) & & & & & & & \\
\hline Sigmoilopsis mediterranensis Bogdanovitch, 1950 & & & & & & & \\
\hline Sigmoilinita asperula (Karrer, 1868) & & & & & & & \\
\hline S. tenuis (Czjzek, 1848) & & & & & & & \\
\hline Articulina nitida d'Orbigny, 1865 & & & & & & & \\
\hline A. oligocaenica Cuvillier \& Sacal, 1949 & & & & & & & \\
\hline A. sulcata Reuss, 1850 & & & & & & & \\
\hline Miliola prisca (d’Orbigny, 1905) & & & & & & & \\
\hline M. pseudosaxorum (Schlumberger, 1905) & & & & & & & \\
\hline M. tournoueri (Schlumberger, 1883) & & & & & & & \\
\hline Pseudohauerina ornatissima (Karrer, 1868) & & & & & & & \\
\hline Peneroplis orbicularis d'Orbigny, 1852 & & & & & & & \\
\hline Dendritina arbuscula d'Orbigny, 1826 & & & & & & & \\
\hline Spirolina cylindracea (Lamarck, 1806) & & & & & & & \\
\hline S. pedum d'Orbigny, 1850 & & & & & & & \\
\hline Bullalveolina bulloides (d'Orbigny, 1826) & & & & & & & \\
\hline Sous-ordre LAGENINA & & & & & & & \\
\hline Alfredosilvestris levinsoni Andersen, 1961 & & & & & & & \\
\hline Neugeborina ewaldi (Reuss, 1851) & & & & & & & \\
\hline N. longiscata (d'Orbigny, 1846) & & & & & & & \\
\hline Chrysalogonium lanceolum Cushman \& Jarvis, 1934 & & & & & & & \\
\hline C. longicostatum Cushman \& Jarvis, 1934 & & & & & & & \\
\hline C. resupinatum (Gümbel, 1870) & & & & & & & \\
\hline
\end{tabular}




\begin{tabular}{|c|c|c|c|c|c|c|c|}
\hline \multirow{2}{*}{$\begin{array}{r}\text { Étages/séries } \\
\text { Zones de foraminifères planctoniques }\end{array}$} & \multirow[t]{2}{*}{ ÉOCENE } & \multicolumn{4}{|c|}{ RUPÉLIEN } & \multicolumn{2}{|c|}{ CHATTIEN } \\
\hline & & P18 & P19 & P20 & P21a & P21b & P22 \\
\hline \multirow{2}{*}{\multicolumn{8}{|c|}{$\begin{array}{l}\text { Sous-ordre LAGENINA (suite) } \\
\text { C. tenuicostatum Cushman \& Bermúdez, } 1936\end{array}$}} \\
\hline & \multicolumn{7}{|c|}{ C. tenuicostatum Cushman \& Bermúdez, 1936} \\
\hline \multicolumn{8}{|l|}{ C. vicksburgense Todd, 1952} \\
\hline \multicolumn{8}{|l|}{ Dentalina acuta d'Orbigny, 1846} \\
\hline \multicolumn{8}{|l|}{ D. acuticosta Reuss, 1850} \\
\hline \multicolumn{8}{|l|}{ D. albatrossi (Cushman, 1923) } \\
\hline \multicolumn{8}{|l|}{ D. capitata (Boll, 1846) } \\
\hline \multicolumn{8}{|l|}{ D. contorta (Hantken, 1868) } \\
\hline D. fissicostata Gümbel, 1870 & & & & & & & \\
\hline Enantiodentalina cf. eocenica (Mallory, 1959) & & & & & & & \\
\hline Grigelis coarctatus (Hantken, 1875) & & & & & & & \\
\hline G. hispidus (Soldani, 1791) & & & & & & & \\
\hline Laevidentalina cooperensis (Cushman, 1933) & & & & & & & \\
\hline L. elegans (d'Orbigny, 1846) & & & & & & & \\
\hline L. sp. 4 Sztrákos, 1993 & & & & & & & \\
\hline Nodosaria cf. radicula (Linnaeus, 1758) & & & & & & & \\
\hline N. rudis d'Orbigny, 1846 & & & & & & & \\
\hline N. soluta (Reuss, 1851) & & & & & & & \\
\hline Pseudonodosaria brevis (d'Orbigny, 1846) & & & & & & & \\
\hline P. discreta (Reuss, 1850) & & & & & & & \\
\hline P. inflata (Bornemann, 1855) & & & & & & & \\
\hline Pyramidulina latejugata (Gümbel, 1870) & & & & & & & \\
\hline P. raphanistra (Linnaeus, 1758) & & & & & & & \\
\hline Svenia bulbosa (Halkyard, 1919) & & & & & & & \\
\hline S. monroei (Todd, 1952) & & & & & & & \\
\hline Lingulina glabra Hantken, 1875 & & & & & & & \\
\hline L. seminuda Hantken, 1875 & & & & & & & \\
\hline Parafrondicularia striata (Hantken, 1875) & & & & & & & \\
\hline Lenticulina cf. alatolimbata (Gümbel, 1870) & & & & & & & \\
\hline L. arcuatostriata (Hantken, 1868) & & & & & & & \\
\hline L. budensis (Hantken, 1875) & & & & & & & \\
\hline L. calcar (Linnaeus, 1758) & & & & & & & \\
\hline L. clypeiformis (d'Orbigny, 1846) & & & & & & & \\
\hline L. cultrata (Montfort, 1808) & & & & & & & \\
\hline L. depauperata (Reuss, 1851) & & & & & & & \\
\hline L. falcifer (Stache, 1865) & & & & & & & \\
\hline L. globosa (Hantken, 1875) & & & & & & & \\
\hline L. inornata (d'Orbigny, 1846) & & & & & & & \\
\hline L. limbosa (Reuss, 1863) & & & & & & & \\
\hline L. limbata (Bornemann, 1855) & & & & & & & \\
\hline L. platyptera (Reuss, 1870) & & & & & & & \\
\hline L. princeps (Reuss, 1865) & & & & & & & \\
\hline L. pseudovortex (Cole, 1927) & & & & & & & \\
\hline L. terryi (Coryell \& Embich, 1937) & & & & & & & \\
\hline L. texana (Cushman \& Applin, 1926) & & & & & & & \\
\hline L. umbonata (Reuss, 1851) & & & & & & & \\
\hline L. vortex (Fichtel \& Moll, 1798) & & & & & & & \\
\hline Percultazonaria asperuliformis (Nuttall, 1930) & & & & & & & \\
\hline P. fragaria (Gümbel, 1870) & & & & & & & \\
\hline P. pseudodecorata (Hagn, 1952) & & & & & & & \\
\hline Saracenaria arcuata (d'Orbigny, 1846) & & & & & & & \\
\hline S. hantkeni Cushman, 1933 & & & & & & & \\
\hline S. cf. italica (Defrance, 1824) & & & & & & & \\
\hline S. minima (Hantken, 1875) & & & & & & & \\
\hline S. propinqua (Hantken, 1875) & & & & & & & \\
\hline Frondovaginulina tenuissima (Hantken, 1875) & & & & & & & \\
\hline Palmula inglisiana (Puri, 1957) & & & & & & & \\
\hline Amphicoryna badenensis (d'Orbigny, 1846) & & & & & & & \\
\hline A. bullosa (Galloway \& Heminway, 1941) & & & & & & & \\
\hline A. crassa (Hantken, 1868) & & & & & & & \\
\hline A. ehrenbergiana (Neugeboren, 1851) & & & & & & & \\
\hline A. scalaris (Batsch, 1791) & & & & & & & \\
\hline A. spinicosta (d'Orbigny, 1846) & & & & & & & \\
\hline A. sublineata (Brady, 1884) & & & & & & & \\
\hline
\end{tabular}


ANNEXE 1. - Suite/Continuation.

\begin{tabular}{|c|c|c|c|c|c|c|c|}
\hline \multirow{2}{*}{$\begin{array}{r}\text { Étages/séries } \\
\text { Zones de foraminifères planctoniques }\end{array}$} & \multirow[t]{2}{*}{ ÉOCENE } & \multicolumn{4}{|c|}{ RUPÉLIEN } & \multicolumn{2}{|c|}{ CHATTIEN } \\
\hline & & P18 & P19 & P20 & P21a & P21b & P22 \\
\hline \multicolumn{8}{|l|}{ Sous-ordre LAGENINA (suite) } \\
\hline \multicolumn{8}{|l|}{ Astacolus nummuliticus (Gümbel, 1870) } \\
\hline \multicolumn{8}{|l|}{ A. sulzensis (Hermann, 1903) } \\
\hline \multirow{2}{*}{\multicolumn{8}{|c|}{ Hemirobulina gr. glabra (d'Orbigny, 1826) }} \\
\hline \multirow{2}{*}{\multicolumn{8}{|c|}{$\begin{array}{l}\text { Hemirobulina hantkeni (Bandy, 1949) } \\
\text { H. inconspicua (Hussey, 1949) }\end{array}$}} \\
\hline & & & & & & & \\
\hline \multicolumn{8}{|l|}{ H. pediformis (Bornemann, 1855) } \\
\hline \multicolumn{8}{|l|}{ H. tumida (Reuss, 1851) } \\
\hline \multicolumn{8}{|l|}{ Marginulina behmi (Reuss, 1866) } \\
\hline M. hirsuta d'Orbigny, 1826 & & & & & & & \\
\hline M. multiplicata Bergquist, 1942 & & & & & & & \\
\hline M. oligocaenica Hermann, 1917 & & & & & & & \\
\hline M. propinqua Hantken, 1883 & & & & & & & \\
\hline Vaginulinopsis beyrichi (Reuss, 1856) & & & & & & & \\
\hline V. cumulicostata (Gümbel, 1870) & & & & & & & \\
\hline V. minuta (Hantken, 1875) & & & & & & & \\
\hline V. schwageri (Hantken, 1875) & & & & & & & \\
\hline Planularia karolyi Cicha \& Rögl, 1998 & & & & & & & \\
\hline P. moravica (Karrer, 1865) & & & & & & & \\
\hline Vaginulina legumen (Linnaeus, 1758) & & & & & & & \\
\hline Spirolingulina inflata (Sztrákos, 1979) & & & & & & & \\
\hline S. polymorpha (O. G. Costa, 1861) & & & & & & & \\
\hline Lagena acuticosta Reuss, 1862 & & & & & & & \\
\hline L. asperoides Galloway \& Morrey, 1929 & & & & & & & \\
\hline L. gracilicosta Reuss, 1858 & & & & & & & \\
\hline L. semistriata Williamson, 1858 & & & & & & & \\
\hline L. strumosa Reuss, 1858 & & & & & & & \\
\hline L. tenuis ornata Reuss, 1863 & & & & & & & \\
\hline L. sp. & & & & & & & \\
\hline Pygmaeoseistron vulgaris (Williamson, 1858) & & & & & & & \\
\hline Globulina cf. alabamensis Cushman \& McGlamery, 1939 & & & & & & & \\
\hline G. gibba gibba (d'Orbigny, 1846) & & & & & & & \\
\hline G. gibba punctata d'Orbigny, 1846 & & & & & & & \\
\hline G. inaequalis Reuss, 1850 & & & & & & & \\
\hline G. minuta (Römer, 1838) & & & & & & & \\
\hline G. muensteri (Reuss, 1846) & & & & & & & \\
\hline G. punctata d'Orbigny, 1846 & & & & & & & \\
\hline G. rotundata Bornemann, 1855 & cf. & & & & & & \\
\hline G. tuberculata d'Orbigny, 1846 & & & & & & & \\
\hline Guttulina austriaca d'Orbigny, 1846 & & & & & & & \\
\hline G. communis (d'Orbigny, 1826) & & & & & & & \\
\hline G. pulchella d'Orbigny, 1839 & & & & & & & \\
\hline Pyrulina polita (Terquem, 1882) & & & & & & & \\
\hline Pyrulinoides curvatura (Cushman \& Stainforth, 1945) & & & & & & & \\
\hline Sigmomorphina amygdaloides (Reuss, 1856) & & & & & & & \\
\hline S. regularis (Römer, 1838) & & & & & & & \\
\hline Ramulina globulifera Brady, 1879 & & & & & & & \\
\hline Buchnerina orbignyana orbignyana (Seguenza, 1862) & & & & & & & \\
\hline Buchnerina orbignyana selseyensis (Heron-Allen \& Earland, 1909) & & & & & & & \\
\hline B. bicarinata (Terquem, 1882) & & & & & & & \\
\hline B. sp. 5. Sztrákos, 2000 & & & & & & & \\
\hline Favulina geometrica (Reuss, 1863) & & & & & & & \\
\hline F. hexagona (Williamson, 1848) & & & & & & & \\
\hline Homalohedra cf. bifurcata (Leroy, 1944) & & & & & & & \\
\hline Lagnea radiatomarginata (Parker \& Jones, 1865) & & & & & & & \\
\hline Fissurina carinata Reuss, 1863 & & & & & & & \\
\hline Fissurina lacunata (Burrows \& Holland, 1895) & & & & & & & \\
\hline F. perforata (Mobius, 1880) & & & & & & & \\
\hline F. cf. praeclara Cushman \& Renz, 1946 & & & & & & & \\
\hline F. cf. quadrata (Williamson, 1858) & & & & & & & \\
\hline Glandulina glans (d'Orbigny, 1865) & & & & & & & \\
\hline G. gracilis Reuss, 1866 & & & & & & & \\
\hline G. laevigata d'Orbigny, 1826 & & & & & & & \\
\hline G. obtusa (Egger, 1857) & & & & & & & \\
\hline
\end{tabular}




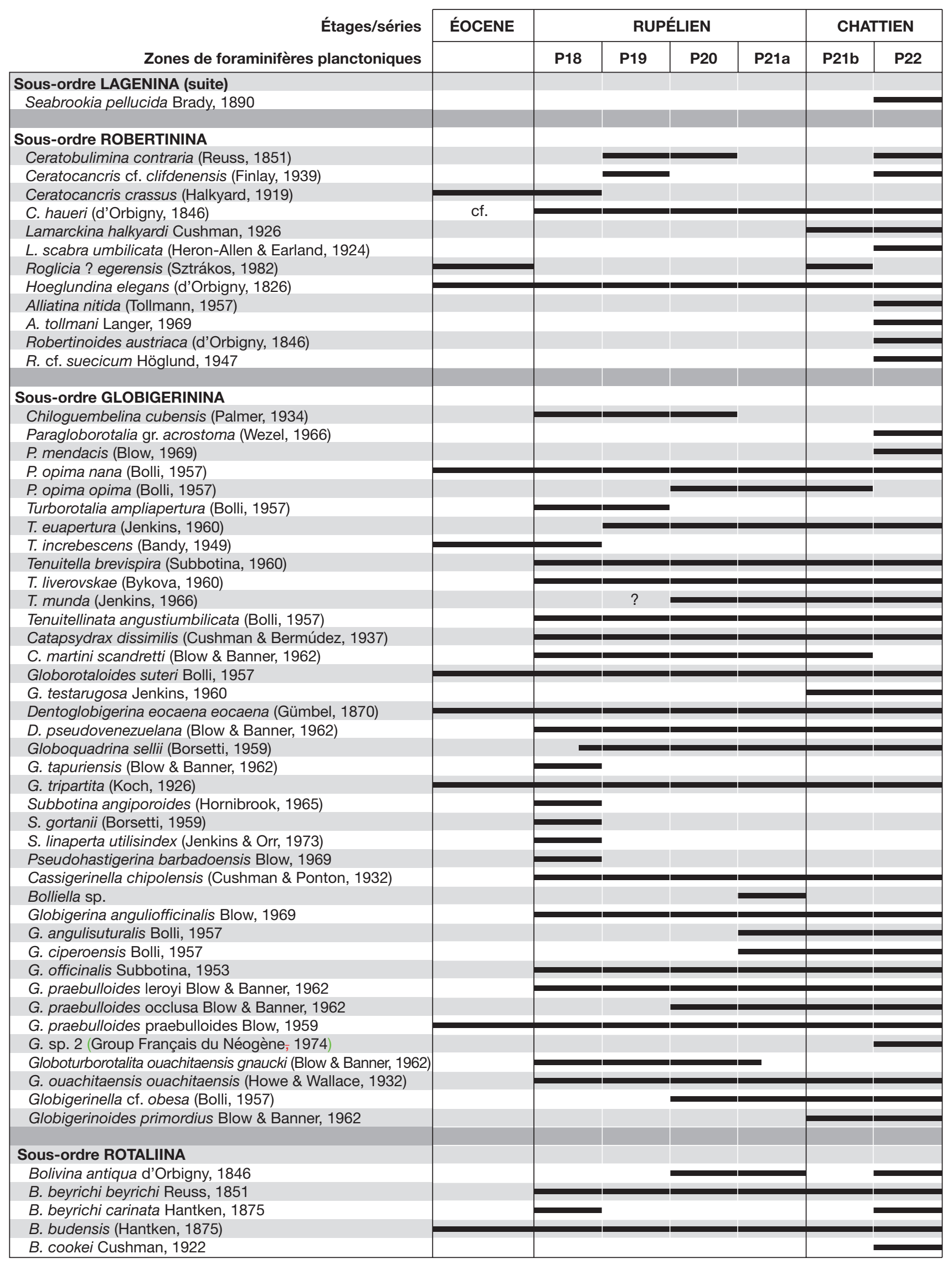


ANNEXE 1. - Suite/Continuation.

\begin{tabular}{|c|c|c|c|c|c|c|c|}
\hline \multirow{2}{*}{ Zones de foraminifères planctoniques } & \multirow[t]{2}{*}{ ÉOCENE } & \multicolumn{4}{|c|}{ RUPÉLIEN } & \multicolumn{2}{|c|}{ CHATTIEN } \\
\hline & & P18 & P19 & P20 & P21a & P21b & P22 \\
\hline \multicolumn{8}{|l|}{ Sous-ordre ROTALIINA (suite) } \\
\hline \multirow{2}{*}{\multicolumn{8}{|c|}{$\begin{array}{l}\text { Bolivina crenulata Cushman, } 1936 \\
\text { B. elongata Hantken. } 1875\end{array}$}} \\
\hline & & & & & & & \\
\hline \multicolumn{8}{|l|}{ B. fastigia Cushman, 1936} \\
\hline \multirow{2}{*}{\multicolumn{8}{|c|}{ B. hebes Macfadyen, 1930}} \\
\hline B. liebusi Hofmann, 1967 & & ? & & & & & \\
\hline \multicolumn{8}{|l|}{ B. molassica Hofmann, 1967} \\
\hline \multicolumn{8}{|l|}{ B. nobilis Hantken, 1875} \\
\hline \multicolumn{8}{|l|}{ B. oligocaenica Spandel, 1909} \\
\hline B. pulchra Terquem, 1882 & & & & & & & \\
\hline B. reticulata Hantken, 1875 & & & & & & & \\
\hline B. cf. reticulata Hantken, 1875 & & & & & & & \\
\hline B. semistriata Hantken, 1868 & & & & & & & \\
\hline B. striatocarinata Cushman, 1936 & & & & & & & \\
\hline B. terquemi Lindenberg, 1965 & & & & & & & \\
\hline B. vaceki bavarica Lühr, 1962 & & & & & & & \\
\hline Loxostomoides zsigmondii (Hantken, 1868) & & & & & & & \\
\hline Inflatobolivinella subrugosa (Butt, 1966) & & & & & & & \\
\hline Rugobolivinella poignantae Hayward, 1990 & & & & & & & \\
\hline Bolivinita concavomoenia Poag, 1966 & & & & & & & \\
\hline Cassidulina alabamensis Bandy, 1949 & & & ? & & $?$ & & \\
\hline C. cruysi Marks, 1951 & & & & & & & \\
\hline C. laevigata d'Orbigny, 1826 & & & & & & & \\
\hline C. vitalisi Majzon, 1948 & & & & & & & \\
\hline Cassidulinoides bodeni Hagn, 1952 & & & & & & & \\
\hline Globocassidulina alpina Sztrákos \& Du Fornel, 2003 & & & & & & & \\
\hline G. globosa (Hantken, 1875) & & & & & & & \\
\hline G. ornata Sztrákos, 2000 & & & & & & & \\
\hline G. subcalifornica (Drooger, 1953) & & & & & & & \\
\hline G. subglobosa (Brady, 1884) & & & & & & & \\
\hline Burseolina inexculta (Franzenau, 1889) & & & & & & & \\
\hline Turrilina alsatica Andreae, 1882 & & & & & & & \\
\hline Virgulopsis pupoides (Nyírő, 1954) & & & & & & & \\
\hline V. tuberculata (Egger, 1857) & & & & & & & \\
\hline Rectobolivina costifera (Cushman, 1936) & & & & & & & \\
\hline R. reticulosa (Cushman, 1936) & & & & & & & \\
\hline R. sanctipauli Hayward \& Poignant, 1985 & & & & & & & \\
\hline Rectuvigerina elegans (Hantken, 1875) & & & & & & & \\
\hline Tubulogenerina conica Heron-Allen \& Earland, 1909 & & & & & & & \\
\hline T. Iunata Gibson \& Poignant, 1991 & & & & & & & \\
\hline Bulimina alsatica Cushman \& Parker, 1937 & & & & & & & \\
\hline B. rostrata Brady, 1884 & & & & & & & \\
\hline B. sculptilis Cushman, 1923 & & & & & & & \\
\hline Globobulimina pyrula (d’Orbigny, 1846) & & & & & & & \\
\hline G. primitiva (Todd, 1952) & & & & & & & \\
\hline Buliminella elegantissima (d’Orbigny, 1839) & & & & & & & \\
\hline Eouvigerina sp. & & & & & & & \\
\hline Uvigerina acutocostata Hagn, 1956 & & & & & & & \\
\hline Uvigerina bealli Bermúdez, 1949 & & & & & & & \\
\hline U. cocoaensis cocoaensis Cushman, 1925 & & & & & & & \\
\hline U. cocoaensis topilensis Cushman, 1925 & & $?$ & & & & & \\
\hline U. eocaena eocaena Gümbel, 1870 & & & & & & & \\
\hline U. gallowayi Cushman, 1929 & & & & & & & \\
\hline U. gracilis Reuss, 1851 & & & & & & & \\
\hline U. hantkeni Cushman \& Edwards, 1937 & & & & & & & \\
\hline U. moravia Boersma, 1984 & & & & & & & \\
\hline Angulogerina angulosa (Williamson, 1858) & & & & & & & \\
\hline A. germanica Cushman \& Edwards, 1938 & & & & & & & \\
\hline A. globosa (Stoltz, 1925) & & & & & & & \\
\hline A. muralis (Terquem, 1882) & & & & & & & \\
\hline A. tenuistriata (Reuss, 1870) & & & & & & & \\
\hline Dymia labrum (Subbotina, 1953) & & & & & & & if. \\
\hline Kolesnikovella tubulifera (Kaasschieter, 1961) & & & & & & & \\
\hline Trifarina bradyi Cushman, 1923 & & & & & & & \\
\hline
\end{tabular}




\begin{tabular}{|c|c|c|c|c|c|c|c|}
\hline \multirow{2}{*}{$\begin{array}{r}\text { Étages/séries } \\
\text { Zones de foraminifères planctoniques }\end{array}$} & \multirow[t]{2}{*}{ ÉOCENE } & \multicolumn{4}{|c|}{ RUPÉLIEN } & \multicolumn{2}{|c|}{ CHATTIEN } \\
\hline & & P18 & P19 & P20 & P21a & P21b & P22 \\
\hline \multicolumn{8}{|l|}{ Sous-ordre ROTALIINA (suite) } \\
\hline \multirow{2}{*}{\multicolumn{8}{|c|}{$\begin{array}{l}\text { Trifarina budensis (Hantken, 1868) } \\
\text { Reussella byramensis Cushman \& Todd, } 1946\end{array}$}} \\
\hline & & & & & & & \\
\hline \multicolumn{8}{|l|}{ R. cognata (Reuss, 1865) } \\
\hline \multicolumn{8}{|l|}{$\begin{array}{l}\text { R. elongata (Terquem, 1882) } \\
\text { R. moodysensis Bandy, } 1949\end{array}$} \\
\hline R. oligocaenica Cushman \& Todd, 1946 & & & & & & & \\
\hline \multirow{2}{*}{\multicolumn{8}{|c|}{$\begin{array}{l}\text { R. oberburgensis (Freyer, 1864) } \\
\text { R. pulchra Cushman, } 1945\end{array}$}} \\
\hline & & & & & & & \\
\hline \multirow{2}{*}{\multicolumn{8}{|c|}{$\begin{array}{l}\text { R. spinulosa spinulosa Reuss, } 1850 \\
\text { R. spinulosa laevioata Cushman } 1945\end{array}$}} \\
\hline & & & & & & & \\
\hline \multicolumn{8}{|l|}{ Coryphostoma sinuosa (Cushman, 1936) } \\
\hline \multirow{2}{*}{\multicolumn{8}{|c|}{$\begin{array}{l}\text { Fursenkoina acuta (d'Orbigny, 1846) } \\
\text { F. halkyardi (Cushman, 1936) }\end{array}$}} \\
\hline & & & & & & & \\
\hline \multicolumn{8}{|l|}{ Sigmavirgulina tortuosa (Brady, 1884) } \\
\hline $\begin{array}{l}\text { Caucasina coprolithoides (Andreae, 1884) } \\
\text { C. cf. elongata (d'Orbigny, 1846) }\end{array}$ & & ? & & & & & \\
\hline Drepaniota lorifera (Halkyard, 1919) & & & & & & & \\
\hline Ellipsoglandulina labiata (Schwager, 1866) & & & & & & & \\
\hline E. laevigata Silvestri, 1900 & & & & & & & \\
\hline E. vasarhelyii (Hantken, 1868) & & & & & & & \\
\hline Ellipsoidina ellipsoides Seguenza, 1859 & & & & & & & \\
\hline Nodosarella sp. & & & & & & & \\
\hline Pleurostomella acuta Hantken, 1875 & & & & & & & \\
\hline P. alternans Schwager, 1866 & & & & & & & \\
\hline P. incrassata Hantken, 1883 & & & & & & & \\
\hline Nodogenerina adolphina (d'Orbigny, 1846) & & & & & & & \\
\hline N. hoernesi (Hantken, 1868) & & & & & & & \\
\hline N. lepidula (Schwager, 1866) & & & & & & & \\
\hline $\begin{array}{l}\text { N. rohri Cushman \& Stainforth, } 1945 \\
\text { Siphonodosaria annulifera (Cushman \& Bermúdez, 1936) }\end{array}$ & & & & & & & \\
\hline $\begin{array}{l}\text { Siphonodosaria annulifera (Cushman \& Bermúdez, 1936) } \\
\text { S. camerani (Dervieux, 1894) }\end{array}$ & & & & & & & \\
\hline S. emaciata (Reuss, 1851) & & & & & & & \\
\hline S. verneuilii (d'Orbigny, 1846) & & & & & & & \\
\hline Stilostomella gracillima (Cushman \& Jarvis, 1934) & & & & & & & \\
\hline S. monilis (Silvestri, 1872) & & & & & & & \\
\hline S. nuttalli (Cushman \& Jarvis, 1934) & & & & & & & \\
\hline S. pyrula (d'Orbigny, 1826) & & & & & & & \\
\hline Baggina dentata Hagn, 1956 & & & & & & & \\
\hline Cancris auriculus (Fichtel \& Moll, 1798) & & & & & & & \\
\hline C. subconicus (Terquem, 1882) & & & & & & & \\
\hline C. vicksburgensis Todd, 1952 & & & & & & & \\
\hline Valvulineria complanata (d'Orbigny, 1846) & & & & & & & \\
\hline V. palmarealensis (Nuttall, 1932) & & & & & & & \\
\hline V. sculpturata (Cushman, 1935) & & & & & & & \\
\hline Eponides repandus (Fichtel \& Moll, 1798) & & & & & & & \\
\hline Schlosserina asterites (Gümbel, 1870) & & & & & $\mathrm{R}$ ? & & \\
\hline Stomatorbina torrei (Cushman \& Bermúdez, 1937) & & & & $\mathrm{R}$ ? & & & \\
\hline $\begin{array}{l}\text { Neoeponides navarraensis (Colom \& Ruiz de Gaona, 1950) } \\
\text { N. schreibersii (d'Orbigny, 1846) }\end{array}$ & & $\mathrm{R}$ ? & & $\mathrm{R}$ ? & & & \\
\hline Discorbina mira (Cushman, 1922) & & & & & & & \\
\hline D. trocha (Römer, 1838) & & & & & & & \\
\hline Trochulina discoides (d'Orbigny, 1826) & & & & & & & \\
\hline Neoconorbina patella (Egger, 1857) & & & & & & & \\
\hline Neoconorbina terquemi (Rzehak, 1888) & & & & & & & \\
\hline Rosalina cf. bractifera (Le Calvez, 1949) & & & & & & & \\
\hline R. parisiensis d'Orbigny, 1826 & & & & & & & \\
\hline R. semiporata semiporata (Egger, 1857) & & & & & & & \\
\hline R. semiporata douvillei (Cushman, 1928) & & & & & & & \\
\hline Sphaeroidina bulloides d’Orbigny, 1826 & & & & & & & \\
\hline Glabratella cf. globigeriniformis (Heron-Allen \& Earland, 1924) & & & & & & & \\
\hline Glabratella neumannae Rahaghi, 1977 & & & & & & & \\
\hline Heronallenia lingulata (Burrows \& Holland, 1895) & & & & & & & \\
\hline Elongobula pulchra (Terquem, 1882) & & & & & & & \\
\hline
\end{tabular}


ANNEXE 1. - Suite/Continuation.

\begin{tabular}{|c|c|c|c|c|c|c|c|}
\hline \multirow{2}{*}{$\begin{array}{r}\text { Étages/séries } \\
\text { Zones de foraminifères planctoniques }\end{array}$} & \multirow[t]{2}{*}{ ÉOCENE } & \multicolumn{4}{|c|}{ RUPÉLIEN } & \multicolumn{2}{|c|}{ CHATTIEN } \\
\hline & & P18 & P19 & P20 & P21a & P21b & P22 \\
\hline \multicolumn{8}{|l|}{ Sous-ordre ROTALIINA (suite) } \\
\hline \multicolumn{8}{|l|}{ Siphonina reticulata Czjzek, 1848} \\
\hline \multicolumn{8}{|l|}{ S. subreticulata Myatlyuk, 1953} \\
\hline \multirow{2}{*}{\multicolumn{8}{|c|}{$\begin{array}{l}\text { Cibicidoides pachydermus (Rzehak, 1886) } \\
\text { C. pseudoungerianus (Cushman, 1922) }\end{array}$}} \\
\hline & & & & & & & \\
\hline \multicolumn{8}{|l|}{ C. pygmaeus (Hantken, 1875) } \\
\hline \multicolumn{8}{|l|}{ C. ungerianus (d'Orbigny, 1846) } \\
\hline C. tenellus (Reuss, 1864) & & ? & & & & & \\
\hline \multirow{2}{*}{\multicolumn{8}{|c|}{$\begin{array}{l}\text { Biapertorbis alteconicus Pokornỳ, } 1956 \\
\text { B. biaperturatus Pokornỳ, } 1956\end{array}$}} \\
\hline B. biaperturatus Pokornỳ, 1956 & & & & & & & \\
\hline \multicolumn{8}{|l|}{ Discorbitura sp. } \\
\hline Planulina compressa (Hantken, 1875) & & & & & & & \\
\hline P. costata (Hantken, 1875) & & & & & & & \\
\hline P. renzi Cushman \& Stainforth, 1945 & & & & & & & \\
\hline Cibicides cf. austriacus (d'Orbigny, 1846) & & & & & & & \\
\hline C. boueanus (d'Orbigny, 1846) & & & & & & & \\
\hline C. crassiperforatus Trunkó, 1965 & & & & & & & \\
\hline Falsocibicides aquitanicus Poignant, 1958 & & & & & & & \\
\hline Falsoplanulina ammophila (Gümbel, 1870) & & & & & & & \\
\hline Fontbotia cf. wuellerstorfi (Schwager, 1866) & & & & & & & \\
\hline Lobatula lobatula (Walker \& Jacob, 1798) & & & & & & & \\
\hline Stichocibicides moravicus Pokornỳ, 1956 & & & & & & & \\
\hline Cycloloculina annulata Heron-Allen \& Earland, 1909 & & & & & & & \\
\hline C. costellata (Terquem, 1882) & & & & & & & \\
\hline Planolinderina escornebovensis Freudenthal, 1969 & & & & & & & \\
\hline Planorbulina difformis Römer, 1838 & & & & & & & \\
\hline P. mediterranensis d'Orbigny, 1826 & & & & & & & \\
\hline Planorbulinella larvata (Parker \& Jones, 1865) & & & & & & & \\
\hline "Halkyardia" dalmatina (de Witt Puyt, 1941) & & & & & & & \\
\hline H. maxima Cimerman, 1969 & & & & & & & \\
\hline H. minima (Liebus, 1911) & & & & & & & \\
\hline Carpenteria rotaliformis Chapman \& Crespin, 1930 & & & & & & & \\
\hline Pseudobiarritzina proteiformis (Goës, 1882) & & & & & & & \\
\hline Victoriella abnormis (Hantken, 1875) & & & & & & & \\
\hline Sphaerogypsina globula (Reuss, 1848) & & & & & & & \\
\hline Epistomaria rimosa (Parker \& Jones, 1865) & & & & & & & \\
\hline E. separans Le Calvez, 1949 & & & & & & & \\
\hline Nuttallides sp. & & & & & & & \\
\hline Asterigerinata falcilocularis (Subbotina, 1960) & & $?$ & & & & & \\
\hline Asterigerinoides guerichi (Franke, 1912) & & & & & & & \\
\hline Biasterigerina planorbis (d'Orbigny, 1846) & & & & & & & \\
\hline Eoeponidella zealandica (Hornibrook, 1961) & & & & & & & \\
\hline Asterigerina carinata d’Orbigny, 1839 & & & & & & & \\
\hline A. dollfusi Cushman, 1928 & & & & & & & \\
\hline Amphistegina cf. bikinensis Todd \& Post, 1954 & & & & & & & \\
\hline A. hauerina (d’Orbigny, 1846) & & & & & & & \\
\hline A. vulgaris (d'Orbigny, 1846) & & $?$ & & & & & \\
\hline Nephrolepidina morgani (Lemoine \& Douvillé, 1904) & & & & & & & \\
\hline N. praemarginata (R. Douvillé, 1908) & & & & & & & \\
\hline Eulepidina dilatata (Michelotti, 1861) & & & & & & & \\
\hline E. formosoides (H. Douvillé, 1924) & & & & & & & \\
\hline Nonion commune (d'Orbigny, 1846) & & & & & & & \\
\hline N. durhami Mallory, 1959 & & & & & & & \\
\hline N. elongatum (d'Orbigny, 1826) & & & & & & & \\
\hline N. granosum (d'Orbigny, 1826) & & & & & & & \\
\hline N. grateloupi (d'Orbigny, 1852) & & & & & & & \\
\hline N. lamarcki ? (d'Orbigny, 1852) & & & & & & & \\
\hline N. ovatum Chalilov, 1956 & & & & & & & \\
\hline Nonionella liebusi Hagn, 1952 & & & & & & & \\
\hline N. wemmelensis Kaasschieter, 1961 & & & & & & & \\
\hline Thyromata curvisepta (Subbotina, 1936) & & & & & & & \\
\hline Astrononion budense Sztrákos, 1979 & & & & & & & \\
\hline A. stelligerum (d'Orbigny, 1839) & & & & & & & \\
\hline Cribropullenia sp. & & & & & & & \\
\hline
\end{tabular}




\begin{tabular}{|c|c|c|c|c|c|c|c|}
\hline \multirow{2}{*}{$\begin{array}{r}\text { Étages/séries } \\
\text { Zones de foraminifères planctoniques }\end{array}$} & \multirow[t]{2}{*}{ ÉOCENE } & \multicolumn{4}{|c|}{ RUPÉLIEN } & \multicolumn{2}{|c|}{ CHATTIEN } \\
\hline & & P18 & P19 & P20 & P21a & P21b & P22 \\
\hline \multicolumn{8}{|l|}{ Sous-ordre ROTALIINA (suite) } \\
\hline \multicolumn{8}{|l|}{ Melonis pompilioides (Fichtel \& Moll, 1798) } \\
\hline \multirow{2}{*}{\multicolumn{8}{|c|}{ M. cf. trinitatensis (Cushman \& Stainforth, 1945) }} \\
\hline \multirow{2}{*}{\multicolumn{8}{|c|}{$\begin{array}{l}\text { Pullenia bulloides (d'Orbigny, 1826) } \\
\text { P. quinqueloba (Reuss, 1851) }\end{array}$}} \\
\hline & & & & & & & \\
\hline \multicolumn{8}{|l|}{ Almaena abrardi (Poignant, 1965) } \\
\hline \multicolumn{8}{|l|}{ A. delmasi (Rey, 1958) } \\
\hline \multicolumn{8}{|l|}{ A. epistominoides (Marie, 1950) } \\
\hline \multicolumn{8}{|l|}{ A. escornebovensis (Sigal, 1950) } \\
\hline A. hieroglyphica (Sigal, 1950) & & & & & & & \\
\hline A. obesa (Sigal, 1950) & & & & & & & \\
\hline A. osnabrugensis (Römer, 1838) & & & & & & & \\
\hline A. taurica Samoylova, 1940 & & & & & & & \\
\hline Chilostomella cylindroides Reuss, 1851 & & & & & & & \\
\hline Chilostomella ovoidea Reuss, 1850 & & & & & & & \\
\hline Chilostomelloides oviformis (Sherborn \& Chapman, 1886) & & & & & & & \\
\hline Chilostomina pustulosa Finger \& Gaponoff, 1896 & & & & & & & \\
\hline Quadrimorphinella incauta Vetrova, 1975 & & & & & & & \\
\hline Quadrimorphina petrolei (Andreae, 1884) & & & & & & & \\
\hline Alabamina wolterstorffi (Franke, 1925) & & & & & & & \\
\hline Svratkina perlata (Andreae, 1884) & & & & & & & \\
\hline Charltonina budensis (Hantken, 1875) & & & & & & & \\
\hline Cribroparella pteromphalia (Gümbel, 1870) & & & & & & & \\
\hline Oridorsalis umbonatus (Reuss, 1851) & & & & & & & \\
\hline Anomalinoides affinis (Hantken, 1875) & & & & & & & \\
\hline A. granosa (Hantken, 1875) & & & & & & & \\
\hline A. similis (Hantken, 1875) & & & & & & & \\
\hline Heterolepa dutemplei (d'Orbigny, 1846) & & & & & & & \\
\hline Heterolepa eocaena (Gümbel, 1870) & & & & & & & \\
\hline H. megomphala (Gümbel, 1870) & & & & & & & \\
\hline Escornebovina cuvillieri (Poignant, 1965) & cf. & & & & & & \\
\hline E. leganyii (Kenawy \& Nyírő, 1967) & cf. & & & & & & \\
\hline Gyroidinoides cf. cushmani Boomgart, 1949 & & & & & & & \\
\hline G. dissimilis (Cushman \& Renz, 1947) & & & & & & & \\
\hline G. girardana (Reuss, 1851) & & & & & & & \\
\hline G. laevigata (d'Orbigny, 1826) & & & & & & & \\
\hline G. mamillata (Andreae, 1884) & & & & & & & \\
\hline G. octocamerata (Cushman \& Hanna, 1927) & & & & & & & \\
\hline G. planulata (Cushman \& Renz, 1941) & & & & & & & \\
\hline Rotaliatina sp. & & & & & & & \\
\hline Gyroidina altispira Cushman \& Stainforth, 1945 & & & & & & & \\
\hline G. parva (Cushman \& Renz, 1941) & & & & & & & \\
\hline Anomalinulla byramensis (Cushman \& Todd, 1946) & & & & & & & \\
\hline Gavelinella acuta (Plummer, 1927) & & $\mathrm{R} ?$ & & $\mathrm{R} ?$ & $\mathrm{R} ?$ & & \\
\hline Hansenisca allani (Finlay, 1939) & & & & & & & \\
\hline H. poignantae Sztrákos, 1993 & & & & & & & \\
\hline H. soldanii (d’Orbigny, 1826) & & & & & & & \\
\hline H. elegans (d'Orbigny, 1846) & & & & & & & \\
\hline H. propinqua (Terquem, 1882) & & & & & & $\mathrm{R}$ ? & \\
\hline Riminopsis rotula (d’Orbigny, 1846) & & & & & & & \\
\hline Paralabamina toulmini (Brotzen, 1948) & & & & & & & \\
\hline Karreria fallax Rzehak, 1891 & & & & & & & \\
\hline Coleites cancellatus (Cushman \& Bermúdez, 1936) & & & & & & & \\
\hline Buccella hannai (Phleger \& Parker, 1951) & & & & & & & \\
\hline Droogerinella ovata (Halkyard, 1919) & & & & & & & \\
\hline Neorotalia burdigalensis (d’Orbigny, 1852) & & & & & & & \\
\hline N. lecalvezae (Boulanger \& Poignant, 1971) & & & & & & & \\
\hline N. lithothamnica (Uhlig, 1886) & & & & & & & \\
\hline N. choctawensis (Cushman et McGlamery, 1938) & & & & & & & \\
\hline N. tuberculata (Schubert, 1901) & & & & & & & \\
\hline Pararotalia armata (d'Orbigny, 1826) & & & & & & & \\
\hline P. cf. byramensis (Cushman, 1922) & & & & & & & \\
\hline P. canui (Cushman, 1928) & & & & & & & \\
\hline P. parva (Cushman, 1922) & & & & & & & \\
\hline
\end{tabular}


ANNEXE 1. - Suite/Continuation.

\begin{tabular}{|c|c|c|c|c|c|c|c|}
\hline \multirow{2}{*}{$\begin{array}{r}\text { Étages/séries } \\
\text { Zones de foraminifères planctoniques }\end{array}$} & \multirow[t]{2}{*}{ ÉOCENE } & \multicolumn{4}{|c|}{ RUPÉLIEN } & \multicolumn{2}{|c|}{ CHATTIEN } \\
\hline & & P18 & P19 & P20 & P21a & P21b & P22 \\
\hline \multirow{2}{*}{\multicolumn{8}{|c|}{$\begin{array}{l}\text { Sous-ordre ROTALIINA (suite) } \\
P . \text { verriculata (Howchin \& Parr, 1938) }\end{array}$}} \\
\hline \multirow{2}{*}{\multicolumn{8}{|c|}{$\begin{array}{l}\text { P. verriculata (Howchin \& Parr, 1938) } \\
\text { Ammonia praebeccarii Poignant, } 1999\end{array}$}} \\
\hline & & & & & & & \\
\hline \multicolumn{8}{|l|}{ Chapmanina gassinensis (A. Silvestri, 1905) } \\
\hline \multicolumn{8}{|l|}{ Sherbornina atkinsoni Chapman, 1922} \\
\hline \multicolumn{8}{|l|}{ Cribrononion dollfusi (Cushman, 1936) } \\
\hline \multirow{2}{*}{\multicolumn{8}{|c|}{$\begin{array}{l}\text { Elphidiella cryptostoma (Egger, 1857) } \\
\text { E. minuta (Reuss, 1865) }\end{array}$}} \\
\hline & & & & & & & \\
\hline \multicolumn{8}{|l|}{ E. subnodosa (Römer, 1838) } \\
\hline \multicolumn{8}{|l|}{ Elphidium crispum (Linnaeus, 1758) } \\
\hline \multicolumn{8}{|l|}{ E. flexuosum (d'Orbigny, 1846) } \\
\hline \multicolumn{8}{|l|}{ E. cf. hauerinum (d'Orbigny, 1846) } \\
\hline \multicolumn{8}{|l|}{ E. karpaticum Myatlyuk, 1950} \\
\hline \multicolumn{8}{|l|}{ E. latidorsatum (Reuss, 1864) } \\
\hline \multicolumn{8}{|l|}{ E. percrassum Galloway \& Heminway, 1951} \\
\hline \multicolumn{8}{|l|}{ Miogypsinoides bantamensis Tan Sin Hok, 1936} \\
\hline \multicolumn{8}{|l|}{ M. borodinensis Hanzawa, 1940} \\
\hline \multicolumn{8}{|l|}{ M. complanata (Schlumberger, 1900) } \\
\hline \multicolumn{8}{|l|}{ M. dehaartii (Van der Vlerk, 1924) } \\
\hline \multicolumn{8}{|l|}{ M. formosensis Yabe \& Hanzawa, 1928} \\
\hline \multicolumn{8}{|l|}{ M. lateralis Hanzawa, 1940} \\
\hline \multicolumn{8}{|l|}{ M. mauretanicus Brönnimann, 1940} \\
\hline \multicolumn{8}{|l|}{ M. ubaghsi Tan Sin Hok, 1932} \\
\hline \multicolumn{8}{|l|}{ Cycloclypeus eidae Tan Sin Hok, 1932} \\
\hline \multirow{2}{*}{\multicolumn{8}{|c|}{$\begin{array}{l}\text { Heterostegina heterostegina (Silvestri, 1907) } \\
\text { Grzybowskia assilinoides (Blanckenhorn, 1890) }\end{array}$}} \\
\hline & & & & & & & \\
\hline \multicolumn{8}{|l|}{$\begin{array}{l}\text { Grzybowskia assilinoides (Blanckenhorn, 1890) } \\
\text { Spiroclypeus blanckenhorni ornata Henson, } 1937\end{array}$} \\
\hline Planostegina costata (d'Orbigny, 1839) & & & & & & & \\
\hline Nummulites bouillei de la Harpe, 1879 & & & & & & & \\
\hline N. fichteli Michelotti, 1841 & & & & & & & \\
\hline N. incrassatus de la Harpe, 1896 & & & & & & & \\
\hline N. vascus Joly \& Leymerie, 1848 & & & & & & & \\
\hline Operculina complanata (Defrance, 1822) & & & & & & & \\
\hline
\end{tabular}

